\title{
VI Zusammenfassung. Historisch-politische Kontextualisierung und abschließende Bewertung
}

Der Monat leistete zweifelsohne einen bedeutenden Beitrag bei der Demokratisierung und »Verwestlichung « der bundesrepublikanischen Nachkriegsgesellschaft sowie in der facettenreichen kulturpolitischen und ideologischen Auseinandersetzung mit dem sowjetischen Kommunismus. Insofern erfüllte die 1948 gegründete Zeitschrift ihre zentrale Funktion im Kontext der amerikanischen Deutschlandpolitik. Die durch den ausgebrochenen Kalten Krieg weltpolitisch zugespitzte Situation, die in der Berliner Blockade 1947/48 durch Stalin einen ersten Höhepunkt besaß, erforderte einen veränderten Charakter der amerikanischen Besatzungspolitik gegenüber dem zukünftigen Rechtsnachfolger des zusammengebrochenen >Dritten Reiches‘. Denn angesichts des sowjetischen Bedrohungspotenzials bestand im Rahmen der Politik der "Re-Orientation" das Ziel darin, Westdeutschland zu einem strategisch wichtigen Bündnispartner zu machen und dessen Bevölkerung dauerhaft und tiefgreifend für die »eigene Sache« zu gewinnen, sodass mit Blick auf die Umerziehung der Deutschen ein flexiblerer Ansatz notwendig wurde. Hierbei griff man explizit die demokratischen Grundtendenzen der »Re-Education « auf und passte sie den neuen politischen Bedingungen an. In diesem Zusammenhang avancierte Der Monat zu einem ganz entscheidenden Instrument, um unter genuin antikommunistischen Vorzeichen die Werte der liberalen Demokratie amerikanischer (bzw. westlicher) Provenienz der westdeutschen Bevölkerung zu vermitteln. Mit knapp 25000 Exemplaren war das Periodikum eines der auflagenstärksten Zeitschriftenorgane in den 1950er-Jahren und konnte der anvisierten Zielgruppe, in erster Linie Bildungsbürger, Intellektuelle, Akademiker und Studenten, aber auch Politiker, ein unverstelltes Bild westlicher, primär amerikanischer Hochkultur vermitteln, um gleichzeitig auf hohem Niveau eine antikommunistische Diskussion zu führen.

Damit verbundenen war indes ein fundamentaler Wandel der amerikanischen Besatzungspolitik. Im Rahmen der grundsätzlichen politischen Konzeptionen der vier Alliierten stand diese nach dem militärischen Sieg über das nationalsozialistische Herrschaftssystem anfangs ausdrücklich im Zeichen einer harten Bestrafung der Deutschen sowie einer umfassenden Demokratisierungspolitik, denn Deutschland wurde als »besiegter Feindstaat« (Truman) besetzt. Bereits im Verlauf des Zwei- 
ten Weltkrieges kamen in den staatlichen Regierungsstellen der Vereinigten Staaten Planungen in Gang, wie die tatsächliche Nachkriegspolitik in Deutschland aussehen solle. Daran waren auch und vor allem deutsche Emigranten, Intellektuelle und Wissenschaftler um Neumann im OSS-Apparat, der zentralen amerikanischen Nachrichten- und Geheimdienstbehörde, maßgeblich beteiligt. Vor dem Hintergrund der von 1942 bis 1945 erstellten analytisch ausgerichteten (militär-)politischen Expertisen über das nationalsozialistische Herrschaftssystem und den insbesondere nach dem Überfall auf die Sowjetunion im Juni 1941 begangenen staatlichen Massenverbrechen setzten konkrete Überlegungen ein, wie die deutsche Gesellschaft grundlegend reformiert werden könne. Die weitgefassten Ziele dieser Reformpolitik fanden ihren Niederschlag in den vier großen »Ds«: Denazification, Demilitarization, Decartelization und Democratization.

Zunächst wurden allerdings aufgrund alliierter Übereinkunft die Hauptverantwortlichen für den Zweiten Weltkrieg und für die Kriegsverbrechen vom Nürnberger Militärtribunal angeklagt und verurteilt. Der Nürnberger Hauptkriegsverbrecherprozess brachte die Entschlossenheit der vier Alliierten zum Ausdruck, unter anderem die unmittelbare Führungsspitze des »Hitlerregimes« sowie der nationalsozialistischen Regierung und der Wehrmacht zu bestrafen. Die US-Regierung nutzte beispielsweise auch in den zwölf Nürnberger Nachfolgeprozessen gegen die Elite aus der Justiz, Wehrmacht, Diplomatie, Beamtenschaft, Ärzteschaft, Wirtschaft und Wissenschaft sowie gegen höhere SS-Führer, um insgesamt 177 weitere hochrangige Exponenten des nationalsozialistischen Systems anzuklagen. Darüber hinaus ging die amerikanische Militärregierung angesichts der von den Alliierten auf der Potsdamer Konferenz getroffenen Vereinbarungen im Kontext der Entnazifizierungspolitik besonders rigoros vor und war geprägt durch harte Bestrafungen und gesamtgesellschaftlich nachhaltige Sanktionen.

Insofern richtete sich die in der deutschen Öffentlichkeit weit verbreitete Skepsis und Kritik an der Entnazifizierung besonders gegen die US-Militärregierung, an der sich nicht nur die evangelische Kirche beteiligte, sondern auch die von prominenten Intellektuellen und Publizisten herausgegebenen Zeitschriften wie beispielsweise Der Ruf, Die Wandlung oder die Frankfurter Hefte. Damit verbunden war ein generelles Problem, das vor allem die amerikanische Besatzungspolitik in der ersten Phase, d.h. bis Ende 1947/Anfang 1948, im Ganzen betraf, in der die rigide Entnazifizierung mit umfassenden Demokratisierungsmaßnahmen koinzidierte. Im Rahmen des anspruchsvollen und ambitionierten Programms der »Re-Education« sollten der autoritären gesellschaftlichen und ideengeschichtlichen Tradition in Deutschland demokratische Werte entgegengesetzt werden. Mit Blick auf die Konstituierung einer grundsätzlichen demokratischen politischen Kultur in Deutschland wurde im Kontext der Umerziehungspolitik neben dem Bildungswesen und Rundfunk auch dem gesamten Medienbereich ein großer Stellenwert beigemessen. Hierbei spielten vor allem die (Tages- und Wochen-)Presse und die kulturpolitischen Zeitschriften eine besondere Rolle, die auch die Auseinandersetzung mit der Geschichte des >Dritten Reiches in unterschiedlichem Maße ins Licht rückten. Insbesondere die große Anzahl allgemeiner politisch-kultureller Zeitschriften besaß in der "Stunde null« neben der großen Auflagenstärke vor allem aufgrund ihrer konzeptionellen Anlage eine wichtige Funktion bei eben jener Konstituierung einer grundsätzlichen demokratischen politischen Kultur sowie eines demokratisch-parlamentarischen Systems im Nachkriegsdeutschland. 
Die in den einflussreichen Zeitschriften Die Wandlung, Der Ruf und Frankfurter Hefte - die stellvertretend für viele andere standen - in unterschiedlicher Qualität zum Ausdruck gebrachte Skepsis und Kritik am Nürnberger Militärtribunal und an den Entnazifizierungsmaßnahmen brachte die amerikanische Besatzungsmacht sozusagen kulturpolitisch unter Zugzwang. Zudem stellte sich als ein zentrales Problem dar, dass sich in der deutschen Bevölkerung nach der anfänglichen breiten Zustimmung für den Hauptkriegsverbrecherprozess im Kontext mit den zwölf Nachfolgeprozessen und den Entnazifizierungsmaßnahmen immer mehr eine ablehnende Haltung breitmachte, die keineswegs zufällig mit einer Ablehnung einer angeblichen deutschen »Kollektivschuld« angesichts der nationalsozialistischen Verbrechen korrespondierte und in eine »Opfermentalität« mündete. Damit verbunden war die Gefahr, dass die amerikanische Umerziehungspolitik scheitern könnte. Gleichzeitig musste die amerikanische Besatzungsmacht feststellen, dass insbesondere bei zahlreichen deutschen Künstlern, Schriftstellern und Intellektuellen die Kulturpolitik in der sowjetischen Besatzungspolitik ein nicht geringes Interesse fand. In diesen Kreisen war man sehr aufgeschlossen gegenüber der sowjetischen Kulturpolitik, weil hier die Forderung nach einer Auseinandersetzung mit der Geschichte des >Dritten Reiches`häufig mit der Kritik am Kapitalismus - den sie für das Aufkommen des »Hitlerfaschismus« mitverantwortlich machten - und der Hoffnung nach einem alternativen Wirtschaftssystem koinzidierte. Infolgedessen schien diesem Personenkreis die sowjetische Kulturpolitik mit dem anvisierten Konzept der »Stunde null« überaus attraktiv, weil hierdurch nicht zuletzt die Möglichkeit zu bestehen schien, die radikale Neugestaltung sowohl der gesellschaftlichen als auch der wirtschaftlichen Verhältnisse in Deutschland zu erreichen; was sich in vielen Fällen mit dem Wunsch nach einer sozialistischen Utopie verband. Zudem erwies es sich in der unmittelbaren Nachkriegszeit als ein entscheidender Vorteil, dass die SMAD-Kulturbürokratie das ideologisch-politische Modell des Sozialismus den deutschen Intellektuellen in einer Form präsentierte, das bemerkenswert liberale und pragmatische Züge aufwies, das sich also ohne den stalinistischen Hintergrund zeigte. Vor dem Hintergrund der nationalsozialistischen Vergangenheit gelang es den Sowjets, erfolgreich einen antifaschistisch-»demokratischen « Grundkonsens zu begründen, der einerseits Künstler und Intellektuelle aus dem bürgerlich-liberalen, sozialdemokratischen und auch dem katholischen Lager und andererseits einen nicht unerheblichen Teil der linksintellektuellen Emigranten sowie apolitische Künstler und Intellektuelle, die während der NS-Diktatur im »inneren Exil« lebten, ansprach. Mittel dazu waren insbesondere die Forderung nach der Einheit der Arbeiterbewegung und der seit 1946 einsetzenden konsequenten Adaption des nationalen Gedankens. In diesem Zusammenhang gelang den Sowjets mit dem Kulturbund zur demokratischen Erneuerung Deutschlands unter dem Präsidenten Johannes R. Becher ein entscheidender kulturpolitischer Schachzug, der sich am zonenübergreifenden Erfolg ablesen ließ und weit über den Intellektuellenkreis hinausging. Dass es sich beim Kulturbund um eine "fellow traveller«-Bewegung handelte, die in der konzeptionellen Tradition Willi Münzenbergs stand, war freilich anfangs nur »Experten « ersichtlich, sodass bei den »Altmeistern« der kommunistischen Agitations- und Propagandamethoden um Koestler die Alarmglocken klingelten, weil sie die politischen Gefahren erkannten, zumal die sowjetischen Besatzungsbehörden mit der kulturpolitischen Monatszeitschrift Aufbau über ein weiteres einflussreiches Organ verfügten. 
Infolgedessen existierten mehrere wichtige Gründe, die die amerikanische $\mathrm{Mi}$ litärregierung unter Clay veranlassten, den Monat ins Leben zu rufen. Hierbei stand freilich die Gründung in einem unmittelbaren Zusammenhang mit der allgemeinen Entwicklung der internationalen Beziehungen zwischen den beiden Großmächten. Der fundamentale Systemkonflikt wirkte sich auch und vor allem auf die Deutschlandfrage aus, spitzte sich in den Vorgängen des Jahres 1947 (Gründung der »Bizone« und somit Herausbildung eines westdeutschen Kernstaates, Verkündung der Trumandoktrin und des Marshallplanes, Kominform-Gründung im September und Verkündung der »Zwei-Lager-Theorie« durch Schdanow) zu und brach sich beim ersten gesamtdeutschen Schriftstellerkongress in Berlin im Oktober 1947 Bahn. Der hier zwischen der sowjetischen Delegation und Lasky ausgetragene Streit war nicht nur ein Symptom für den ausbrechenden Kalten Krieg, sondern besiegelte zudem symbolisch die Teilung der deutschen Intellektuellen entlang des Ost-West-Konfliktes.

Indes kam für führende Vertreter der US-amerikanischen Regierung der Ausbruch des Kalten Krieges keineswegs überraschend. Der politisch-ideologische Grundwiderspruch zwischen liberaler Demokratie und kommunistischer Sowjetdiktatur bestand seit der Russischen Oktoberrevolution, die einen »Weltbürgerkrieg der Werte« (Dan Diner) auslöste. Für einflussreiche amerikanische Politiker aus dem Außenministerium und dem diplomatischen Dienst stand fest -Kennan stand hier stellvertretend -, dass der existenzielle Kampf zwischen dem freien Westen und dem totalitären Sowjetkommunismus systemimmanenten Bedingungen entsprach. Auch angesichts der konkret gemachten persönlichen Erfahrungen mit dem stalinistischen Terror in den 1930er-Jahren machte sich dieser Personenkreis keine Illusion über die wahre Natur des sowjetischen Herrschaftssystems. Sie waren der politischen Grundüberzeugung der »Riga-Fraktion« verpflichtet, wonach der aus der Russischen Revolution von 1917 entsprungene Sowjetstaat ein feindliches Wertesystem verkörperte, das den amerikanischen Ordnungsprinzipien in der Innen- und Außenpolitik diametral entgegengesetzt war. Die überzeugten politischen Antikommunisten fungierten bereits zeitweise als politische Berater in der Ära von Roosevelt sowie als russlandpolitische Experten im State Department, prägten indes vor allem die Nachkriegspolitik des neuen Präsidenten Truman entscheidend mit. Ihrer Auffassung nach war der Kampf zwischen den Vereinigten Staaten und der Sowjetunion als einzig verbliebene Supermächte nach dem gemeinsamen Sieg über den Nationalsozialismus nur eine Frage der Zeit, und mit Blick auf die Anti-Hitler-Koalition operierte dieser Personenkreis in dem Bewusstsein, dass sie ausschließlich durch die im Laufe des Jahres 1941 entstandene tatsächliche Bedrohungssituation zusammengehalten wurde: Der gemeinsame Kampf gegen den Nationalsozialismus war die Klammer dieser unnatürlichen Interessengemeinschaft des Augenblicks. Zudem teilten sie die Überzeugung, dass die Vereinigten Staaten eine Vorreiterrolle zu spielen hätten im Kampf der westlichen Demokratien gegen die Sowjetunion und ihre Satellitenstaaten. Sie hingen der für die außenpolitische Strategie im Kalten Krieg maßgeblichen traditionellen Vorstellung an, wonach antidemokratische Mächte auf Dauer eine Bedrohung der vitalen Interessen der Vereinigten Staaten darstellten. Ihr zentrales Thema war die Frage, wie die Übernahme Europas durch die Sowjetunion verhindert werden könne.

Nachdem sich die USA bereits auf der Grundlage von Kennans Vorschlägen im Verlauf des Jahres 1946 an die Containment-Politik als außenpolitische Strategie zur Eindämmung der als aggressiv-expansionistisch beurteilen sowjetischen Politik 
orientierte, entwarf der anerkannte Russlandfachmann nach seiner Ernennung zum Direktor des Politischen Planungsstabes im Außenministerium im Frühjahr 1947 einen ganz im Zeichen des antikommunistischen Grundkonsenses in der amerikanischen Führung stehenden Masterplan für den Kalten Krieg. Während mit der am 12. März 1947 verkündeten Trumandoktrin die Entschlossenheit der USA zum Ausdruck gebracht werden sollte, den vom Kommunismus bedrohten Staaten Hilfe zu leisten, der Marshallplan gedacht war als ein Instrument, die westeuropäischen Staaten vor dem Kommunismus zu bewahren und als ein weltweites Bollwerk zur Absicherung des amerikanischen Einflusses, fiel der CIA eine besondere Funktion zu.

Dabei war die Gründung der CIA am 18. September 1947 ein wichtiger Baustein in der Veränderung der Geheimnis- und Sicherheitsarchitektur der Vereinigten Staaten, die sich auch im neugeschaffenen Nationalen Sicherheitsrat ausdrückte. Indes war die Genesis und Entwicklung der CIA mit Problemen für das demokratische Verfassungssystem und die amerikanische Öffentlichkeit behaftet und betraf speziell Fragen fehlender oder unzureichender demokratischer Legitimation und Kontrolle des Geheimdienstes. Die von der CIA praktizierte Geheimhaltung bereitete sogar alsbald führenden Regierungspolitikern Sorgen. Gesetzliche Grundlage bildete das von Truman unterzeichnete Nationale Sicherheitsgesetz vom 26. Juli 1947. Demnach war die CIA als ein Geheimdienst im traditionellen Sinne geplant, deren vornehmliche Aufgabe im Sammeln, Auswerten und der Weitergabe von sicherheitsrelevanten Informationen bestand. Zudem sollte sie den Nationalen Sicherheitsrat beraten sowie nicht genau festgelegte Aufgaben und Pflichten wahrnehmen, die nachrichtendienstliche Aktivitäten betreffen, welche die nationale Sicherheit berühren und von Zeit zu Zeit vom Nationalen Sicherheitsrat angeordnet werden. Eine Gesetzeslücke ermöglichte verdeckte Geheimoperationen in ausländischen Staaten, und insofern wurde eine scharfe Trennung zwischen nachrichtendienstlichem und geheimdienstlichem Aktionsfeld nicht aufrechterhalten. Die Durchführung von verdeckten Operationen war nur mit direkter oder stillschweigender Genehmigung des Nationalen Sicherheitsrates möglich. Hierbei agierte die CIA nach dem Motto, wonach zur Abwehr der kommunistischen Gefahr der Zweck die Mittel heiligt und rechtsstaatliche Grundsätze außer Kraft gesetzt werden konnten. Es herrschte die Überzeugung vor, dass im Umgang mit einem gefährlichen Gegner, der sich an keinerlei (demokratische) Spielregeln hielt, auch die eigene Seite solche Regeln missachten dürfte.

Zwei auf der Basis von Kennans politischen Vorstellungen vom Nationalen Sicherheitsrat erstellten Direktiven für geheime Operationen waren für den amerikanischen Geheimdienst im Bereich der politischen Kriegsführung richtungsweisend. In der ersten Direktive (NSC-4) vom 19. Dezember 1947 wurde der CIA-Direktor in einem streng geheimen Anhang (NSC-4A) angewiesen, »verdeckte psychologische Aktivitäten« zur Abwehr sowjetischer und sowjetisch gesteuerter Aktivitäten durchzuführen. Da indes unklar blieb, welche Verfahren zur Koordinierung bzw. Genehmigung solcher Aktivitäten befolgt werden sollten, wurde sie am 18. Juni 1948 durch eine neue, eindeutiger formulierte Direktive ersetzt (NSC-10/2), die es der CIA erlaubte, ein breites Spektrum von Geheimoperationen durchzuführen. Neben Propaganda, Wirtschaftskrieg, Präventivmaßnahmen einschließlich Sabotage, Gegensabotage, Zerstörung und Evakuierung zählten hierzu subversives Vorgehen gegen feindliche Staaten einschließlich der Unterstützung von Widerstandsbewegungen, Guerilla und Flüchtlingsbewegungen. Die CIA wurde dazu verpflichtet, sämtliche Geheimoperationen, von denen es bald 
Hunderte gab, so durchzuführen, dass sich die Regierung zu jedem Zeitpunkt glaubhaft davon distanzieren könne. Zudem sah die Direktive NSC-10/2 die Einrichtung einer speziellen Abteilung für verdeckte Aktionen (covert actions) vor, die zwar in die CIA integriert wurde, jedoch politisch und personell dem Planungsstab des Außenministeriums unterstellt war und mithin unter der Kontrolle Kennans stand. Diese »Eingreiftruppe (Tim Weiner) fungierte unter dem Namen Office of Policy Coordination (OPC) - ein Deckname, mit dem die Arbeit dieser Gruppe kaschiert werden sollte -, die am 1. September 1948 unter dem Leiter Frank G. Wisner ihre Arbeit aufnahm.

Zur eigentlichen Geburtsstunde der verdeckten Operationen der CIA im Kalten Krieg wurden aber bereits die italienischen Parlamentswahlen im April 1948, die die Verantwortlichen als Erfolg ansehen konnten (die Christdemokraten gewannen mit ausreichendem Vorsprung und konnten eine Regierung ohne die Kommunistische Partei bilden). Aber: Abgesehen davon, dass dieser verdeckten CIA-Operation die demokratische Legitimation fehlte (sie wurde nicht vom Kongress abgesegnet) und schlichtweg illegal war (sie begann schon vor der offiziellen Genehmigung durch den Nationalen Sicherheitsrat und beinhaltete zum Beispiel auch die Ermordung von führenden kommunistischen Politikern und Gewerkschaftsfunktionären), kam hier eine CIA-Praxis zum Vorschein, die im Hinblick auf die Finanzierung von verdeckten Operationen einen richtungsweisen Charakter besaß. Da die CIA zu diesem Zeitpunkt noch über keinen eigenen Etat verfügte, wurden Gelder aus dem für den Wiederaufbau Europas vorgesehenen Währungsstabilitätsfonds abgezweigt und an vom amerikanischen Geheimdienst gegründete Tarnorganisationen weitergeleitet. Eine der einflussreichen Tarnorganisationen trug den Namen »Kongreß für kulturelle Freiheit« und war eine der erfolgreichsten und wirkungsmächtigsten von der CIA initiierten verdeckten Operationen.

Obwohl im April 1948 die politische Entwicklung in Italien zugunsten der Vereinigten Staaten entschieden worden war, war sich die amerikanische Regierung darüber im Klaren, dass der Hauptschauplatz im Kalten Krieg in Deutschland und speziell in Berlin lag, wo sich der amerikanische und sowjetische Geheimdienst mit allen Mitteln der Spionage und Gegenspionage bekämpften. Besonders der Beginn der sowjetischen Blockade Westberlins im Juni 1948 setzte die Vereinigten Staaten massiv unter Druck und ließ nach Ansicht der CIA-Führung die Gefahr einer offenen militärischen Konfrontation konkret werden. Die Berlinblockade löste einen beispiellosen Ausbau der verdeckten Operationen der CIA aus, die mit Blick auf die gesamte »Ostarbeit« des Geheimdienstapparates darauf ausgelegt wurden, das gegnerische System zu schwächen und das eigene zu stärken. Waren die Vereinigten Staaten und die Sowjetunion im Zweiten Weltkrieg noch verbündete im Kampf gegen den Nationalsozialismus, machte der US-Geheimdienst nun in der weltweiten Auseinandersetzung mit dem Kommunismus mit zahlreichen rechtsgerichteten Diktaturen sowie Personen und Gruppen aus dem faschistischen resp. nazistischen Lager gemeinsame Sache (so übernahm der CIA-Apparat zum Beispiel im Juli 1949 die »Organisation Gehlen« von der US-Armee, zu dessen Personal auch Dutzende prominenter Kriegsverbrecher zählte, und begann sie in einen westlichen Nachrichtendienst umzuwandeln; zudem unterstützte der amerikanische Geheimdienst die rechtsradikale Gruppe Bund Deutscher Jugend). Außerdem machten Umsturzversuche und Unterstützung von antikommunistischen »Rebellen« hinter dem Eisernen Vorhang einen wichtigen Teil der verdeckten Operationen der CIA aus. In dieselbe Richtung zielte die sogenannte Psychologi- 
sche Kriegsführung in den sowjetisch kontrollierten Staaten in Ostmitteleuropa, mit der beabsichtigt wurde, die kommunistischen Staaten von innen zu untergraben, zu destabilisieren und damit einen Regierungswechsel vorzubereiten. Demzufolge bildete der »Kongreß für kulturelle Freiheit« im Rahmen der verdeckten CIA-Operationen einen wichtigen Bestandteil eines Netzwerkes von Gruppen und Organisationen im Kalten Krieg, ein Geflecht höchst unterschiedlicher Agenturen mit ebenso mannigfaltigen Aufgabenbereichen innerhalb des Gesamtzusammenhanges der Auseinandersetzung zwischen den liberaldemokratischen Staaten des Westens und der kommunistischen Welt. Hierbei verfolgten der »Kongreß für kulturelle Freiheit« und die mit ihm organisatorisch und personell eng verbundene Zeitschrift Der Monat im Hinblick auf den deutschen Sprach- und Kulturraum ganz spezielle Ziele.

Insofern war die Gründung der kulturpolitischen Zeitschrift Der Monat sowie der im Anschluss an den in Westberlin veranstalteten "Kongreß für kulturelle Freiheit« (1950) ins Leben gerufenen, gleichnamigen liberal-antikommunistisch ausgerichteten Intellektuellenorganisation der weltpolitischen Situation geschuldet. Ihren Entstehungskontext bildeten primär der Kalte Krieg sowie die aus den Resultaten des Zweiten Weltkrieges notwendig gewordenen Versuche, das neu konstituierte, liberaldemokratische kapitalistisch organisierte Hegemonialsystem der Vereinigten Staaten im Rahmen des Systemkonfliktes mit der Sowjetunion zu stabilisieren. Beide Institutionen waren Instrumente der US-amerikanischen Außenpolitik, mit denen die Werte des Westens gegenüber der kommunistischen Herausforderung öffentlichkeitswirksam vertreten wurden. Während Der Monat in erster Linie auf Deutschland ausgerichtet war, engagierte sich der »Kongreß für kulturelle Freiheit« in der politisch-ideologischen Auseinandersetzung mit dem Kommunismus stalinistischer Couleur weltweit. Während der »Kongreß « vornehmlich von finanziellen Mitteln der CIA abhing, die anfangs direkt und später unter strengster Geheimhaltung über die »dummy foundations (zum Beispiel der Ford oder der Rockefeller Foundation) ausgezahlt wurden, war die Finanzierung der »Lasky-Zeitschrift« weitaus komplizierter und ist mit Blick auf die Frage des Geldgebers in der neuesten Forschung umstritten. Unbestritten erhielt Der Monat anfangs seine finanziellen Mittel von der US-amerikanischen Militärregierung, also von OMGUS und später von der HICOG. Ob die CIA möglicherweise bereits vor dem Juli 1958 das Zeitschriftenprojekt mit Geldern ausstattete, also bevor die Pariser Zentrale des »Kongreß« als Geldgeber in Erscheinung trat, konnte in dieser Untersuchung nicht geklärt werden. Gleichwohl gibt es genügend Anhaltspunkte dafür, dass möglicherweise Der Monat bereits von Beginn an durch CIA-Gelder (mit-) finanziert wurde, nämlich aus »Vertraulichen Fonds« des Marshallplanes oder ab Oktober 1954 durch die Ford Foundation und mithin in Form von verdeckt gezahlten Geldern.

Allerdings war das Zeitschriftenprojekt innerhalb der US-amerikanischen Besatzungsbehörden zu Beginn nicht unumstritten. Nicht zu Unrecht befürchteten Vertreter der »OMGUS-Linken«, d.h. Befürworter einer harten Bestrafung der Deutschen, dass Clay und Lasky fortan gegenüber den Deutschen einen entspannteren politischen Kurs fahren würden, als es das bis dahin gültige Reeducation-Konzept vorsah. Ihrer Auffassung nach bestand die Gefahr, dass anstatt einer offensiven Umerziehung bei gleichzeitigem defensivem Antikommunismus ein offensiver Antikommunismus an die Stelle tritt, der nicht zuletzt die Maßnahmen der Reeducation-Politik gefährden könnte bzw. zu relativieren drohte. Nachdem allerdings spätestens mit dem Sieg 
Trumans bei den Präsidentschaftswahlen 1948 die amerikanische Politik unter dem Primat des Antikommunismus stand, konnten sich Clay und Lasky auch gegenüber den politischen Kontrahenten innerhalb der amerikanischen Besatzungsbehörden durchsetzen. ${ }^{1}$ Infolgedessen wurde angesichts des ausgebrochenen Kalten Krieges ein neuer Blick auf die Deutschen geworfen, sodass das zentrale politische Ziel darin bestand, den ehemaligen Kriegsgegner zum »Partner « zu machen und Westdeutschland zum Bollwerk gegen den Sowjetkommunismus auf- und auszubauen. In diesem politischen Fahrwasser befand sich auch Lasky, der in diesem Zusammenhang, ohne die Auseinandersetzung mit der Geschichte des >Dritten Reiches zialistischen Vergangenheit abschwächen zu wollen, die Auffassung vertrat, dass die Gefahr durch den Stalinismus größer wäre als die von einem »längst überwundenen Faschismus« ausgehende Gefahr. Dies schlug sich in der beschriebenen besonderen antitotalitären Antikommunismuskonzeption nieder. Obwohl das facettenreiche Totalitarismusphänomen sowohl nationalsozialistischer als auch sowjetischer Couleur ausführlich ins Licht gerückt wurde, dominierte die antikommunistische Ausrichtung. Da allerdings Der Monat nicht als ein ausschließlich negativ abgrenzendes Propagandainstrument gedacht war, koinzidierte der grundsätzliche Antikommunismus mit der Fokussierung der westlichen Individual- und Freiheitsrechte, die freilich im Kontext der »Re-Orientation«-Funktion der Zeitschrift standen.

Ähnlich wie die von der amerikanischen Militärregierung in München im Oktober 1945 herausgegebene Neue Zeitung, die zur bedeutendsten deutschsprachigen Tageszeitung der ersten Besatzungsjahre avancierte, leistete Der Monat einen entscheidenden Beitrag bei der »Amerikanisierung« bzw. »Verwestlichung« der Deutschen. Nachdem in den Jahren des >Dritten Reiches das »Fenster zur kulturellen Welt« verschlossen war, konnte das Zeitschriftenorgan durch die facettenreiche inhaltliche Ausrichtung tatsächlich den Lesern den Eindruck vermitteln, endlich wieder an den intellektuellen Debatten des Westens teilzuhaben. In der Zeitschrift veröffentlichten Autoren, die, nachdem sie insbesondere in der unmittelbaren Anfangsphase aus den Vereinigten Staaten kamen, zur Créme de la Créme des westlich-demokratischen Lagers schlechthin zählten und zu den Themen Literatur, Theater, Film, Kunst, Philosophie, Politik, Soziologie, Geschichte und Nationalökonomie schrieben. Im Zentrum des proamerikanischen Denkens standen vor dem Hintergrund der amerikanischen Unabhängigkeitserklärung von 1776 Reflexionen über die Bedeutung der individuellen Freiheitsrechte als herausragender Topos des liberal-demokratischen Systems.

Die Freiheitsthematik wurde zudem ausdrücklich mit dem hervorgehobenen und ausführlich behandelten Aspekt von der Funktion der kulturellen Freiheit für den liberalen Westen verbunden und besaß sowohl für den berühmten Westberliner »Kongreß für kulturelle Freiheit« im Juni 1950 als auch für die im Anschluss an die »heißen Tage« gegründete gleichnamige Institution eine herausragende Bedeutung. Individuelle und kulturelle Freiheit waren im Monat Grundkonstituenten nicht nur des amerikanischen Systems, sondern von westlicher Zivilisation überhaupt, als deren eigentlicher

1 Als Rechtfertigung für diesen Übergang der US-amerikanischen Deutschlandpolitik lässt sich der Beitrag Melvin J. Laskys, Die kurze Geschichte des Morgenthau-Plans. Ein dokumentarischer Rückblick, in: Der Monat 1 (1949), H. 10, S. 7-17 lesen, der die Cenesis des legendären sogenannten Morgenthauplans und vehemente Kontroverse zwischen Befürwortern und Gegnern innerhalb der US-Regierungsspitze beschreibt. 
Modellfall gleichwohl die Vereinigten Staaten erschien. Da das Zeitschriftenorgan jedoch für die amerikanische Regierung auch die politische Funktion besaß, angesichts des Kalten Krieges Westdeutschland militärisch zu einem strategisch wichtigen Bündnispartner zu machen - die Gründung der Bundeswehr und die Wiederbewaffnungsproblematik waren Schwerpunktthemen - und mithin die Bedeutung der deutschen Westorientierung hervorzuheben, stand proamerikanisches und -europäisches Denken keineswegs im Widerspruch zueinander, sondern ergänzten sich. Deshalb koinzidierte die grundsätzliche Thematisierung der europäischen Einigung, d.h. der Aufbau eines politisch und ökonomisch neuen Europas, mit dem Ziel der transatlantischen Ausrichtung, in deren Mittelpunkt die Rolle Westdeutschlands stand.

Dem politischen Selbstverständnis nach verstand sich Der Monat als eine antitotalitäre Zeitschrift und fühlte sich den liberal-demokratischen Werten verpflichtet. Ex negativo bedeutete dies die Ablehnung und Gegnerschaft $\mathrm{zu}$ allen nicht demokratischen Herrschaftsregimen wie unter anderem des deutschen Nationalsozialismus, des italienischen Faschismus, rechtsgerichteten Diktaturen in Spanien, Portugal oder auch in Mittel- und Südamerika sowie des sowjetkommunistischen Herrschaftssystem einschließlich seiner Satellitenstaaten. Als totalitäre Herrschaftssysteme wurden der Nationalsozialismus und der Sowjetkommunismus - insbesondere in seiner stalinistischen Phase - apostrophiert. In Anbetracht der antitotalitären Grundposition folgte daraus, dass die Analyse und Beschreibung des nationalsozialistischen und des sowjetkommunistischen Herrschaftssystems, der Vergleich der beiden Regime und die zeitgenössischen Totalitarismustheorien zu Schwerpunktthemen avancierten.

Analog zu Eric Voegelins ideengeschichtlichem Erklärungsansatz wurden der Nationalsozialismus und der Sowjetkommunismus (sowie der italienische Faschismus) generell als Produkte des Säkularisierungsprozesses angesehen. Obwohl sich die einzelnen Autoren nicht ausdrücklich auf den deutschen Emigranten beriefen, besaß gleichwohl der 1938 in seinem gleichnamigen Buch entwickelte Begriff respektive das (Forschungs-)Paradigma »Politische Religion« einen entscheidenden Einfluss bei der (vergleichenden) Analyse der modernen politischen Gewaltregime. Die Ideologien wurden als das Ergebnis einer innerweltlichen Religion aufgefasst, die das Kollektiv der Rasse, der Klasse, der Nation oder des Staates als Realissimum erlebten, nämlich als »Abfall von Gott«, d. h. der Abkehr von der »überweltlichen Religion« des Christentums. $^{2}$

In diesem Zusammenhang wurde das Konzept der »Politischen Religion« unausgesprochen als grundsätzlicher analytischer Rahmen verwendet, um das Auftauchen der politischen Massenbewegung nach dem Ersten Weltkrieg in Deutschland und der Sowjetunion (sowie in Italien) zu erklären. Sie wurden als ein Ausdruck einer fundamentalen Krise der westlichen Zivilisation verstanden, die aus dem Verlust des (christlichen) religiösen Glaubens und der Abwendung von Gott resultierte. Dieser bereits im

2 So wurde beispielsweise von Hans Kohn das Phänomen des Nationalismus ausdrücklich als >Ersatzreligion< aufgefasst, das sowohl für den Nationalsozialismus als auch für den Sowjetkommunismus charakteristisch war. 
18. Jahrhundert in Gang gekommene Prozess habe demnach im 19. und in verstärktem Maße im 20. Jahrhundert zu einer fortschreitenden Verweltlichung, zu Entseelung und Veräußerlichung, zu reinem Macht- und Erwerbsstreben sowie schließlich zu Atheismus und Nihilismus geführt und das widerchristliche Totalitarismusphänomen erst möglich gemacht. Hierbei kam im Monat zur Sprache, dass sowohl der Nationalsozialismus als auch der Sowjetkommunismus vorhandene religiöse Bedürfnisse der Individuen ausnutzten. Die mentalen und (sozial-)psychologischen Voraussetzungen für die Anfälligkeit der einzelnen sogenannten verlassenen und ängstlichen Menschen in der modernen (kapitalistischen) Industriegesellschaft für das Totalitarismusphänom lagen dem Monat zufolge darin, dass in einer Welt ohne Gott eine existenzielle geistige Leere entstanden ist. Hierbei wurde generell angesprochen, dass sowohl im Nationalsozialismus als auch im Sowjetkommunismus ein messianischer Führerkult bzw. -glaube existierte und dass Hitler und Stalin (sowie Lenin) als gottähnliche Herrscher betrachtet wurden, in die die Massen ihre heilsgeschichtlichen Erlösungsvorstellungen hineinprojizierten.

Zudem fungierte implizit als weiterer Interpretationsrahmen beim Vergleich der beiden totalitären Bewegungen die sozialreligiöse Variante der Totalitarismustheorie des englischen Kulturhistorikers Norman Cohn. Entsprechend seiner Studie The Pursuit of the Millennium (1957) bestand demnach eine wesentliche Gemeinsamkeit darin, dass die in den Ketzerbewegungen des Mittelalters anzutreffende revolutionäre Eschatologie im >Dritten Reich und dem (sowjetischen) Kommunismus fortlebten und dass die eigene Partei die innerweltliche Heilserlösung verwirklichen werde. ${ }^{3}$

Das Paradigma der »Politischen Religion« diente also im Monat als grundsätzlicher Rahmen, um die totalitären Gewaltregime, die politischen Massenbewegungen und ihre Ideologien $\mathrm{zu}$ interpretieren. Insofern knüpfte die Zeitschrift an eine weit verbreitete zeitgenössische wissenschaftliche und publizistische Diktaturkritik an, die die Neuartigkeit der totalitären Diktaturen im Vergleich zu den aus der Geschichte bekannten despotischen, autokratischen oder tyrannischen Staatsformen mit dem quasi-religiösen Charakter begründeten. So betonte bereits Carlton J. H. Hayes auf der berühmt gewordenen wissenschaftlichen Konferenz im November 1939 in Philadelphia, die sich zum ersten Mal ausdrücklich auf die Totalitarismustheorie bezog, dass sowohl der Nationalsozialismus (bzw. Faschismus) als auch der Kommunismus aus dem »Verfall der traditionellen Religion und [der] Verdunkelung von religiösen Werten« hervorgingen, aus der Sehnsucht der Massen, die entstandene religiöse Leere »mit irgendeinem neuen Glauben auszufüllen«. In eben diesen neuen Diktaturen

3 Gleichwohl spielten zentrale Gesichtspunkte aus Norman Cohns Totalitarismusinterpretation in erster Linie bei der Auseinandersetzung mit dem (sowjetischen) Kommunismus eine Rolle, ohne dass sich die Autoren des Monat hier ausdrücklich auf die Untersuchungsergebnisse von Cohn zu beziehen brauchten. Denn obwohl Cohn beide totalitären Systeme in der Tradition der europäischen Ketzerund Sektenbewegungen wurzeln ließ, lag es nahe, bestimmte von ihm herausgearbeitete Phänomene vornehmlich auf den Kommunismus zu beziehen, zumal von den Renegaten. Denn gerade sie hatten sozusagen aus erster Hand erfahren, wie sich die Tradition des apokalyptisch-messianischen Dualismus oder Chiliasmus in säkularisierter Form im Kommunismus wiederfanden: Zum Beispiel der an die christlichen Sekten im Mittelalter erinnernde permanente Kampf um die reine »Lehre«, niedergelegt »in (durchaus wechselnden) >Generallinien< im Kommunismus, von der der Cläubige abkommen konnte, wenn er sich dem Wechsel der Generallinie nicht schnell genug anpaßte«. Imanuel Ceiss, Die Totalitarismen unseres Jahrhunderts, in: Jesse, Totalitarismus im 20. Jahrhundert S. 160-175, hier S. 169. 
würden »wesenhaft religiöse Element[e]« und »religiöse Gefühle« angesprochen. »Als Hohepriester neuer und glühender Religionen« appellierten die »Diktatoren von heute an die Massen. Als Neubekehrte«, so Hayes, antworteten »die Massen enthusiastisch und fanatisch « auf diesen Appell. ${ }^{4}$ Auch Aron benutzte, wie gezeigt, im selben Jahr ausdrücklich den Begriff der "politischen Religion«, als er den unterschiedlichen politischen, soziologischen und ideengeschichtlichen Ursprüngen des Nationalsozialismus, des italienischen Faschismus und des sowjetischen Kommunismus nachging. ${ }^{5}$

Nicht zuletzt mit Blick auf den sowjetischen Kommunismus wurde im Monat der Begriff "politische Religion« angewandt. So wurde nicht nur die Theorie und Praxis des Marxismus respektive des Kommunismus als innerweltliche Religion verstanden und sogar als »Islam des 20. Jahrhunderts « (Monnerot) apostrophiert, ${ }^{6}$ sondern spielte bereits bei der Thematisierung der historisch-politischen und ideengeschichtlichen Ursprünge des linken Totalitarismus in einigen Beiträgen eine Rolle. Zum eigentlichen Bezugspunkt wurde hierbei die jakobinische Tradition der Französischen Revolution, deren quasi-religiöser Charakter angesprochen wurde. Man betrachtete sie mehr oder weniger als Antizipation der sich nach der Oktoberrevolution von 1917 entwickelnden sowjetischen `Schreckensherrschaft sowie, ganz generell, als Beispiel für die Idee und Praxis einer `Volksdemokratie als »totalitäre Demokratie«.

In prononcierter Form wurde die Parallelität von Demokratie und Totalitarismus in dem Beitrag Totalitäre Demokratie von Talmon untersucht. In der deutschen Übersetzung des Eingangs- und Schlusskapitels seiner 1952 in London erschienenen Studie The Origins of Totalitarian Democracy sowie in den einleitenden Worten der Redaktion des Monat kam mit Blick auf den linken Totalitarismus in seiner realhistorischen Gestalt des Stalinismus zum Ausdruck, dass durch die Gleichsetzung der Freiheit mit Tugend und Vernunft im Sinne von Rousseaus Vorstellung einer »volontè générale« jene »totalitäre Demokratie« theoretisch begründet wurde, die später von Robespierre in der jakobinischen Phase der Französischen Revolution sowie durch Babeufs Plan einer egalitären kommunistischen Gesellschaft zum ersten Mal in die Praxis umgesetzt wurde. Im Gegensatz zur liberalen Demokratie zeichnete sich - wie gesehen ${ }^{7}$ für Jacob L. Talmon die totalitäre insbesondere durch den Mangel an empiristischem Pragmatismus aus, verzichtete auf das Prinzip »trial and error « und ging von der Annahme aus, dass es die Wahrheit ausschließlich in der Politik gäbe und diese mithin alle menschlichen und gesellschaftlichen Bereiche beherrschte. Nach Talmon konnte in diesem Zusammenhang von einem »politischen Messianismus " gesprochen werden, da der Vorstellung über die Rolle der Politik im menschlichen Dasein, der Traum einer "vorausbestimmten harmonischen und vollkommenen Ordnung« korrespondierte,

4 Carlton Joseph Huntley Hayes, The Novelty of Totalitarianism in the History of Western Civilisation (1940), hier nach der dt. Ausg. in: Seidel/Jenkner, Wege der Totalitarismus-Forschung, S. 86-100, hier S. $90 \mathrm{f}$.

5 Raymon Aron, Das Zeitalter der Tyranneien (Mai 1939), in: Stark, Raymond Aron und der Cestaltwandel des Totalitarismus, S. 186-208; siehe die entsprechenden Ausführungen im Einleitungskapitel.

6 Vgl. François Bondy, Der expropriierte Marxismus, in: Der Monat 2 (1950), H. 21, S. 309-313 (Rezension).

7 Siehe die entsprechenden Ausführungen im Einleitungskapitel. 
»auf welche die Menschen unwiderstehlich zustreben und bei der sie unweigerlich anlangen müssen . $^{8}$

Für Talmon besaßen Vorstellungen einer in der Geschichte angelegten vollkommenen, herrschaftsfreien Ordnung, in der alle gesellschaftlichen Widersprüche und Konflikte aufgelöst sind, und die Doktrin des Gemeinwillens alle Eigenschaften einer »weltlichen Religion«. Die totalitäre Demokratie als eine Diktatur war für ihn dadurch gekennzeichnet, dass sie sich auf die Begeisterung der Volksmassen stützt, wodurch sie sich von traditionellen Autokratien unterschied. Für ihn war sie das Ergebnis der Verknüpfung der Idee des 18. Jahrhunderts von der »natürlichen Ordnung« und der rousseauschen Idee von der Selbstentfaltung und Selbstbestimmung des Volkes. Durch diese Synthese wurde der Rationalismus in eine neue Art von Religion verwandelt. ${ }^{9}$

Der Vergleich zwischen dem Nationalsozialismus und dem Sowjetkommunismus besaß für den in dieser Arbeit zugrunde liegenden Untersuchungszeitraum (Oktober 1948 bis April 1960) eine zentrale Bedeutung. Indes beschränkte sich hierbei die ausdrückliche vergleichende Analyse der beiden totalitären Herrschaftssysteme primär bis zum Tod Stalins, der für den Monat grundsätzlich eine historische Zäsur darstellte. In diesem Zusammenhang besaß die 1951 in den Vereinigten Staaten erschienene Totalitarismusstudie The Origins of Totalitarianism von Arendt einen herausragenden Stellenwert. Insbesondere durch die arendtsche Untersuchung wurden das Wesen und das Prinzip des Totalitarismus charakterisiert, zudem dienten ihre entscheidenden analytischen Definitionsmerkmale für das Bestimmen der neuen Staatsform zahlreichen Autoren, um die totalitären Regime aus Deutschland und der Sowjetunion vergleichend $\mathrm{zu}$ beschreiben und $\mathrm{zu}$ analysieren. Danach war es vor allem die enge Affinität zwischen Ideologie und Terror, die den spezifischen totalitären Charakter des nationalsozialistischen und des sowjetischen Herrschaftssystems in seiner realhistorischen Gestalt des Stalinismus bestimmte und die unter anderem die differentia spezifica sowohl zu traditionellen als auch zeitgenössischen (prä-)faschistischen oder diktatorialen Herrschaftssystemen ausmachte.

Vor dem Hintergrund der wechselvollen Geschichte des Totalitarismusbegriffes seit den 1920er-Jahren und besonders mittels wesentlicher Gesichtspunkte sowie analytischer Definitionsmerkmale aus Arendts Totalitarismusstudie war im Monat beim Vergleich des Nationalsozialismus mit dem Stalinismus die wesentliche Erkenntnis, dass es sich in beiden Fällen um Einparteienregime handelte, in der eine kleine (kriminelle) Führungsgruppe, an deren Spitze freilich Hitler und Stalin standen, durch die spezifische Methode des Terrors ihre totale Herrschaft sicherte. $\mathrm{Zu}$ den entscheidenden Herrschaftsinstrumenten avancierten für die Autoren die Geheimdienstapparate der Gestapo und des NKWD. Vor diesem Hintergrund wurde beim vergleichenden Blick auf das >Dritte Reich und den Stalinismus deutlich, dass es sich um allumfassende, alles verschlingende Herrschaftssysteme handelte, in denen durch einen all-

8 ] [acob] L. Talmon, Totalitäre Demokratie, in: Der Monat 4 (1952), H. 44, S. 155-164, hier. S. 156. Vgl auch F[ritz] R[ené] Allemann, Eine Geistesgeschichte des Totalitarismus, in: Der Monat, 16 (1963), H. 183, S. 88-92; hierbei handelte es sich um eine Rezension der beiden Bücher von Talmon: Die Ursprünge der totalitären Demokratie, Köln und Opladen 1961 sowie Politischer Messianismus. Die romantische Phase, Köln und Opladen 1963.

9 Siehe ebd., S. 157-164. 
gegenwärtigen Terror die gesamte Gesellschaft atomisiert, die Angst allgegenwärtig war und es keinen Freiraum geben sollte und in denen die politische Ideologie nicht in irgendeiner Weise präsent war. Gleichwohl war es nicht nur ebendieser lückenlose Herrschaftscharakter, der nach Auffassung der meisten Autoren den deutschen und sowjetischen Totalitarismus auszeichnete, sondern zudem der auf den »Geist und die Seele« (Harald Hurwitz) der einzelnen Menschen abzielende totale Herrschaftsanspruch; diese theoretische Erkenntnis kam stellvertretend in der Veröffentlichung des abgedruckten Buches 1984 von Orwell zum Ausdruck.

Zum Inbegriff der totalitären Herrschaftssysteme des Nationalsozialismus und des Sowjetkommunismus stalinistischen Typs wurde für den überwiegenden Teil der Autoren des Monat das System der Konzentrationslager. Nicht nur für Arendt zählte es $\mathrm{zu}$ den grundlegenden Ansichten, dass die deutschen und die sowjetischen Lager als Laboratorien für ihren genuinen Anspruch dienten, dass Menschen total beherrschbar waren. Analog zu dieser Erkenntnis vertrat Der Monat die generelle Auffassung, dass sowohl für das nationalsozialistische als auch für das stalinistische Herrschaftsregime, deren gemeinsames Wesen der (permanente) Terror war, das System der Konzentrationslager zentraler Bestandteil war und dass sie ohne die Lager im Grunde genommen nicht existieren konnten.

Die beiden totalitären Einparteienregime verkörperten für den Monat und »seine« Autor/-innen die Prototypen der antidemokratischen Herrschaftsmodelle, die sich qua definitionem den existenziellen Kampf gegen die westlichen liberal-demokratischen Staaten zum Ziel gesetzt hatten. Hierbei wurden in einigen Beiträgen neben den ideenauch die gesellschaftsgeschichtlichen und politischen Voraussetzungen für die staatliche Machteroberung der nationalsozialistischen und bolschewistischen Massenbewegung thematisiert. Vor dem Hintergrund der Französischen Revolution und der allgemeinen europäischen Entwicklung des 19. Jahrhunderts - mit dem Entstehen der nationalistischen und sozialistischen Massenbewegungen nach »der « 1848er-Revolution - wurde im Ausbruch des Ersten Weltkrieges die entscheidende historische Zäsur gesehen, weil er zur materiellen »Not der Massen« (Löwenthal) führte. Damit waren die politischen, wirtschaftlichen und sozialen Probleme der Menschen in Deutschland und Russland infolge der rasanten industriellen Entwicklung nach dem Ersten Weltkrieg gemeint, die auf einer allgemeinen Ebene angesprochen wurden. Insofern erfolgte beim Vergleich der beiden totalitären Staaten keine Analyse der genauen komplexen länderspezifischen Bedingungen, die zur staatlichen Machteroberung der Nazis und der Bolschewiki führten.

Analog zur Entwicklung des Totalitarismusbegriffes nach Beendigung des Zweiten Weltkrieges vollzog sich auch im Monat in der veränderten politischen und militärischen Landschaft des Kalten Krieges ein entscheidender Perspektivenwechsel, weg von einem eher antifaschistischen und antinazionalsozialistischen hin zu einem primär antikommunistisch ausgerichteten Totalitarismusverständnis. Bildete bis dahin der Nationalsozialismus bzw. der Faschismus das Modell, an dem die kommunistische Variante gemessen wurde, übernahm im Monat die stalinistische Sowjetunion diese Rolle. Hierbei lag die Zeitschrift ganz auf der Linie von Schlesinger jr., der in seinem 1949 erschienenen und im Monat abgedruckten Buch The Vital Center. The Politics of Freedom den Nationalsozialismus im Gegensatz zur Sowjetunion als noch nicht voll ausgereiftes Muster totalitärer Herrschaft kennzeichnete. Auf diese Weise verblieb der stalinistische Bolschewismus als eigentlicher Modellfall des Totalitarismus. 
Insofern war der Vergleich des Nationalsozialismus und des Stalinismus im Monat insgesamt betrachtet dadurch geprägt, dass er sich im Fahrwasser der zeitgenössischen politisch-wissenschaftlichen Sowjetforschung der 1950er-Jahre befand und in diesem Zusammenhang eine normative Funktion besaß. Denn bei dem Vergleich des deutschen und des sowjetischen Totalitarismus ging es nämlich primär um ein politisches Urteil, dessen zentrales Ziel angesichts des Kalten Krieges die grundsätzliche Delegitimation des sowjetischen Kommunismus war - einschließlich der von Moskau dominierten osteuropäischen Satellitenstaaten und der SED-Diktatur. Dies kam insbesondere in der Auffassung zum Ausdruck - ohne hierbei die zeitgenössischen Forschungsergebnisse zur Geschichte des >Dritten Reiches`heranzuziehen -, die sowjetisch-kommunistische Parteidiktatur als den eigentlichen Typus totalitärer Herrschaft einzustufen, weil sie im Gegensatz zum Nationalsozialismus die Wirtschaftsstruktur des Privateigentums radikal verändert und mithin die »Einheit von Staat und Gesellschaft« (Schlesinger jr.) realisiert hatte.

Dass es bei der vergleichenden Analyse des Nationalsozialismus und des Sowjetkommunismus im Monat primär um ein politisches Urteil ging, wurde auch und vor allem bei der ausführlichen Auseinandersetzung mit dem deutsch-sowjetischen Nichtangriffsvertrag deutlich. So wurde in dem zweiteiligen Beitrag zum HitlerStalin-Pakt von Rossi (H.11 und 12) unter anderem durch einen instrumentellen Gebrauch von einzelnen Nürnberger Prozessdokumenten nicht nur Stalin als eigentlich handelnder Akteur und territorialer Nutznießer betrachtet, sondern im Grunde genommen auch als derjenige, der selber die Hauptverantwortung für den deutschen Überfall auf die Sowjetunion trug und zudem eine Mitverantwortung für die nationalsozialistischen Massenverbrechen an den Millionen jüdischer Menschen innerhalb des Generalgouvernements Polen besaß. Ausgeblendet wurde von Rossi (als auch von anderen Autoren) vor allem, dass nach dem Überfall der Wehrmacht auf die Sowjetunion im September 1941 auch die sowjetische Bevölkerung und die sowjetischen Juden zu den Opfern der deutschen Massenverbrechen zählten.

Parallelen hierzu existierten auch beim Vergleich des nationalsozialistischen und des stalinistischen Terrors, der in der Regel abstrakt oder im Rahmen von allgemeinen philosophischen Reflexionen über den Konnex von Ideologie und Terror erfolgte. Die konkreten Massenverbrechen des deutschen Nationalsozialismus (und mithin auch die Vernichtung der europäischen Juden) und des sowjetischen Totalitarismus wurden hierbei allerdings nicht ausdrücklich verglichen.

Dies kam auch bei der Gegenüberstellung der nationalsozialistischen und der stalinistischen Konzentrationslager zum Ausdruck, die fast ausschließlich im Rahmen von abstrakten Reflexionen erfolgte. Während allerdings das sowjetische Konzentrationslagersystem im Monat ausführlich beschrieben und analysiert wurde und hierbei auch der konkrete Terror zur Sprache kam - unter anderem durch die Rezension von Büchern ehemaliger Häftlinge der stalinistischen Lager oder im Rahmen der ausführlichen Berichterstattung über die sogenannten Krawtschenko- und Rousset-Prozesse in Paris (siehe Kap. III) -, war die Einbeziehung der deutschen Lager nicht nur bei der vergleichenden Analyse der beiden totalitären Diktaturen von untergeordneter Bedeutung; hier fungierten im Grunde genommen die Konzentrationslager des "SS-Staates« ausschließlich als Negativfolie für die stalinistischen Lager. Wie in dem Kapitel IV.1 gezeigt werden konnte, veröffentlichte das Zeitschriftenmedium keinen Beitrag, der sich ausdrücklich mit dem deutschen System der »Konzentrations- und 
Vernichtungslager« (Hannah Arendt) auseinandersetzte. Außerdem rückten bei der vergleichenden Beschreibung und Analyse der ökonomischen Bedeutung der Konzentrationslager für die beiden totalitären Herrschaftssysteme, mit Ausnahme der kurzen Ausführungen von Arendt zur Rolle der Lager und der `Sklavenarbeit für die Finanzierung des SS-Apparates und des NKWD in der Veröffentlichung Die Geheimpolizei (H.46), dieser zentrale Aspekt nahezu ausnahmslos mit Blick auf den sowjetischen Staat in den Fokus.

Die Ergebnisse der qualitativen und quantitativen Analyse des Nationalsozialismus und des Sowjetkommunismus im Kapitel IV der vorliegenden Untersuchung brachten weitere Unterschiede bei der Auseinandersetzung mit den beiden totalitären Regimen zutage, die im Folgenden resümierend gegenübergestellt werden sollen.

Die quantitative Auswertung ergab, dass die ausdrückliche Thematisierung, Beschreibung und Analyse der Geschichte des >Dritten Reiches` in 60 Beiträgen ${ }^{10}$ und des Sowjetkommunismus in knapp 250 Beiträgen erfolgte. Während die 60 Beiträge zur Geschichte des >Dritten Reiches` von knapp 30 Personen veröffentlicht wurden und sich letztlich Trevor-Roper (neun Beiträge) sowie Hofer (fünf Beiträge) als die eigentlichen NS-Experten herauskristallisierten, wurden die knapp 250 Beiträge zur Geschichte des sowjetischen (bzw. internationalen) Kommunismus von 122 Autoren verfasst. Die meisten Beiträge veröffentlichten die ehemaligen Kommunisten Salter (neun), Borkenau (zehn) und Löwenthal (17), Lasky (elf) und Lüthy (18).

Während sich unter den Autoren, die sich ausdrücklich mit der Geschichte des >Dritten Reiches< auseinandersetzten, nur vereinzelt prominente deutsche und internationale NS-Forscher befanden (u.a. Trevor-Roper, Hofer), veröffentlichte mit Blick auf den sowjetischen Kommunismus ein großer Teil der renommierten internationalen Vertreter der sogenannten Sowjetforschung der 1950er-Jahre.

Substanzielle Unterschiede ergab auch und vor allem die qualitative Analyse der Beiträge zur Geschichte des Nationalsozialismus und des Sowjetkommunismus:

- Während vom nationalsozialistischen Herrschaftssystem im Gegensatz zum angloamerikanischen polykratischen Forschungsansatz (z. B. Arendt, Reitlinger, Neumann) ein personenzentriertes, stark hitlerzentriertes Bild gezeichnet wurde (die Geschichte des >Dritten Reiches`wurde fast ausschließlich unter die Kategorie Hitler subsumiert und durch ihn erklärt), das mit einer totalitarismustheoretischen Perspektive korrespondierte (gemeinhin wurden neben Goebbels und dem Herrschaftsinstrument der Propaganda insbesondere Himmler und der Terrorapparat der SS und der Gestapo in den Blick genommen), erfolgte die Analyse des sowjetischen Herrschaftssystems differenzierter. Vor dem Hintergrund, dass zwischen drei Herrschaftsphasen unterschieden werden musste, rückten insbesondere der Stalinismus und der Nachstalinismus ins Zentrum. Im Hinblick auf das stalinistische Herrschaftssystem galt folgende Unterscheidung: In den bis zum Tod Stalins veröffentlichten Beiträgen wurde als interpretatorischer (Forschungs-)Ansatz ein personen-, d.h. stalinzentriertes Modell favorisiert, das mit einer totalitarismustheoretischen Perspektive koinzidierte. Gleichwohl kam

10 Zudem ging die Zeitschrift in knapp 50 Beiträgen »indirekt bzw. nebenbei« und in 40 Beiträgen aus einer explizit totalitarismustheoretischen Perspektive (wie zum Beispiel in den Auszügen aus Arendts Totalitarismusstudie) auf die Ceschichte des >Dritten Reiches`ein. 
hierbei zum Ausdruck, dass Stalin nach dem Tod Lenins lange Jahre keineswegs der alleinige >Herr und Meister der KPdSU und nicht von Anbeginn der Alleinverantwortliche und -herrscher des nachleninistischen Regimes war. Auch und vor allem für die späten 1920er- und frühen 1930er-Jahre wurde aufgrund von zum Teil fundamentalen Meinungsverschiedenheiten sowie Rivalitäts- und Richtungskämpfen in der sowjetischen Staatspartei und im Politbüro nicht von einem genuinen Stalinregime und einer monolithischen Herrschaftsstruktur ausgegangen. Und in den Veröffentlichungen nach Stalins Tod wurde wiederum sowohl für den Stalinismus als auch für den Nachstalinismus ein polykratischer Interpretationsansatz favorisiert, der seinen Ausdruck in der »Viersäulentheorie« (Parteiapparat, Geheimpolizei, Armee und staatliche Wirtschaftsverwaltung) fand; insofern schlug sich hier unausgesprochen der zur Erforschung des NS-Staates bezogene Analyseansatz des Behemoth-Autors Neumann nieder.

- Während die Auseinandersetzung mit dem nationalsozialistischen Terror in erster Linie abstrakt erfolgte, besaß demgegenüber die Auseinandersetzung mit dem konkreten stalinistischen Terror eine große Bedeutung.

- Während die Thematisierung, Beschreibung und Analyse der konkreten deutschen Massenverbrechen sowie der Vernichtung der europäischen Juden eine untergeordnete Bedeutung besaß und neben Hitler nahezu ausschließlich mit dem anonymen SS-Apparat Himmlers sowie dem Namen Heydrich in Verbindung gebracht wurde, konnten die konkreten stalinistischen Massenverbrechen ausführlich zur Sprache gebracht und substanziell untersucht werden. Auch wenn für den Monat zweifelsohne primär Stalin persönlich die Verantwortung trug und der stalinistische Terror durch den NKWD durchgeführt wurde, wurde gleichwohl hervorgehoben, dass nicht zuletzt der »Große Terror« in den Jahren 1934 bis 1938 (der damals zum Synonym des stalinistischen Terrors wurde) nicht auf die totalitäre Machtstellung und den "pathologischen Verfolgungswahn« des Kremlchefs sowie die genuine Verfolgungs- und Verhaftungspraxis des sowjetischen Geheimdienstapparat reduziert werden konnte. Denn angesichts der nach dem Kirow-Mord am 1. Dezember 1934 in Gang gekommenen Parteisäuberung und des politischen Terrors gegen die Bevölkerung entstand nämlich tatsächlich in der Sowjetunion ein gesellschaftliches Klima, in dem alle Bürger verdächtigt und zum »Feind« erklärt werden konnte und gewissermaßen der gesamte Alltag des Sowjetbürgers von einer »Feindobsession« bzw. »Feindparanoia« infiziert war, sodass schließlich die von Arendt in ihrer Totalitarismusstudie beschriebene und analysierte "Atomisierung« entstand, d.h. jene »Massengesellschaft terrorisierter und isolierter Individuen«. Diese wiederum hatte die gegenseitige Denunziation der einzelnen Parteimitglieder der KPdSU (einschließlich der Politemigranten der Komintern, der KPD und weiterer Funktionäre einzelner KPs) und der Menschen untereinander (sogar bis in die eigene Familie) sowie bei den sowjetischen Sicherheitsorganen zur Folge. Hierdurch wurde der stalinistische Terror nicht nur weiter in Gang gehalten, also permanent, sondern radikalisierte sich mittels der selbstreferenziellen bürokratischen Verfolgungslogik der Sicherheitsorgane zusätzlich.

- Während der stalinistische Terror trotz kaum vorhandenen zuverlässigen und »elementaren Dokumenten und Statistiken« (Arendt) ausführlich und substanziell untersucht und interpretiert wurde und sowohl die konkreten Massenverbrechen als auch die tatsächlichen Terrormethoden in den Fokus rückten (beispielsweise 
anhand von Erfahrungsberichten ehemaliger Kommunisten, die die Gewalt- und Folterpraxis des NKWD-Apparates und seiner Funktionäre eingehend beschrieben), wurden die nationalsozialistischen Massenverbrechen und die Vernichtung der europäischen Juden ausschließlich in vier Beiträgen konkret beschrieben und analysiert; diese vier Beiträge waren empirisch ausgerichtet. Neben den beiden Beiträgen von Lüthy Der Führer persönlich. Gedanken beim Lesen zweier Biographien und Laqueur Die Affäre Kastner handelte sich um die beiden Veröffentlichungen von Westphal Noch einmal »Die verhinderten Hochverräter u und von Arendt Bei Hitler $z u$ Tisch. Die Beiträge von Westphal und Arendt blieben in diesem Zusammenhang die beiden einzigen Veröffentlichungen, die sich ausdrücklich auf schriftliche Dokumente der Nürnberger Prozesse bezogen und vor allem auch benannten.

- Während die allgemeine zeitgenössische Forschungsliteratur im Hinblick auf die Auseinandersetzung mit der Geschichte des >Dritten Reiches< im Monat nur partiell eine Rolle spielte, besaß demgegenüber die Sowjetforschung von Anbeginn einen herausragenden Stellenwert. Bei der Analyse des Nationalsozialismus hatten im Grunde genommen nur die Bücher eine erkennbare Bedeutung (in Form einer Buchrezension, eines Vorabdruckes etc.), die entweder mit der stark hitlerzentrierten und totalitarismustheoretischen Perspektive korrespondierten, oder den deutschen national-konservativen Widerstand des 20. Juli, die sogenannte Memoirenliteratur sowie ganz allgemein den Zweiten Weltkrieg zum Gegenstand hatten. Demgegenüber wurden die bedeutendsten Bücher der Sowjetforschung im Monat rezensiert, (teil-)abgedruckt oder beeinflussten erkennbar die Beschreibung und Analyse des Sowjetkommunismus.

- Während im Monat bei der Beschreibung und Analyse des Nationalsozialismus insgesamt betrachtet die komplexe Vorgeschichte der staatlichen Machteroberung der »Hitlerbewegung« keinen breiten Raum einnahm (verantwortlich gemacht wurden insbesondere der Versailler Vertrag und Reichspräsident Hindenburg), ging man auf die historisch-politischen, gesellschaftlichen und ideengeschichtlichen Bedingungen der bolschewistischen Machtergreifung ausdrücklich ein. Mit Blick auf die NS-Herrschaft bedeutete dies, dass die tatsächlichen politischen, wirtschaftlichen und sozialen Voraussetzungen für den Aufstieg der (nationalistischen) NS-Massenbewegung Ende der 1920er-Jahre genauso wenig in den Mittelpunkt gerückt wurden wie die tatsächlichen Bedingungen, die zum Untergang der Weimarer Republik führten und zur Machtübertragung auf Hitler durch rechtskonservative, bürgerlich-aristokratische Führungsgruppen.

- Während die Machteroberung und -konsolidierung des »Führerstaates« im Monat nicht näher beschrieben und analysiert wurde, besaß insbesondere die innenpolitische Entwicklung des bolschewistischen Regimes nach der Oktoberrevolution eine zentrale Bedeutung. Insofern wurde weder die innenpolitische noch die außenpolitische Entwicklung Deutschlands in den Jahren 1933 bis 1938 fokussiert, sodass sowohl die nationalsozialistische »udenpolitik« als auch der Terror gegen die KPD oder die SPD nicht in das Zentrum des Erkenntnisinteresses rückte.

Daraus folgt, dass es dem Monat im Gegensatz zur Geschichte des Sowjetkommunismus um keine aufklärerische Auseinandersetzung mit dem Nationalsozialismus ging. Angesichts der Untersuchungsergebnisse wird hier mit Blick auf die eigentliche Bedeutung der Totalitarismusstudie Arendts in dem Zeitschriftenorgan die These ver- 
treten, dass sie eine doppelte Funktion besaß: eine antikommunistische und im $\mathrm{Zu}$ sammenhang des von der Zeitschrift favorisierten Bildes des Nationalsozialismus. Vor dem Hintergrund des Anspruches, zwei als totalitär definierte Herrschaftssysteme unter einen Begriff zu subsumieren und gleichzeitig abzulehnen, bezog sich das arendtsche Totalitarismusparadigma im Monat nach dem Untergang des NS-Regimes aktuell politisch im Grunde genommen in erster Linie auf die stalinistische Sowjetunion und ihre Satellitenstaaten. Ebendiese Tendenz wurde durch die Veröffentlichung der beiden Kapitel Totalitäre Propaganda (H.33/Juni 1951) und Die Geheimpolizei (H. 46/Juli 1952) dadurch bestärkt, dass in beiden Fällen der umfangreiche, sich primär auf die Geschichte des >Dritten Reiches bezogene Fußnotenapparat der Totalitarismusstudie Arendts nicht mit abgedruckt wurde..$^{11}$ Zudem wurden zentrale analytische Definitionsmerkmale Arendts zur Bestimmung einer totalitären Herrschaft benutzt, um das sowjetkommunistische Herrschaftssystem substanziell $\mathrm{zu}$ analysieren und nicht zuletzt den stalinistischen Terror in den 1930er-Jahren zu interpretieren. Andererseits lag mit Blick auf die Analyse des NS-Herrschaftssystems im Monat auch und vor allem durch die Veröffentlichung der beiden Kapitel Totalitäre Propaganda und Die Geheimpolizei der Schwerpunkt auf den repressiven und massenkommunikativen Machtmitteln, der exzessiven Propaganda und ihrer chiliastischen Ideologie, der Einparteienherrschaft und dem Personenkult. Vom NS-Staat konnte auf diese Weise das Bild eines monolithisch-totalitären Machtapparates gezeichnet werden, der hierarchisch nach dem Führerprinzip durchorganisiert war, in dem ein gigantischer Lenkungsapparat existierte, der die Massen zugleich umfassend ideologisierte, mobilisierte und kontrollierte, der sie führte und verführte. Unter Ausblendung zentraler Untersuchungsteile und -ergebnisse (z. B. der antisemitischen und imperialistischen Vorgeschichte des NS-Staates, ${ }^{12}$ dem Aufstieg der NS-Massenbewegung in der Weimarer Republik oder der spezifischen Strukturlosigkeit des »Führerstaates ${ }^{13}$ ) wurde so ein simplifizierendes und dämonisierendes Bild des >Dritten Reiches` gezeichnet.

11 Insofern passte der einzige veröffentlichte Leserbrief zu den beiden Beiträgen Hannah Arendts von Walter Birkhahn (Zur Praxis des Polizeistaates, in: Der Monat 4 [1952], H. 47, S. 545) in dieses Bild. Während Birkhahn zu Beginn der Auffassung war, dass Arendts Aufsatz Die Geheimpolizei in Deutschland besondere Aufmerksamkeit verdiene, »wo man zweimal in einer Ceneration das Heranwachsen und die unheilvollen Wirkungen eines Polizeistaates beobachten konnte«, bezogen sich die weiteren Ausführungen in erster Linie auf die Terrorpraxis des Stalinismus sowie auf den Zusammenhang von kommunistischer Ideologie und Terror. Insgeheim folgte Walter Birkhahn also in diesem Zusammenhang der antikommunistischen Funktion des Monat: Einerseits konzedierte er, dass es sowohl einen deutschen als auch einen sowjetischen Totalitarismus gab, anderseits hatte er mit seine Ausführungen, weil der Nationalsozialismus besiegt war, den Sowjetkommunismus und das SED-Regime im Auge.

12 Die Ausführungen in der Veröffentlichung des Kapitels »Der imperialistische Charakter« aus der Totalitarismusstudie von Arendt bezogen sich ausschließlich auf den englischen Imperialismus, genauer, auf den imperialistischen Charakter des Kolonialsystems Großbritanniens und waren auf die konkrete Vorgeschichte des Nationalsozialismus zweifelsohne nicht zu übertragen, zumal der Beitrag ohne einführende, erläuternde Worte der Zeitschriftenredaktion erschien.

13 Arendt beobachtete damals eine Hierarchielosigkeit als Strukturphänomen, ohne dass dies irgendeine analytisch-politische Bedeutung in der »Lasky-Zeitschrift« hatte, wonach der deutsche »Führerstaat «eben nicht durch die vielbeschworene, immer wieder angesprochene dämonische Willenskraft Hitlers charakterisiert war, sondern dadurch, dass die »typische Eskalation der Ziele und der Gewaltanwendung« (Hans Mommsen) aus der inneren Notwendigkeit entsprang, eben die »Bewegungs«- 
Gleichzeitig konnten die NS-Massenverbrechen im Allgemeinen und die Vernichtung der europäischen Juden im Besonderen auf die kleine Führungsclique um Hitler sowie die Herrschaftsinstitutionen der SS und der Gestapo reduziert werden. Somit konnte nicht zuletzt die Mitverantwortung und Mitwirkung der diplomatischen, bürokratischen, militärischen, medizinischen und wirtschaftlichen Eliten in das verbrecherische System kaschiert werden.

In diesem Zusammenhang wurde durch die von der Zeitschriftenredaktion vertretene Auffassung einer klaren Trennung von Regime, d.h. der unmittelbaren Führungsgruppe, und dem deutschen Volk bei der Auseinandersetzung mit dem Nationalsozialismus eine entscheidende Weiche gestellt. Denn diese Trennung stellte eine Komplexitätsreduktion dar, weil sie der deutschen Bevölkerung den Platz eines »verführten Volkes« zuwies und somit auf eine Exkulpation der ehemaligen »Volksgemeinschaft« hinauslief. Insofern war die Ausblendung bestimmter Themenschwerpunkte und Aspekte der zurückliegenden nationalsozialistischen Vergangenheit im Monat keineswegs dem Zufall geschuldet - wie zum Beispiel der genauen historisch-politischen Bedingungen, die zum 30. Januar 1933 geführt hatten, oder der innen- und außenpolitischen Entwicklung der NS-Diktatur. ${ }^{14}$ Auch wenn unter anderem aufgrund der zeitgenössischen Forschungsergebnisse zur Geschichte des >Dritten Reiches $<$ die zentrale Bedeutung der autoritären Tradition der deutschen Staatsbürokratie und die stark ausgeprägten antidemokratischen Vorstellungen bei den politischen Parteien und der deutschen Elite außer Zweifel stand, so entsprach es ebenfalls einer historischen Tatsache, dass die deutsche Bevölkerung in erheblichem Maße bereits in den Wahlen Ende der 1920er-Jahre und zu Beginn der 1930er-Jahre der »Hitler-Partei« ihren Zuspruch aussprach. Zudem waren es neben den innenpolitischen auch die außenpolitischen >Erfolge des NS-Regimes, die in der deutschen Bevölkerung den Glauben an den »Führer« verstärkte, der nach dem »Anschluss« Österreichs im März 1938 und insbesondere nach dem Einmarsch der Wehrmacht in Paris im Juni 1940 seinen Höhepunkt erreichte.

Insofern existierten angesichts zentraler Erkenntnisse im Hinblick auf die Analyse des Nationalsozialismus im Monat insgesamt betrachtet starke Parallelen zu dem Bild, das führende deutsche Historiker und Publizisten nach dem Ende des Zweiten Weltkrieges von der Geschichte des >Dritten Reiches` gezeichnet hatten. Abgesehen von der in der westdeutschen Nachkriegsgesellschaft weithin verbreiteten Vorstellung, die nationalsozialistischen Massenverbrechen auf die kleine kriminelle Führungsclique um Hitler sowie die Herrschaftsinstitutionen der SS und Gestapo zu reduzieren, war es insbesondere die Auffassung, dass die »Hitler-Diktatur« einen Einbruch in der deutschen (sowie der europäischen) Geschichte darstellte und im Grunde genommen als ein Betriebsunfall der Weltgeschichte zu betrachten sei, der sich in Deutschland ereignete, allerdings in jedem Land möglich gewesen wäre, die Gemeinsamkeiten aufwiesen. Bekanntlich versuchten der Nestor der deutschen Geschichtswissenschaft,

Struktur aufjeden Fall aufrechtzuerhalten. Für Arendt stand fest, dass sich die Stellung des »Führers« aus seiner »Funktion für die Bewegung«ergab (Elemente und Ursprünge totaler Herrschaft, S. 576).

14 So erklärt sich die vollkommene Ausblendung der NS-Außenpolitik von 1933 bis 1938 auch dadurch, dass die Redaktion des Monat und ein größerer Teil der konservativen Autoren nichts dagegen einzuwenden hatten und insbesondere das 'Sprengen ‘ der Fesseln des Versailler Vertrages im Crunde genommen begrüßten. Insofern lag hier eine bemerkenswerte Affinität im politischen Denken vor. 
Friedrich Meinecke, mit seinem einflussreichen Essay Die deutsche Katastrophe (1946) und Gerhard Ritters Buch Europa und die deutsche Frage. Betrachtungen über die geschichtliche Eigenart des deutschen Staatsdenkens (1948) den Nationalsozialismus aus einer negativen gesamteuropäischen Entwicklung heraus zu erklären, die mit der Französischen Revolution begann und die angeblich parallel zu der generell gesunden und positiven Entwicklung des deutschen Staates existiert hat. Das >Dritte Reich erschien hierbei als Katastrophe, die über Deutschland hereinbrach, als ein historischer Zufall (zumeist mit Hindenburg assoziiert) angesehen wurde und sich größtenteils auf den "Dämon« Hitler zurückführen ließ, sodass auch hier die spezifische Vorgeschichte des NS-Regime keinen besonderen Stellenwert besaß. Vor diesem Hintergrund war es nicht verwunderlich, dass die Redaktion des Monat den nicht zuletzt unter einigen führenden englischen Historikern verbreiteten Ansichten vehement entgegentrat, demzufolge der Nationalsozialismus in die Kontinuität der deutschen Geschichte zu rücken sei. Beabsichtigt war, die historischen Tiefenschichten des >Dritten Reiches`, die zweifelsohne auch in der spezifischen politischen Entwicklung Deutschlands nach der Revolution von 1848 lagen, nicht ausdrücklich zu beleuchten und vor allem die preußische Tradition von einer prinzipiellen Verdächtigung auszunehmen, dem Nationalsozialismus in irgendeiner Form den Boden mit vorbereitet zu haben. ${ }^{15}$

Insofern nutzte die Zeitschriftenredaktion das auch und vor allem durch die lebensgeschichtlichen Erfahrungen entstandene, häufig eine existenzielle Signatur aufweisende theoretische und historisch-analytische Wissen zu den Ursprüngen und zur Entwicklung des nationalsozialistischen Totalitarismusphänomens im Gegensatz zum sowjetischen von zahlreichen einflussreichen Mitarbeitern nicht aus. Prominente Autoren wären, wie es ihre wissenschaftlichen, politischen oder publizistischen Veröffentlichungen zeigten, prädestiniert gewesen, über die Geschichte des Nationalsozialismus in all seinen sowohl vielschichtigen als auch verbrecherischen Dimensionen aufzuklären. ${ }^{16}$

\section{III}

Vor dem Hintergrund der von der Redaktion des Monat in den Jahren der Ägide Laskys vorgenommenen klaren Trennung vom NS-Regime, d.h. dem dämonisch-übermächtigen Hitler mitsamt seiner kriminellen Führungsclique, und dem deutschen Volk wurde im Hinblick auf die Auseinandersetzung mit der unmittelbar zurückliegenden deutschen Vergangenheit, wie gesehen, eine entscheidende Weiche gestellt: Durch diese Komplexitätsreduktion wurde der deutschen Bevölkerung der Platz eines »verführten Volkes « zugewiesen, die in Anbetracht der begangenen NS-Massenverbrechen auf eine Exkulpation der ehemaligen »Volksgemeinschaft« hinauslief. In diesem $\mathrm{Zu}$ sammenhang vertrat Arendt eine entschieden entgegengesetzte Auffassung. So war sie 1975 angesichts der von Konrad Adenauer in den Nachkriegsjahren vertretenen Be-

15 Siehe bes. Golo Mann, Geschichtsschreibung als Realpolitik. Über A. J. P. Taylor und die Tragödie Mitteleuropas, in: Der Monat 4 (1951), H. 38, S. 130-140 (Sammelrezension). Vgl. hierzu auch A. J. P. Taylor, Die Realität der Geschichte. Eine Antwort, in: Der Monat 4 (1952), H. 43, S. 40-44, sowie Golo Mann, Ein Schlußwort, in: Ebd., S. $44 \mathrm{f}$.

16 Siehe hierzu insgesamt Kap. II. 
hauptung, dass die »Mehrheit des deutschen Volkes gegen Hitler gewesen sei«, rückblickend der Meinung:

Das ist eine Lüge. Wenn man das prozentual ausdrücken will, dann kann man sagen, 10 Prozent waren immer hundertprozentig dafür, 10 Prozent waren immer hundertprozentig dagegen, die übrigen 80 Prozent haben ihre Meinung von Jahr zu Jahr geändert. Ohne diesen Rückhalt im Volk hätte Hitler natürlich niemals regieren können. Keiner von solchen Leuten wie Hitler kann allein regieren, so etwas gibt es nicht. ${ }^{17}$

Indes stand die hier zum Ausdruck kommende »Theorie totalitärer Komplizenschaft« (Norbert Frei) bereits im Mittelpunkt des von Arendt in der vierten Ausgabe der Zeitschrift Die Wandlung im Jahre 1946 veröffentlichten Aufsatzes über »[o]rganisierte Schuld« und lag später ihrer Interpretation des Nationalsozialismus als ein System »totaler Herrschaft « insgesamt zugrunde; ${ }^{18}$ zudem schlug sie sich nieder in Arendts 1950 zunächst nur in der US-amerikanischen Zeitschrift Commentary erschienenen Deutschlandbericht über die Nachwirkungen des Naziregimes, wo sie unter anderem den Lebenslügen der Adenauer-Deutschen nachspürte und angesichts der Wirklichkeit der NS-Verbrechen und der Todesfabriken auch und vor allem eine spezifische Realitätsflucht der Deutschen konstatierte, die mit der Flucht vor der Verantwortung korrespondierte, die ihnen das »Hitlerregime « aufbürdete. ${ }^{19}$ So stellte Arendt am Anfang des ursprünglich in der Schlussphase des Zweiten Weltkrieges verfassten Textes über Organisierte Schuld ${ }^{20}$ fest, dass die von der NS-Führung selbst noch in der sich anbahnenden militärischen Niederlage behaupteten Geschlossenheit des deutschen Volkes keinesfalls als »bloße Propaganda« missverstanden werden durfte und »alle Hoffnungen der Alliierten auf ideologisch nichtinfizierte Teile des Volkes [...] Illusion seien«. Während das Regime anfangs versuchte, die Berichte über die Massenmorde möglichst geheim zu halten, wurden sie Arendt zufolge im Laufe des Krieges von den Nazis selbst auf dem Wege der »inszenierten Flüsterpropaganda« in Umlauf gebracht und von ihnen am Ende "völlig offen als Liquidierungsmaßnahmen« zugegeben, sodass auch »diejenigen >Volksgenossen<, welche man aus organisatorischen Gründen nicht hat in die >Volksgemeinschaft des Verbrechens aufnehmen können, wenigstens in die Rolle der Mitwisser und Komplizen gedrängt« wurden. Die totale Mobilmachung endete »in der totalen Komplizität des deutschen Volkes «. ${ }^{21}$

17 Legitimität der Lüge in der Politik? Hannah Arendt in der Diskussion mit Sebastian Haffner, Bernard Vogel und Hans-Friedrich Hölters, in: Reif, Gespräche mit Hannah Arendt, S. 101-126, hier S. 115.

$18 \mathrm{Vgl}$. Arendt, Elemente und Ursprünge totaler Herrschaft, S. 574, sowie dies., Totalitäre Propaganda, S. 258.

19 Siehe dies., Besuch in Deutschland sowie die entsprechenden Ausführungen über Arendt in Kap. II.4.8.

20 In der redaktionellen Vorbemerkung der Zeitschrift erfolgte der Hinweis, dass es »wichtig zu wissen« sei, dass der Aufsatz von Arendt »im November 1944 in Amerika verfasst und in englischer Übersetzung im Januar 1945 in der Zeitschrift Jewish Frontier veröffentlicht worden ist« (Arendt, Organisierte Schuld, S. 333).

21 Ebd., S. 334. Bei aller berechtigten Kritik, die man an der Zeitschrift Die Wandlung aus unterschiedlicher Sichtweise üben kann, muss gleichwohl beim Vergleich mit dem Monat mit Blick auf die Auseinandersetzung mit der Geschichte des >Dritten Reiches` zum einen und Arendts Untersuchung Elemente und Ursprünge totaler Herrschaft zum anderen ausdrücklich hervorgehoben werden: Die 
Arendts radikale Überlegungen $\mathrm{zu}$ dem vergangenheitspolitischen Thema der Kollektivschuld und -verantwortung des deutschen Volkes im Hinblick auf den gesellschaftlichen Umgang mit der Hypothek des NS-Regimes und »der in seinem Namen unter den Bedingungen organisierter Komplizenschaft begangener Verbrechen « blieben, nachdem sich bereits Jaspers aus einer deutlich nachsichtigeren Perspektive entwickeltes politisch-pragmatisches Modell über die Schuldfrage aus dem Winter 1945/46 als zu anspruchsvoll erwies, ${ }^{22}$ im Nachkriegsdeutschland praktisch unbeachtet und wurden auch im Monat nicht aufgegriffen. ${ }^{23}$ Insofern existierten an diesem angesichts der individuellen bzw. gesamtgesellschaftlichen Verstrickung in das NSRegime und den deutschen Massenverbrechen vergangenheitspolitisch überaus aufgeladenen Punkt Gemeinsamkeiten zwischen der besiegten »Volksgemeinschaft« und dem Monat: Sie lagen in der rigorosen Abwehr aller nicht auf Hitler, der unmittelbaren NS-Führung sowie dem durch Himmler und Heydrich personifizierten SS-Apparat beschränkten Vorwürfe. Nachdem sich in den unmittelbaren Nachkriegsjahren vor dem Hintergrund einer angeblichen »Kollektivschuldthese ${ }^{24}$ bei der besiegten $\gg$ Volksgemeinschaft« die Überzeugung verfestigte, dass die Alliierten eine kollektive Bestrafung beabsichtigten und sich daraufhin in Westdeutschland die angesprochene breite Abwehrfront gegen die (13) Nürnberger Prozesse und die Entnazifizierungspolitik konstituierte, wurde dieser vergangenheitspolitische Komplex im Monat systematisch ausgeblendet.

Dasselbe galt für zentrale Themen und Aspekte der politisch-justiziellen Auseinandersetzung mit der NS-Diktatur und ihren Gewaltverbrechen, zumal dann, wenn sie mit Blick auf die bundesrepublikanische Nachkriegsgesellschaft der späten 1940er-

Wandlung veröffentlichte einzelne Vorfassungen späterer Unterkapitel ihrer Totalitarismusstudie, wenn auch mit teilweise starken Abweichungen, die für Arendt von eminenter Bedeutung waren. Die Kapitel »Über den Imperialismus« (später: »Das Bündnis zwischen Kapital und Mob«), »Es gibt nur ein einziges Menschenrecht« (später: »Die Aporien der Menschenrechte«) und »Parteien und Bewegungen « (später: »Partei und Bewegung«) für die Untersuchung der Vorgeschichte des Totalitarismusphänomens, das Kapitel »Die Konzentrationsläger« (später: »Die Konzentrationslager«), um das spezifische Wesen der totalen Herrschaft zu analysieren. Zur Erinnerung: Diese Kapitel wurden aber damals von Arendt noch ausdrücklich zur genuinen Beschreibung und Analyse des NS-Herrschaftssystems geschrieben, ohne den Vergleich mit dem Stalinismus zu ziehen. Das heißt, abgesehen von der zugrunde liegenden Interpretation Arendts wurden bei der genuinen Beschreibung und Analyse des NS-Herrschaftssystems und seiner Vorgeschichte in Die Wandlung zentrale Aspekte und Themen ins Licht gerückt, die dann im Monat nicht zufällig ausgeblendet wurden oder nur im Hinblick auf die »Rot=Braun-Cleichung«Bedeutung erlangten.

22 In Kap. I.4.1 zeigte ich, dass Jaspers einen Unterschied machte zwischen einer moralischen Kollektivschuld, deren Instanz ausschließlich die individuelle Selbstprüfung sein müsse, und einer strafrechtlichen Kollektivschuld für die Beteiligung an den NS-Verbrechen, die er ausschließlich für eine »kleine Minderheit« gelten lassen wollte. Indes stand für Jaspers außer Frage, dass jeder einzelne Deutsche eine »politische Haftung « zu übernehmen habe, denn der »Verbrecherstaat« fiel dem »ganzen Volk zur Last«.

23 Insofern lag der Monat im Trend der kulturpolitischen Zeitschriften in Westdeutschland, in denen die Diskussion über die »Schuldfrage« Ende der 1940er-Jahre im Übergang zur Gründung der Bundesrepublik abrupt endete. Zum Verlauf dieser Debatte vgl. Barbro Eberan, Die Debatte um die Schuldfrage 1945-1949, München 1983.

24 Vgl. Norbert Frei, Von deutscher Erfindungskraft oder: Die Kollektivschuldthese in der Nachkriegszeit, in: Rechtshistorisches Journal 16 (1997), S. 621-634. 
sowie 1950er-Jahre politische Brisanz besaßen und sie sogar von Fall zu Fall die Maßnahmen der Westalliierten und nicht zuletzt der US-Militärregierung selbst zur »Denazification « Westdeutschlands konterkarierten. Hierbei lagen keine ausdrücklichen Vorgaben der amerikanischen Besatzungsmacht unter General Clay und später in Gestalt des Hohen Kommissars McCloy vor. Die Tatsache, dass Der Monat als offizielles Organ ungewöhnlich viel Freiheit besaß, resultierte gerade aus dem Umstand, dass Lasky von Anbeginn gewisse Grenzen respektierte und insbesondere die ausdrückliche Auseinandersetzung mit bestimmten kontroversen Fragen der deutschen Innenpolitik und der amerikanischen Innen- und Außenpolitik vermied. ${ }^{25}$ Nach der Ablösung von staatlichen Stellen und dem Übergang 1954 zur Ford Foundation sowie 1958 zum »Kongreß für kulturelle Freiheit« erklärte sich die ungewöhnlich große Freiheit der Zeitschrift aus der Tatsache, dass Lasky sowohl die inhaltliche Gesamtkonzeption als auch die Grenzen selbst festlegen konnte. ${ }^{26}$ Somit bedurfte es insgesamt betrachtet keiner direkten Einflussnahme seitens der staatlichen Stellen, zumal der CIA und der Abteilung für verdeckte Aktionen, oder der Pariser Zentrale des »Kongresses für kulturelle Freiheit«.

Während sich ein großer Teil der ehemaligen nationalsozialistischen »Täter- und Mitläufer-Gesellschaft« angesichts der Zerstörungen des Landes und des materiellen Elends, der eigenen Kriegstoten, der Kriegsniederlage, von Gefangenschaft und der vielfach als ungerecht empfundenen umfassenden Entnazifizierung in den frühen Nachkriegsjahren in eine »Opfergemeinschaft « verwandelte, ${ }^{27}$ die nicht nur eine Gesamtverantwortung für den Zweiten Weltkrieg und die Folgen ablehnte, sondern sich mit der Gründung der Bundesrepublik (in den regelmäßig durchgeführten Umfragen zum NS-Themenkomplex) für eine Beendigung der NS-Prozesse und überhaupt gegen eine Auseinandersetzung mit der NS-Vergangenheit aussprach, ging Der Monat in erster Linie auf bestimmte Aspekte und Fälle der vergangenheitspolitischen Dimension der NS-Diktatur ein: Die Zeitschrift setzte sich primär mit der NS-Vergangenheit auseinander, wenn es sich um Themen, aktuelle Anlässe oder Skandale handelte, die für die junge, in ihrem (internationalen) Ansehen und in ihrer Glaubwürdigkeit noch nicht über alle Zweifel erhabene Bundesrepublik eine hohe symbolische, geschichtsund imagepolitische Bedeutung besaßen. ${ }^{28}$

Hauptaugenmerk galt hierbei insbesondere dem grundsätzlichen Gedenken der von den Deutschen, oder wie es nicht selten hieß, im »deutschen Namen« begangenen Massenverbrechen, speziell an den europäischen Juden, wobei die »eigenen« Toten, zumal die im Zweiten Weltkrieg getöteten Wehrmachtssoldaten, keineswegs dem

25 Vgl. Hochgeschwender, Freiheit in der Offensive?, S. 162; Hurwitz, Der heimliche Leser, S. 19.

26 Mit Blick auf die Vereinigten Staaten folgte daraus, dass es wie gesehen fortan keineswegs um ein unkritisches »Amerikabild « ging und sich mehrere Beiträge mit zwei zentralen innenpolitischen Problemen auseinandersetzten: dem »McCarthyismus-Phänomen« und der »Negerfrage«.

27 Als Opfer verstanden sich nicht zuletzt die sogenannten Schicksalsgruppen, die Kriegsheimkehrer und -versehrten, die Hinterbliebenen und Ausgebombten sowie die »Heimatvertriebenen und Entnazifizierungsgeschädigten«.

28 Vor diesem Hintergrund kritisierte man immer wieder das bei vielen Intellektuellen grassierende Unbehagen bzw. die Verachtung gegen die junge Bundesrepublik, in der sie sich heimatlos fühlten und dies in dem politisch wirkungsmächtigen Schlüsselwort »Restauration «zum Ausdruck brachten. Vgl. besonders die scharfsinnige Analyse in dem Beitrag: Fritz René Allemann, Restauration im Treibhaus. Gedanken über ein Buch und eine Epoche, in: Der Monat 6 (1954), H. 67, S. 81-85 (Rezension). 
Vergessen anheimfielen. Neben dem Erinnern an den »Holocaust«, dessen Name erst Jahrzehnte später diesen Verbrechenskomplex bezeichnete, wurde der Singularitätscharakter der Vernichtung der europäischen Juden hervorgehoben, der sich aus zwei Gründen ergab: zum einen aus der industriell betriebenen Ermordung von fünf bis sechs Millionen Juden in den östlichen Vernichtungslagern, zum anderen aus der Tatsache, dass sich zum ersten Mal in der Menschheitsgeschichte ein Staat zum Ziel gesetzt hatte, alle Mitglieder einer nach religiösen und politischen Kriterien definierten Gruppe, unabhängig von Alter und Geschlecht, auszurotten. Hierbei wurden die historisch beispiellosen Verbrechen gemeinhin mit dem in Polen gelegenen größten Vernichtungslager »Auschwitz« umschrieben, wobei Auschwitz seinerzeit nicht nur eine unbekannte Ortschaft im Osten blieb, mithin ein ortloser Erinnerungsort, sondern auch ein Verbrechensort, an dem leibhaftige Deutsche als Täter nur schwer vorstellbar waren. ${ }^{29}$ Neben dem generellen Gedenken an den Holocaust wurde hierbei besonders an die Entrechtung, Verfolgung, Deportation und Ermordung einzelner Juden erinnert: Exemplarisch stand hier das jüdische Mädchen Anne Frank. ${ }^{30}$

Daneben besaß die Erinnerung an die Verfolgung und/oder Ermordung von wichtigen Vertretern der Emigranten, der SPD und des national-konservativen Widerstandes gegen die »Hitler-Diktatur« einen großen Stellenwert, wobei wiederum dem Gedenken an die Gruppe des 20. Julis als Verkörperung des »anderen Deutschlands« eine ganz besondere Ehre zuteilwurde. Ausgenommen von dem Opfergedenken waren hierbei insbesondere (deutsche) Kommunisten sowie die sowjetische und osteuropäische Bevölkerung.

In diesem Zusammenhang verfolgte Der Monat das vorrangige Ziel, seiner Leserschaft unmissverständlich ins Bewusstsein zu rücken, dass die Bundesrepublik Deutschland, die sich als Rechtsnachfolger des von den Siegermächten aufgelösten Deutschen Reiches von 1871 verstand und zugleich den Anspruch erhob, mit seinem Vorgänger, der »Hitler-Diktatur «, definitiv zu brechen, ${ }^{31}$ die Erbschaft des Nationalsozialismus anzutreten habe, mit allen darin enthaltenen und anfangs gar nicht absehbaren Risiken und Verbindlichkeiten. ${ }^{32}$ Mit Blick auf die westdeutsche Bevöl-

29 Vgl. z. B. Theodor Heuss, Ein Mahnmal, in: Der Monat 5 (1953), H. 52, S. 355-358. So bedeutsam die Rede des ersten Bundespräsidenten beim feierlichen Staatsakt zur Einweihung eines Mahnmals für die Opfer des Konzentrationslagers Bergen-Belsen am 30. November 1952 für die künftige Auseinandersetzung mit der NS-Verfolgungspolitik und den NS-Verbrechen in der Bundesrepublik war, muss gleichwohl festgehalten werden, dass für Heuss Auschwitz im Grunde genommen kein Begriff war, obwohl er den Begriff gebrauchte und dieser bereits seinerzeit als Synonym für die (abstrakte) Ausrottungspolitik galt.

30 Das 1955 im Fischer-Verlag erschienene Tagebuch von Anne Frank avancierte zu einem Publikumserfolg in der Bundesrepublik. Außerdem sahen Millionen den amerikanischen Spielfilm und die Bühnenfassung. Vgl. Norbert Muhlen, Anne Franks Heimkehr, in: Der Monat 9 (1957), H. 103, S. 79-82.

31 Reichel, Vergangenheitsbewältigung in Deutschland, S. 17.

32 Darum trat der Monat Versuchen in der deutschen Publizistik und Wissenschaft entschieden entgegen, die historisch-politische Verantwortung für die Geschichte des Nationalsozialismus und die deutsche Schuld für den Zweiten Weltkrieg infrage zustellen. Jeder Form des Entstehens einer neuen Dolchstoßlegende sollte die Grundlage entzogen werden. Vgl. hierzu mit Blick auf die Nachkriegsgesellschaft und speziell die westdeutsche Geschichtswissenschaft einflussreiche »Ranke Gesellschaft « den brillanten Beitrag von Walther Hofer, Der missbrauchte Ranke. »Konservative Revolution« in der deutschen Geschichtsschreibung, in: Der Monat 7 (1955), H. 84, S. 542-547 (Rezension). 
kerung folgte daraus die eindeutige Aufforderung, sowohl individuell als auch kollektiv die politisch-moralische Verantwortung für die unmittelbar zurückliegende Geschichte und nicht zuletzt für den Holocaust zu übernehmen. ${ }^{33}$ Aus diesem Grund wurden Versuche in der deutschen Öffentlichkeit, Publizistik oder Wissenschaft, die NS-Verbrechen an den europäischen Juden infrage zu stellen oder zu relativieren, radikal kritisiert und ihnen vehement entgegengetreten. ${ }^{34}$

Angesichts des Holocaust sprach sich Der Monat eindeutig für eine generelle Wiedergutmachung nationalsozialistischen Unrechts gegenüber den jüdischen Überlebenden und speziell dem Staat Israel aus, die man als sühnenden Akt der Westdeutschen betrachtete und als notwendige Voraussetzung für die Wiedereingliederung in die westliche Staatengemeinschaft sowie für die >Aussöhnungく zwischen Juden und Deutschen und jeder Form des Antisemitismus abzuschwören und entschieden entgegenzutreten. ${ }^{35}$

Im Grunde genommen stellte im Kontext der Auseinandersetzung mit der NS-Vergangenheit die Einstellung der Deutschen zu den Juden sowohl für die US-amerikanischen Besatzungsbehörden als auch für den Monat die »Feuerprobe der deutschen Demokratie« (McCloy) dar. Insofern besaß die kritische Auseinandersetzung mit dem Problem des facettenreichen Phänomens des Antisemitismus in der Bundesrepublik Deutschland eine überragende Bedeutung, zumal dann, wenn daraus regelrechte politische Skandale wurden: Wie gesehen im »Fall Harlan« unmittelbar nach Gründung der zweiten deutschen Republik oder aufgrund des »alltäglichen« Antisemitismus, der sich insbesondere in der zweiten Hälfte der 1950er-Jahre in zahlreichen öffentlichen Vorfällen Bahn brach und in dessen Zuge angesichts teilweiser skandalöser Gerichtsurteile auch und vor allem die tiefe Verstrickung der deutschen Justiz in die NS-Diktatur debattiert wurde, ${ }^{36}$ oder anlässlich der Schändung der erst wenige Monate zuvor im Beisein von Bundeskanzler Adenauer eingeweihten neuen Kölner Synagoge am Weihnachtsabend 1959, auf die die internationale und die deutsche Öffentlichkeit mit großer Bestürzung und Empörung reagierte. ${ }^{37}$

Dieser politische Skandal wurde außerdem zum Anlass genommen, sich mit der seinerzeit in der bundesrepublikanischen Öffentlichkeit kontrovers diskutierten Frage auseinanderzusetzen, inwiefern Personen, die einst dem NS-Regime die Gefolgschaft nicht verweigert hatten, jetzt gegen nationalistische, antisemitische und neo-

Vgl. auch die einleitenden Worte der Redaktion zu: Erwacht Deutschland schon wieder? Der neue deutsche Nationalismus und seine Gefahren, in: Der Monat 1 (1949), H. 8/9, S. 3-64, hier S. 3 f.

33 Siehe bes. Rudolf Hagelstange, Sühne und Ehre, in: Der Monat 4 (1952), H. 42, S. 584-590.

34 Neben bereits genannten Beiträgen siehe besonders die sehr beeindruckenden Ausführungen angesichts einer Buchveröffentlichung Peter Kleists von: Hellmut Lindemann, Zweimal Kleist, in: Der Monat 5 (1953), H. 56, S. 209-214, hier S. 212 (Rezension).

35 Einen herausragenden Stellenwert besaß in diesem Zusammenhang der Beitrag von Elliot Cohen, Deutsche und Juden. Eine Rede in Berlin, in: Der Monat 3 (1951), H. 28, S. 375-379.

36 Siehe hierzu im Einzelnen den hervorragenden Aufsatz von Harpprecht Im Keller der Gefühle. Überhaupt wurde in der zweiten Hälfte der 1950er-Jahre die Rolle der deutschen Justiz im Nationalsozialismus kritisch beleuchtet. Stellvertretend hierfür stand ex negativo der bereits erwähnte Beitrag von Walther Hofer, Der »völkische Rechtsstaat«. Zur nationalsozialistischen Rechtspolitik, in: Der Monat 11 (1959), H. 125, S. 46-58.

37 Vgl. Karl Heinz Wocker, Generation ohne Gesicht. Die Zwanzigjährigen im politischen Vakuum, in: Der Monat 12 (1960), H. 139, S. 5-13. 
nazistische Bestrebungen und Taten kämpfen dürften. Gleichwohl kam hierbei auch und vor allem zum Ausdruck, dass der Monat hinsichtlich der Auseinandersetzung mit der persönlichen NS-Vergangenheit auf der Linie lag, die für die gesamten 1950erJahre der Bundesrepublik bestimmend war: Die individuellen Vergangenheiten unter der NS-Diktatur wurden rigoros von der Gegenwart der zweiten deutschen Republik getrennt. Sie wurden entpolitisiert und galten als Teil einer privaten Gesinnung und Lebensgeschichte, die mit der Gegenwart der Bundesrepublik nichts zu tun hatte. Im Kern ging es beim Umgang mit der personellen Hinterlassenschaft des >Dritten Reiches` darum, dass nicht zählte, was jemand in den zwölf Jahren des Nationalsozialismus getan hatte und wie er sich nun zu dieser Vergangenheit verhielt, sonders einzig und allein entscheidend war, was er für die neue Ordnung zu leisten imstande und bereit war und wofür er in seiner Berufsrolle und in der Öffentlichkeit einstand..$^{38}$

38 Vgl. Fritz René Allemann, Zöllner und Pharisäer, in: Der Monat 12 (1960), H. 138, S. 86-88. Das »Problem politischer Ethik« wurde von Allemann speziell mit Blick auf Karl Korn, den Mitherausgeber der Frankfurter Allgemeinen Zeitung, durchdekliniert. Da es sich bei dem Beitrag um eine kritische Auseinandersetzung mit ebendiesem Problem handelte, soll er ausführlich wiedergegeben werden (alle Zitate sind dem Text entnommen). Korn geriet damals in die Kritik, weil er sich in einer Closse vom 28.12. mit der Frage beschäftigte, ob die »Untaten der KöIner Synagogenschänder sauf Hintermänner und moralische Übeltäter hinweist‘, und in diesem Zusammenhang `zu äußerster Wachsamkeit‘ gemahnt«. Korn wurde von den mit der FAZ in einer »bitteren kommerziellen Fehde« lebenden Deutsche Zeitung und der Wirtschaftszeitung zum »Vorwurf gemacht«, dass er »selber 1940 in einer Besprechung ausgerechnet des `) ud-Süß_-Films in der Coebbels-Zeitung Das Reich eben diesem Antisemitismus gehuldigt habe, nach dessen >moralischen Urhebern er heute suche. Da werde also, so hieß es weiter, das ıseltsame Spiek versucht, >Böcke zu Gärtnern umzuschulen<. Und schließlich: >... wir können nicht glauben, daß die Deutschen dadurch in der Welt wieder glaubwürdig werden, daß sie die Dummköpfe mit dem Farbtopf ins Loch stecken und die moralischen Urheber in Dichter-Akademien, in die Filmbewertungsstelle berufen und zu Hüter der Moral küren«. - Die »Korn-Kontroverse« stand als exemplarischer Fall, weil es Allemann damals so schien, als ob es unter den Deutschen so etwas wie Mode wurde, einander gerade dann ihre Vergangenheit vorzuwerfen, wenn es sich darum handelt, gegen eine Wiederkehr dieser Vergangenheit anzugehen. Indes lag für ihn häufig eine >Haltung< zugrunde, »die sich besonders kompromißlos gibt: wer einmal in die Irre gegangen ist, der möge in $\mathrm{Zu}$ kunft schweigen und den Protest gegen den Ungeist, dem er einst selber verfallen war oder mit dem er mindestens Kompromisse geschlossen hat, denen überlassen, die immer unbeugsam geblieben sind«. Und Allemann weiter: »lch kann mir nicht helfen: Diese Meinung kommt mir als ausgemachtes Pharisäertum vor. Ganz gleich, warum Korn 1940 dem Antisemitismus als Publizist wenigstens den kleinen Finger gereicht hat - soll er nicht das Recht haben, heute der drohenden Pest zu wehren, weil er einst in einer schwachen Stunde der Infektion erlag? Er mag, als er seinerzeit die inkriminierten Sätze schrieb, geglaubt haben, taktisch geschickt zu handeln und >Mimikry< zu betreiben, um unter dieser Tarnung Dinge zu sagen, die er sonst nicht hätte sagen können; er ist vielleicht auch einfach schwach geworden, ein Opportunist mehr unter Millionen; ich will nicht einmal ausschließen, daßer, der sicher (nach unverdächtigen Zeugnissen) kein Nazi war, eben doch unbewußt das ein oder andere von der Ideologie aufgenommen und assimiliert hatte, in deren Dunstkreis er lebte. Aber selbst wenn er wirklich geglaubt hätte, was er damals schrieb, selbst wenn er in der Tat einer der intellektuellen Wortführer oder doch der intellektuellen Beschöniger der Hitlerei gewesen sein sollte, wie sein Redaktionskollege Sieburg, der im Ausland als `Evangelist des Dritten Reiches ‘ auftrat - warum in aller Welt dürfte er da in einem Augenblick, da die braunen Ratten wieder aus ihren Löchern zu kriechen scheinen, nicht seine Stimme erheben, um vor dem Gift zu warnen, dessen Träger sie sind und dessen Wirkung er einst am eigenen Leibe und an der eigenen Seele verspürt hat? A Allemann erinnerte die Monat-Leser in seinem Artikel daran, dass ein Großteil des deutschen Volkes, »zeitweise wohl eine Mehrheit« (!), so der Autor, irgendwann und in irgendeiner Weise »auf den Leim gekrochen« war. Für 
Daneben besaß die kritische Auseinandersetzung mit bestimmten politischen Skandalen, mit denen die bundesrepublikanische Nachkriegsgesellschaft immer wieder mit der NS-Vergangenheit konfrontierte wurde, im Monat eine wichtige Funktion. Abgesehen vom »Fall Harlan« sowie einem Beitrag zum spektakulären Remer-Prozess 1952, mit dem die Zeitschrift beabsichtigte, den 20. Juli zu rehabilitieren und den nicht nur in der Bevölkerung, sondern auch in der Bundeswehr selbst umstrittenen, keineswegs populären Widerstand gegen den NS-Unrechtsstaat zu legitimieren, ${ }^{39}$ berichtete man insbesondere ausführlich über die sich Ende Mai 1955 konstituierende breite außerparlamentarische Protestbewegung gegen die Ernennung des rechtsradikalen Verlegers Leonhard Schlüter (FDP) zum Kultusminister des Landes Niedersachsen.

Am 26. Mai war die christlich-konservative Regierung unter Ministerpräsident Heinrich Hellwege (Deutsche Partei) umgebildet worden. Schlüter war als vormaliger niedersächsischer Spitzenkandidat der neonazistischen Deutschen Reichspartei (DRP), nachdem diese in den niedersächsischen Landtag einzog, zur FDP übergetreten und von dieser für ein Ministeramt vorgeschlagen worden. Gegen seine Ernennung protestierten zunächst Rektor, Akademischer Senat und AStA der Universität Göttingen, indem sie ihre Ämter niederlegten. Unterstützt wurde der Protest auch von zahlreichen anderen Universitäten und Professoren des Landes sowie aus Deutschland emigrierten Professoren amerikanischer Universitäten, aber auch von Mitgliedern des internationalen Komitees für Wissenschaft und Freiheit, die eine Protestnote an den Ministerpräsidenten Hellwege sandten, die zuvor im Figaro veröffentlicht wurde. ${ }^{40}$

ihn konnte es sich weder darum handeln, das im Nachhinein »zu entschuldigen, noch darum, es einfach zu vergessen. «Worauf es für Allemann zu diesem Zeitpunkt ankam, war allein Folgendes: »zu verhindern, daß dergleichen noch einmal geschieht, und gegen alles zu kämpfen, was wieder in dieselbe Richtung drängt«. Für Allemann stand fest: „Wer vom Irrwahn angesteckt war, der hat nicht nur das Recht, sich heute zu Worte zu melden, sondern die Pflicht, dieses Wort der radikalen Absage an das auszusprechen, was er vor 20 Jahren geglaubt (oder wobei er mindestens mitgetan oder mitgemurmelt) hat.« Indes war für Allemann das `Recht auf den politischen Irrtum < keinesfall ein »Passepartout, der alle Türen öffnet«. Denn: »Wer als Nazi-Richter im frenetischen Bestreben, sich den Gewaltigen des Dritten Reiches gefällig zu zeigen, ein Über-Soll mit Fallbeil und Stran erfüllen zu müssen glaubte, hat sich sicher dafür disqualifiziert, weiter über kleine oder große Übeltäter zu Cericht zu sitzen. Vollstreckungsbeamte, Ideologen und Handlanger des Nazi-Regimes eignen sich auch dann, wenn sie keine strafrechtlich faßbaren Verbrechen begangen haben, schwerlich als Minister oder Staatssekretäre der jungen Demokratie [...]. Wer Herrn Korn [...] das Recht zuspricht, dem NeoNazismus entgegenzutreten, braucht deswegen noch lange nicht die Legitimation des Herrn Oberländer anzuerkennen, ausgerechnet im Kabinett der Bundesrepublik zu sitzen [...]. Hier allerdings wäre es angemessen, von `Takt zu sprechen. Wo es aber darum geht, zu verhindern, daß der braune Spülicht in Deutschland wieder hochsteigt, da scheint es abwegig, dieses Wort zu gebrauchen: wenn Korn wirklich ein smoralischer Urheber des Antisemitismus gewesen wäre, so würde es noch immer aller Achtung wert sein, wenn er diese Schuld damit sühnen wollte, daß er wenigstens jetzt der antisemitischen Seuche widersteht.«

39 Siehe Rüdiger Proske, Brief aus Braunschweig: Prozeß um den 20. Juli. Die Braunschweiger Verhandlungen gegen Otto Ernst Remer, in: Der Monat 4 (1952), H. 43, S. 16-21.

40 Zu den Unterzeichnern gehörten u. a. die Professoren Raymond Aron (Paris), Otto Hahn (Göttingen), Karl Jaspers (Basel), Sidney Hook (New York), Max von Laue (Westberlin), Salvador de Madariaga (Oxford), Hellmut Plessner (Göttingen), Michael Polany (Manchester), Edward Shils (Chicago) und Bruno Snell (Hamburg). Die Protestnote zählte in diesem Zusammenhang nur zu einer von mehreren Aktivitäten, an der nicht zuletzt die Pariser Zentrale des »Kongresses für kulturelle Freiheit« beteiligt war und die hierbei auf die bewährte Methode zugriff, »große Namen« zum Einsatz zu bringen, d. h. 
Auch eine umfangreiche Berichterstattung in der internationalen Presse verstärkte den Druck, sodass letztlich Hellwege seinen Minister nicht mehr halten konnte und Schlüter bereits nach wenigen Wochen am 9. Juni zurücktreten musste. Politische Brisanz gewann dieser Fall vor allem durch den Umstand, dass nach der Unterzeichnung der Pariser Verträge zehn Jahre nach Kriegsende die Besatzungszeit endete und durch das Inkrafttreten des Vertragswerkes am 5. Mai die Bundesrepublik die volle Souveränität wiedererlangte, die mit der Wiederbewaffnung und der Westintegration verknüpft war. ${ }^{41}$ Darum wies der »Fall Schlüter «, den Jaesrich in Absprache mit der Pariser Zentrale des »Kongresses für kulturelle Freiheit« in einem ausgezeichneten Beitrag beschrieb und analysierte, auch internationale politische Implikationen auf und ging über die auf der Hand liegende Frage einer möglichen Gefahr des Rechtsradikalismus in Niedersachen hinaus. ${ }^{42}$

Im Grunde genommen wurde dieser politische Skandal für den Monat zu einem Lackmustest für die Stabilität der parlamentarischen Demokratie und der politischen Kultur in der Bundesrepublik, mit der man sich angesichts der NS-Vergangenheit in

in diesem Fall: »wichtige Repräsentanten des organisierten linken Antikommunismus« (Hochgeschwender). Bei dem internationalen Komitee für »Wissenschaft und Freiheit« handelte es sich nämlich um eine Organisation, die ein unmittelbares Ergebnis des gleichnamigen Hamburger Kongresses (23. bis 26. Juli 1953) war, den der »Kongreß für kulturelle Freiheit« veranstaltete. Auf die näheren Umstände und die grundsätzliche Ausrichtung der Organisation, deren eigentliche Gründung im Juli 1954 war, kann hier nicht eingegangen werden. Nur so viel: Nach dem Tod Stalins und des einsetzenden Zerfalls der kommunistischen Weltfriedensbewegung hatte sich die Pariser Führung des »Kongresses für kulturelle Freiheit« dazu entschlossen, von dem als verbraucht eingeschätzten radikalen Antikommunismus aus der Hochphase des Ost-West-Konfliktes abzurücken und stattdessen »differenziertere und detailbezogenere Formen der Informationsvermittlung « zu bevorzugen. Fortan sollte neben den Verstößen kommunistischer Bewegungen auch die von nationalistischen, neonazistischen und franquistischen Gruppen sowie staatlicher Stellen gegen die akademische Freiheit und die Freiheit wissenschaftlichen Forschung in den Blick genommen werden und von Fall zu Fall öffentlichkeitswirksam dagegen vorgegangen werden. Auch wenn das »Komitee für Wissenschaft und Freiheit«zweifelsohne eine von der Pariser »Kongreß«-Zentrale mitgelenkte »Filiale« war, führte dies gleichwohl nicht dazu, dass diese sich in vollkommener inhaltlicher Abhängigkeit zur Zentrale befand. Nach bewährter Art gewährte die Pariser Zentrale des »Kongresses für kulturelle Freiheit« auch im Fall des »Komitees für Wissenschaft und Freiheit« eine gewisse Unabhängigkeit. In der Bundesrepublik, das als das bedeutendste Operationsfeld des Kongresses angesehen wurde, operierte das »Komitee für Wissenschaft und Freiheit« überwiegend im Rahmen von »Reorientation«-Aufgaben. Bei dem »Fall Schlüter«, der freilich über den originären Bereich wissenschaftliche Freiheit hinausging, handelte es sich um eine der erfolgreichsten »Reorientation«-Aktionen des »Kongresses für kulturelle Freiheit« überhaupt. Siehe im Einzelnen Hochgeschwender, Freiheit in der Offensive?, S. $438-444$.

41 Ende Februar hatte der deutsche Bundestag der Annahme der Pariser Verträge zugestimmt. Cegen die Verträge und die Wiederbewaffnung hatte eine breite außerparlamentarische Bewegung protestiert. Unter anderem erinnerten zahlreiche Demonstrationen an das Erbe des Nationalsozialismus. Durch die Verabschiedung des »Deutschen Manifestes« auf einer von der SPD und dem DGB organisierten Protestkundgebung in der Frankfurter Paulskirche im Januar 1955 wurde angezeigt, dass sich diese Bewegung insbesondere die Wiedervereinigung zum Ziel gesetzt hatte, also die Wiederherstellung der deutschen Einheit.

42 Hellmut Jaesrich, Die Göttinger Dreitausend. Der Fall Schlüter, in: Der Monat 7 (1955), H. 82, S. $291-301$. 
den kommenden Jahren fortlaufend beschäftigte. ${ }^{43}$ Indes: Es handelte sich hierbei um den ersten bis zu diesem Zeitpunkt erschienenen Beitrag, indem der Monat anhand des konkreten »Falles Schlüter« ausdrücklich und in substanzieller Form auf die neonazistischen und rechtsradikalen Tendenzen in der Bundesrepublik einging sowie eindeutig dagegen Position bezog, ${ }^{44}$ ohne gleichzeitig auf das totalitäre Herrschaftsregime jenseits des »Eisernen Vorhanges« zu verweisen. ${ }^{45}$ Abgesehen von dem »Fall

43 Siehe z. B.: Zwei Stimmen, in: Der Monat 8 (1955), H. 87, S. 87 und die Leserbriefe Antwort eines Heimkehrers, in: Der Monat 8 (1956), H. 88, S. 91 f. sowie Zum Empfang der Heimkehrer, in: Der Monat 8 (1956), H. 89, S. 78, die sich kontrovers mit der Frage beschäftigten, inwiefern die Integration der aus der sowjetischen Gefangenschaft »Heimkehrenden «in die bundesrepublikanische Gesellschaft eine Gefahr für die Demokratie darstellten, weil sich darunter auch ehemalige Nazis und für Verbrechen in deutschen Konzentrationslagern (mit-)verantwortliche SS-Funktionäre und NS-Ärzte befanden. Vgl. auch unter diesem Aspekt den hervorragenden Beitrag: Matthias Walden, Es war so schön ... Die Geschichte einer Fernsehsendung, in: Der Monat 12 (1960), H. 138, S. 23-31. Hier beschrieb der Autor ausführlich sowohl einen von ihm mitproduzierten und im Deutschen Fernsehen gesendeten Beitrag des Sender Freies Berlin (SFB) über das bis dahin tabuisierte Thema der militärischen Tradition und der Traditionsverbände in der Bundesrepublik als auch die Reaktionen in der deutschen Öffentlichkeit (Soldatenverbände etc.) darauf. Hier zeigte sich u. a. ein erschreckendes Maß an Intoleranz, mangelnder politischer Kultur, von Fall zu Fall eine Affinität zum Nationalsozialismus und zur NS-Ideologie, sowie auch eine grundsätzliche Abneigung, sich mit der NS-Vergangenheit auseinanderzusetzen.

44 Eine Ausnahme stellte indes der Beitrag von Arendt Bei Hitler zu Tisch in: Der Monat 4 (1951), H. 37, S. 85-90 (Rezension), dar, auf den ich bereits in Kap. IV.1.8 einging. In diesem Fall setzte sich der Monat indirekt mit dem Neonazismus in der Bundesrepublik auseinander. - Wie gesehen, war der konkrete Anlass für die Arendt-Rezension seitens der Zeitschriftenredaktion nämlich die »bedenkliche Jungfernpublikation « (S. 84) des Münchener Institutes für Zeitgeschichte, das damals noch als das Deutsche Institut für Geschichte der nationalsozialistischen Zeit firmierte. Hier betonte Arendt, dass das vom Münchener Institut herausgegebene Buch Propaganda für Hitler machte, »eine Hilfe also für den deutschen Neonazismus, die Professor Ritter und das beauftragende Institut vermutlich geleistet haben, die aber Herrn Picker, auf dessen Niederschriften die Publikation wesentlich beruht, vielleicht nicht ganz so unvermutet kommt« (ebd., S. 84). Zu den genauen Cründen für die Auffassung Arendts siehe im Einzelnen besonders die einführenden Worte ihres Rezensionsaufsatzes (ebd.), der aufgrund der Beschreibung und Analyse des »Phänomens Hitler « einerseits, den deutschen Massenverbrechen im Allgemeinen und dem nach dem Überfall auf die Sowjetunion im Juni 1941 in Gang kommenden Holocaust im Besonderen meiner Auffassung nach zu dem bedeutendsten Beitrag zur genuinen Untersuchung des »Führerstaates« und seiner Vernichtungspraxis im Monat zählte; zumal Arendt hierbei den Konnex von »Ideologie und Terror « auf analytisch hohem Niveau fokussierte.

45 Siehe z. B.: Melvin J. Lasky, Berliner Tagebuch: Le Rouge et le Brun, in: Der Monat 7 (1955), H. 76, S. 376-378, wo dieser sozusagen eine »Rot=Braun-Cleichung« vornahm. Hier berichtete Lasky im Januarheft luzide von zwei Kundgebungen der neonazistischen »Deutschen Partei« anlässlich der Wahl zum Berliner Abgeordnetenhaus - die unmittelbar vor den Wahlen stattgefundene Kundgebung im Sportpalast wurde immerhin von 8 ooo begeisterten Anhängern besucht -, um sie mit Wahlveranstaltungen der »äußerste[n] Linken in Westberlin aus dem gleichen Anlass zu kontrastieren, die damals die SED nutzte, um einige prominente Redner zu schicken, darunter Johannes R. Becher (übrigens »der erste sowjetdeutsche >Minister«, der Westberlin bisher einen halboffiziösen Besuch abgestattet hat. [S. 376]). Bezeichnenderweise verwendete Lasky zur Kennzeichnung des nicht ausdrücklich genannten MfS das Kürzel »SSD« (S. 377): eine für die Bundesrepublik nicht untypische Vorgehensweise. Durch die Kombination von »SS « und »SD« sollte eine Nähe zum Apparat des NS-Staates suggeriert werden. Vgl. auch: Erwacht Deutschland schon wieder? Der neue deutsche Nationalismus und seine Gefahren, in: Der Monat 1 (1949), H. 8/9, S. 3-64 (mit Beiträgen von Walter L. Dorn, Richard H. S. Crossmann, Raymond Aron, Dolf Sternberger, Paul Sering, Emmanuel Mounier, 
Harlan«, wo der Monat gleichzeitig gegen den wieder aufkommenden Antisemitismus und Nazismus protestierte, wurde die Zeitschrift in kaum einem anderen Fall so eindeutig und überzeugend seinem antitotalitären Selbstverständnis gerecht. Insofern existierten beim »Fall Schlüter« auffallende Parallelen zum »Kongreß für kulturelle Freiheit ${ }^{46}$

\section{Die systematische Ausblendung der westdeutschen "Vergangenheitsbewältigungspolitik" (Ulrich Herbert) im Monat}

Abgesehen von der Tatsache, dass Der Monat bei der Auseinandersetzung mit der NSVergangenheit grosso modo auf der Linie des für die 1950er-Jahre in der westdeutschen Publizistik und Wissenschaft insgesamt gezeichneten Bildes von der NS-Diktatur und seiner Gewaltverbrechen lag, ${ }^{47}$ wurde in diesem Zusammenhang der politisch

Manuel Gasser, A. J. P. Taylor, Peter de Mendelssohn, Wilhelm Röpke, Erik Reger, Eugen Kogon, Franz Borkenau u. a.). Hierbei handelte es sich um den Abdruck von Vorträgen, die auf dem vom Monat veranstalteten Symposium gehalten wurden. In den einleitenden Worten wies die Redaktion darauf hin, dass es dem Symposium darum zu tun war - vor dem Hintergrund des fehlgeschlagenen Versuches von Hitler, dass »Phantom einer Weltherrschaft « zu verwirklichen sowie des Zusammenbruches des >Dritten Reiches $<-$, der Frage nachzugehen, ob von »Deutschland noch ein dritter Weckruf und noch ein schlimmeres Erwachen [droht]?« Denn, so hieß es auf S. 3 weiter: »Die Deutschen scheinen das einzige Volk auf der Erde, das sich veranlaßt fühlt, aus einem natürlichen Weltbürgertum sich von Zeit zu Zeit in einen militanten Nationalismus hineinzusteigern. Sollten sie nicht endlich begreifen, daß sie wach sind, wenn sie weltbürgerlich, und in tiefem Schlaf, wenn sie nationalistisch denken? «In diesem Kontext betonte die Redaktion, dass sich viele Deutsche nach vier Jahren Besatzungsalltag zu den »Erniedrigten und Beleidigten« zählten. Zudem wurde konzediert, dass »Demontagen, Produktionsbeschränkungen und Exportschwierigkeiten« ein Übriges tun, »um ein Nationalgefühl hervorzurufen, dessen Wurzeln Lebensangst und Ressentiment sind « (das damals in der westdeutschen Öffentlichkeit nicht selten von rechtsradikalen oder neonazistischen Gruppen in unterschiedlichster Form zum Ausdruck gebracht wurde). Indes bezog sich die Leitfrage und das -thema des Symposiums sowohl aufWest- als auch auf Ostdeutschland (siehe S. 4.f.). Zu den einzelnen Beiträgen sei erwähnt, dass die Autoren das gestellte Thema fast ausschließlich entweder in Anbetracht des kurz zuvor ausgebrochenen Kalten Krieges erörterten - hier vor allem mit Blick auf eine künftige Realpolitik gegenüber Westdeutschland seitens der Vereinigten Staaten, Englands und Frankreichs - oder auf die Gefahren des deutschen Nationalismus generell eingingen, sodass die konkreten westdeutschen Verhältnisse und mithin die Gefahren des Neonazismus nicht ausdrücklich zur Sprache kamen. Eine Ausnahme stellte der Beitrag von Erik Reger, dem Mitherausgeber des Berliner Tagesspiegel dar, der zumindest daraufhin wies, dass es einen sogenannten Neofaschismus gab, der im Ausland »Anlaß zur Besorgnis« gab, und zudem einen Antisemitismus, der sich, so Reger, »bis zu offener Hetze gegen einen Ankläger von Nürnberg gesteigert« (!) hatte. Erik Reger, Anfangs- oder Enderscheinung?, in: Ebd., S. 53-56, hier S. $55 \mathrm{f}$.

46 Hochgeschwender kommt nämlich mit Blick auf die nach dem Rücktritt Schlüters und dem JaesrichArtikel im Monat auslaufende Kampagne des »Kongresses für kulturelle Freiheit« zu der Einschätzung, dass diese als ein Erfolg bewertete wurde, »auf den man mit einigem Recht Stolz war«. Denn: Nie zuvor hatte der »Kongreß für kulturelle Freiheit« in Westdeutschland »derart klar gegen neonazistische Tendenzen Stellung bezogen, nie zuvor seinen Antitotalitarismus so deutlich zur Geltung gebracht« (Freiheit in der Offensive?, S. 444).

47 Hinsichtlich der Analyse des »Führerstaates« müssen indes drei Ausnahmen gemacht werden. Denn neben der Beleuchtung der Rolle der Justiz als Terrorinstrument des NS-Regimes, der mit dem Hinweis korrespondierte, dass zahlreiche ehemalige NS-Richter ihre berufliche Karriere in der bundesre- 
brisante Komplex der deutschen »Vergangenheitsbewältigungspolitik« systematisch ausgeblendet. ${ }^{48}$ Damit ist speziell die seit 1948 an Durchschlagskraft gewinnende und alsbald massenhaft unterstützte »Kampagnenpolitik « gegen die »Siegerjustiz «" gemeint, die sich gegen Entnazifizierung und Kriegsverbrecherprozesse richtete, in den zwölf Nürnberger Nachfolgeverfahren ihren Hauptangriffspunkt fand und einherging mit einem markanten Einstellungswandel in der westdeutschen Bevölkerung gegenüber dem NS-Regime und der Verfolgung der NS-Täter. ${ }^{50}$ Hierbei koinzidierte die »Schlussstrich«-Mentalität angesichts der bevorstehenden Gründung der Bundesrepublik mit dem Blick nach vorne, der sich in der Idee eines "Neubeginns« manifestierte, und der Hoffnung, die jüngste Vergangenheit am liebsten zu vergessen. Mit anderen Worten: Amnesie und Amnestieforderungen gingen Hand in Hand.

Nachdem es, wie gesehen, seit 1946 von deutscher Seite und hier vor allem vonseiten der Kirchen, der Publizistik sowie speziell von den kulturpolitischen Zeitschriften Ansätze gab, die nicht nur das Nürnberger Militärtribunal, sondern das alliierte Entnazifizierungsprogramm insgesamt in teilweise radikaler Form als schädlich kritisierten und seine schleunigste Beendigung forderten, spitzte sich die Lage seit der Berlinblockade 1948 zu. Denn durch die schrittweise Verschärfung des Kalten Krieges und der damit verbundenen Lockerung der alliierten Säuberungsmaßnahmen verbreitete sich die Kritik und verstärkte sich in Westdeutschland zu einer an Lautstärke und Einfluss beständig zunehmenden Kampagne, die ihren Höhepunkt in den ersten

publikanischen Justiz fortsetzten konnten (vgl. bes. Walther Hofer, Der »völkische Rechtsstaat«. Zur nationalsozialistischen Rechtspolitik, in: Der Monat 11 (1959), H. 125, S. 46-58, sowie den einleitenden Worte der Redaktion auf S. 46), setzte man sich in zwei hier bereits herangezogenen Beiträgen mit der Rolle des Auswärtigen Amtes im Nationalsozialismus auseinander: De Mendelssohn (Die verhinderten Hochverräter) ging in seinem Rezensionsaufsatz, der sich kritisch mit dem militärisch-konservativen Widerstand des 20. Juli auseinandersetzte, besonders auf die Rolle von prominenten Funktionären des Auswärtigen Amtes (Ernst von Weizsäcker, Erich Korth) in der Widerstandsbewegung gegen Hitler und im NS-Staat ein (siehe hierzu die ausführliche Wiedergabe in Kap. IV.1.7). Und in dem Leserbrief zu diesem Beitrag wurde die Rolle des Auswärtigen Amtes (insbesondere von Ernst von Weizsäckers) bei den NS-Massenverbrechen und speziell bei der Vernichtung der europäischen Juden in den Mittelpunkt gerückt; siehe Westphal, Noch einmal >Die verhinderten Hochverräter sowie die entsprechenden Ausführungen in Kap. IV.1.8.

48 Grundlegend für das Folgende: Frei, Vergangenheitspolitik. Ulrich Brochhagen, Nach Nürnberg. Vergangenheitsbewältigung und Westintegration in der Ära Adenauer, Hamburg 1994; ]örg Friedrich, Die kalte Amnestie. NS-Täter in der Bundesrepublik, Frankfurt a. M. 1984; Ulrich Herbert, Best. Biographische Studien über Radikalismus, Weltanschauung und Vernunft, 1903-1989, Bonn 1996, S. 434-444, 535f.; Reichel, Vergangenheitsbewältigung in Deutschland, S. 107-124.

49 Hinter dem politischen Kampfbegriff »Siegerjustiz« stand die Absicht, den Zweiten Weltkrieg und die von den Deutschen begangenen Massenverbrechen unter die Kategorie des »normalen Krieges« zu subsumieren. Nicht die Kriegs- und Zivilisationsverbrechen, sondern ausschließlich der militärische Sieg der Alliierten über die Deutschen sei die eigentliche Grundlage für die Strafverfahren, lautete der Hauptvorwurf. Daraus folgte auch die stereotype Kritik, dass Kriegsverbrechen nicht nur von den Deutschen begangen worden seien und folglich die NS-Prozesse durch nichts anders als die Willkür der Sieger begründet sei. Insofern sahen sich die Vereinigten Staaten nach dem Ausbruch des Koreakrieges 1950 im Grunde genommen zwangsläufig den vornehmlich polemischen Vorwürfen ausgesetzt, speziell mit Blick auf den »Partisanenkampf« Kriegsverbrechen begangen zu haben, die mit den deutschen Verbrechen vergleichbar wären. Herbert, Best, S. 438.

50 Herbert, Best, S. 535. 
vier Jahren der Bundesrepublik erreichte, von einer breiten gesellschaftlichen Zustimmung getragen wurde und besonders die amerikanische Militäradministration unter Druck setzte.

Somit bereitete die einflussreiche Opposition und die in Gang gesetzte Kampagne gegen die Denazifizierungspolitik der Westmächte sozusagen den Boden vor, auf dem dann Bundesregierung und Bundestag durch eine Reihe von amnestiepolitischen Entscheidungen einiges unternahm, die vielen mehr oder weniger belasteten Personen zu entlasten und in die westdeutsche Wiederaufbaugesellschaft zu integrieren.

Im Vordergrund stand die Liquidierung der Folgen der seit Langem unpopulären Entnazifizierung. Schon im Herbst 1949 sprach Bundesjustizminister Thomas Dehler (FDP) gegenüber seinen Länderkollegen davon, dass in gewissen zwischen 1946 und 1948 geführten NS-Verfahren zahlreiche Strafen nicht mehr gerechtfertigt erschienen, und zeigte damit an, welchen Kurs die Verantwortlichen einzuschlagen gedachten, zumal die große Mehrheit der im Bundestag und den Länderparlamenten vertretenen Parteien die Verfahrenseinstellung und Aufhebung aller Sanktionen für die Mitläufer und Minderbelasteten forderten. Kurz vor Weihnachten 1950 beschloss dann der Bundestag eine Vereinheitlichung und baldige Beendigung der Entnazifizierung, die in der Öffentlichkeit als »Befreiung vom Befreiungsgesetz « begrüßt wurde..$^{51}$ Als eine der ersten gesetzgeberischen Maßnahmen der Bundesrepublik wurde im Dezember 1949 das Straffreiheitsgesetz verabschiedet, mit dem Vergehen vor dem 15. September 1949 amnestiert wurden, die mit Gefängnis bis zu sechs Monaten bestraft werden konnten und zumeist in den >verwirrten Zeitverhältnissen (Adenauer) begangen worden waren. Immerhin kamen rund 800000 Personen in den Genuss der »Weihnachtsamnestie«. In den meisten Fällen ging es hierbei um Schwarzmarktdelikte, aber auch um vermutlich mehrere zehntausend Straftäter aus der NS-Zeit. ${ }^{52}$ Zudem profitierten etwa 400000 Personen von dem zweiten Straffreiheitsgesetz, das der Bundestag im Juli 1954 verabschiedete und mit dem insbesondere die "Taten während des Zusammenbruches « amnestiert wurden, also die sogenannten Endphasendelikte. ${ }^{53}$ Beide Bundesamnestien versprachen außerdem den Untergetauchten Straffreiheit ohne Rücksicht auf die Höhe der zu erwartenden Strafe. Überraschenderweise nutzten allerdings von den geschätzten 80000 >Illegalen`, die entsprechend der Gesetzesformulierung unter »Verschleierung des Personenstandes« lebten, nur eine kleine Minderheit aus unterschiedlichen Gründen die straffreie Wiedererlangung ihrer früheren Identität. Nicht zuletzt brachten sie den gesellschaftlich weit verbreiteten »Widerwil-

51 Demnach sollten ab Januar 1951 keine Nazis mehr in die Gruppen III-V (Minderbelastete, Mitläufer, Entlastete) eingestuft werden, sollten Berufs- und Freizügigkeitsbeschränkungen weitgehend, Vermögenssperren ganz aufgehoben und bei Arbeitslagerstrafen vom Begnadigungsrecht großzügig Gebrauch gemacht werden. Nur die Parteien der nationalen Rechten (FDP, DP und DRP) stimmten dagegen, die sogar die sogenannten Hauptbeschuldigten und Belasteten (Gruppe I und II) einbeziehen wollten.

52 Unter den Amnestierten befanden sich auch z. B. solche Straftäter, die sich aktiv an den Pogromen im November 1938 beteiligt hatten.

53 Damit waren die Vergehen gemeint, die zwischen dem 1. Oktober 1944 und dem 31. Juli 1945 begangen worden waren, »in der Annahme einer Amts-, Dienst- oder Rechtspflicht, insbesondere eines Befehlsı, und die mit einer Freiheitsstrafe von bis zu drei Jahren bedroht waren«(Reichel, Vergangenheitsbewältigung in Deutschland, S. 109). 
len« (Fritz Bauer) gegen eine gründliche und fortlaufende politisch-justizielle Bewältigung der Folgen des NS-Regimes zum Ausdruck..$^{54}$

Gleichwohl rückten in der jungen Bundesrepublik zwei andere Folgeprobleme alliierter Vergangenheitsbewältigung in den Mittelpunkt des öffentlichen Interesses, auf die Der Monat ebenfalls nicht einging. In beiden Fällen handelte es sich um Personengruppen, denen für den Bestand und die innere Entwicklung des bisherigen nationalsozialistischen und des neuen demokratischen politischen Systems eine besondere Bedeutung zukam. Neben der kontroversen beruflichen Reintegration und versorgungsrechtlichen Rehabilitierung der nach 1945 wegen NS-Belastung entlassenen rund 430000 Beamten (selbst solche der Gestapo, insofern sie nachweisen konnten, dass sie zur Gestapo versetzt worden waren) und Berufssoldaten durch die Handhabung des Artikels 131 des Grundgesetztes ${ }^{55}$ fand die größte Aufmerksamkeit und Anteilnahme die zwischen Regierung, Alliierten und deutscher Öffentlichkeit zäh und heftig umstrittene Frage der Begnadigung der durch die Militärgerichte verurteilten und in den alliierten Gefängnissen einsitzenden Kriegsverbrecher. Hierbei betrieb vor allem der Heidelberger ’Juristenkreis`, der sich im Frühjahr 1949 konstituiert hatte und im Kern aus den wichtigsten Verteidigern der Angeklagten in den Nürnberger Prozessen (wie Otto Kranzbühler, Hans Laternser und Hellmuth Becker, der Verteidiger von Ernst von Weizsäcker im Nürnberger Wilhelmstraßenprozess) sowie prominenten und angesehenen Kirchenführern bestand, in seiner Rolle als offiziöses Gremium eine einflussreiche »Lobbypolitik«. Dadurch war man imstande, teils mit, teils anstelle der neuen Bundesregierung bei den Hohen Kommissaren für eine generelle Überprüfung der Urteile in den Verfahren gegen NS-Täter sowie für Strafmilderung und Begnadigungen in Einzelfällen zu werben. ${ }^{56}$

In diesem Zusammenhang hatte sich der politische Druck auf die Verantwortlichen auch durch die Urteilsverkündung in zwei NS-Prozessen noch verstärkt, die in der westdeutschen Öffentlichkeit von Anfang an umstritten waren: Im April 1949 ging der Wilhelmstraßenprozess gegen führende Politiker und Beamte des NS-Staates zu Ende, wobei insbesondere die Verurteilung des ehemaligen Staatssekretärs im Auswärtigen Amt, Ernst Freiherr von Weizsäcker, weithin abgelehnt wurde. Und im Dezember desselben Jahres wurde einer der prominentesten Heerführer Hitlers, Generalfeldmarschall Erich von Manstein, durch ein britisches Militärgericht in Hamburg wegen Kriegsverbrechen, die unter seinem Oberbefehl an der Ostfront begangen worden waren (Tötung von Kommissaren und versprengten Rotarmisten sowie von Zivilisten im Zuge von Vergeltungsmaßnahmen), zu einer Haftstrafe von 18 Jahren verurteilt; hierbei hatte sich Churchill als Führer der konservativen Opposition im

54 Ebd.

55 Siehe hierzu ausführlich Frei, Vergangenheitspolitik, S. 69-100; vgl. auch Udo Wengst, Beamtentum zwischen Reform und Tradition. Beamtengesetzgebung in der Gründungsphase der Bundesrepublik Deutschland 1948-1953, Düsseldorf 1988; Curt Garner, Der öffentliche Dienst in den 5oer-Jahren: Politische Weichenstellung und ihre sozialgeschichtlichen Folgen, in: Schildt/Sywottek, Modernisierung im Wiederaufbau, S. 759-790; Hans Mommsen, Die Kontinuität der Institution des Berufsbeamtentums und die Rekonstruktion der Demokratie in Westdeutschland, in: Friedrich Gerhard Schwegmann (Hg.), Die Wiederherstellung des Berufsbeamtentums nach 1945. Geburtsfehler oder Stützpfeiler der Demokratisierung in Westdeutschland? Düsseldorf 1986, S. 65-79.

56 Herbert, Best, S. 439. Zu dem Heidelberger »]uristenkreis« siehe bes. Frei, Vergangenheitspolitik, S. $163 \mathrm{ff}$. 
englischen Unterhaus unter dem Eindruck der Berlinblockade und der sich abzeichnenden »Schicksalsgemeinschaft« von Westdeutschen und Westalliierten vehement gegen den Prozess ausgesprochen. ${ }^{57}$

Spätestens nach dem Ende der letzten NS-Prozesse bemühten sich die Hohen Kommissare als Nachfolger der Militärgouverneure um eine Neuorientierung in der Kriegsverbrecherfrage. Hierbei standen sie vor einem Dilemma: Einerseits wollten sie nicht nur keine Prozesse mehr, sondern auch die politisch und psychologisch nachteiligen Folgen des alliierten Entnazifizierungsprogramms vermeiden, zugleich sollte allerdings verhindert werden, dass dies als eine Zurücknahme der Nürnberger Urteile missverstanden würde. Andererseits sahen sich die Hohen Kommissare, speziell McCloy, der Kampagne ausgesetzt, die auf eine Revision der gefällten Urteile gegen deutsche Kriegsverbrecher und letztlich auf deren Begnadigung abzielte, die nach der durch die »Weihnachtsamnestie« ausgelösten gesteigerten Erwartungshaltung in der deutschen Öffentlichkeit sowie der bevorstehenden Wiederaufrüstung der Bundesrepublik immer massiver wurde. Je näher die deutsche Wiederbewaffnung rückte, desto mehr brach ein regelrechtes »Gnadenfieber« (Robert W. Kempner) aus.

Insgesamt wurden von den westalliierten Militärgerichten in den Nachkriegsjahren rund 5000 Deutsche angeklagt. Gegen etwa 800 von ihnen ergingen Todesurteile, die aber nur in rund 500 Fällen auch vollstreckt wurden. Im Frühjahr 1950 waren noch etwa 3400 verurteilte Kriegsverbrecher in Haft, wobei die Zahl innerhalb von zwei Jahren auf rund 1300 zurückging. Im selben Zeitraum verringerte sich die Zahl der verurteilten Kriegsverbrecher, die in den Gefängnissen der USA, Großbritanniens und Frankreichs einsaßen, also in Landsberg, Werl und Wittlich, von knapp 1000 auf etwa 700 Personen. ${ }^{58}$

In den Mittelpunkt der Kampagne gegen die »Siegerjustiz« rückte das bayerische Landsberger Gefängnis. Selbstverständlich besaß der Ort als ehemalige Haftstätte Hitlers für alle Beteiligten eine hohe politische Symbolik. Entscheidender war allerdings die Tatsache, dass die Vereinigten Staaten, die bei den NS-Prozessen zweifelsohne die politisch-moralische Führungsrolle bei der Bestrafung von Kriegs- und NS-Verbrechen übernommen hatten, hier neben hochrangigen Funktionären der berüchtigten Einsatzgruppen einen nennenswerten Teil der verurteilten militärischen, bürokratischen und wirtschaftlichen NS-Elite inhaftiert hatte. ${ }^{59}$

Dass die Kriegsverbrecherfrage überhaupt für mehrere Jahre zu einem fundamentalen Problem der amerikanischen und der westdeutschen Innen- und Außenpolitik werden konnte, war gleichwohl nicht ausschließlich der veränderten weltpolitischen Lage und ihrer neuen machtpolitischen Konfliktstruktur, der Ost-West-Konfrontation, geschuldet. ${ }^{60}$ Neben der frühen Entscheidung für die Westintegration und

57 Im Gegensatz hierzu wollte die Labour-Regierung unter Clement Attlee und Ernest Bevin sowie der frühere Nürnberger Chefankläger der Briten, Sir Hartley Shawcross, den Prozess gegen Manstein, der am 24. August 1949 begann. Auch der britische Militärgouverneur und spätere Hochkommissar Sir Brian Robertson begrüßte das Verfahren, plädierte allerdings aus politischen Überlegungen für eine geringe Strafe.

58 Reichel, Vergangenheitsbewältigung in Deutschland, S. 117.

59 Vgl. Frei, Vergangenheitspolitik, S. 144.

60 Das Folgende nach Frank M. Buscher, The U. S. War Crimes Trial Programm in Cermany, 1946-1955, New York/Westport/London 1989; Thomas Alan Schwartz, Die Atlantik-Brücke. John McCloy und das 
die Wiederaufrüstung der Bundesrepublik, die aus den ehemaligen Kriegsgegnern politische Bündnispartner machte, war dies auch durch die Beteiligung der Sowjetunion am Nürnberger Militärtribunal begründet, die in der deutschen, aber auch in der amerikanischen Öffentlichkeit frühzeitig einflussreiche Kritiker auf den Plan rief; indes weniger aus Sympathie mit den NS-Führern als aus der Ablehnung des juristischen Verfahrens. So war kein Geringerer als Kennan der Auffassung, dass die Beteiligung von sowjetischen Richtern aufseiten der Anklagevertretung »den einzigen Sinn verhöhn[t]en, den die Prozesse überhaupt haben konnten«, nämlich »Massenverbrechen jeder Art « zu ächten. ${ }^{61}$ Hinzu kamen verstärkt Vorwürfe, wonach die NS-Prozesse gegen elementare rechtsstaatliche Prinzipien verstießen. Neben dem nulla poena sine lege-Einwand, wonach niemand bestraft werden darf aufgrund von Rechtnormen, die erst nach der Tat erlassen worden, bemängelten konservative Kreise in den Vereinigten Staaten vor allem das Fehlen einer Berufungs- und Revisionsinstanz. Die Urteile wurden rechtskräftig, wenn sie der amerikanische Militärgouverneur, später der Hohe Kommissar, bestätigt hatte.

In den Vereinigten Staaten waren zwei NS-Prozesse von herausragender Bedeutung und ein Beweis dafür, welche politische Sprengkraft die Lösung der Kriegsverbrecherfrage besaß; zudem zeigten sie, dass sowohl Härte als auch Milde gegenüber deutschen Kriegsverbrechern anstößig sein konnten. Im Verfahren gegen die schwerer körperlicher Misshandlungen von Häftlingen angeklagte KZ-Aufseherin Ilse Koch, die »Hexe von Buchenwald«, rief die unverständliche Milde Empörung hervor. Nachdem sie in einem der amerikanischen Verfahren gegen das SS-Personal in den NS-Konzentrationslagern, den sogenannten Dachauer Prozessen, durch das Militärgericht zu lebenslanger Haft verurteilt wurde, verkürzte Clay die Strafe auf vier Jahre, was in Senat und Öffentlichkeit zu Protesten führte und eine Untersuchung nach sich zog und schließlich auch eine neue, lebenslange Verurteilung durch ein deutsches Gericht. ${ }^{62}$ Andererseits war es im Malmedyprozess neben den Zweifeln an der Fairness und der Rechtmäßigkeit militärgerichtlicher Strafverfolgung die mutmaßliche Härte der Urteile seitens der Militärs, die in Washington für große Aufregung sorgte und die Anordnung einer mehrmaligen Untersuchung zur Folge hatte. Das Verfahren verfolgte die amerikanische Öffentlichkeit von Anfang an mit besonderem Interesse, weil sie die SS-Massaker an amerikanischen Soldaten und belgischen Zivilisten während

Nachkriegsdeutschland, Frankfurt a. Main/Berlin 1992; ders., Die Begnadigung deutscher Kriegsverbrecher. John J. McCloy und die Häftlinge von Landsberg, in: VfZ 38 (1990), S. 375-414; Reichel, Vergangenheitsbewältigung in Deutschland, S. 117-122; Frei, Vergangenheitspolitik, S. 133-306; Brochhagen, Nach Nürnberg, S. 32-113.

61 Kennan, Memoiren eines Diplomaten, S. 265. - Auf die Tatsache, dass beim Nürnberger Hauptkriegsverbrecherprozess die sowjetischen Verbrechen ausgeblendet wurden, etwa die Beteiligung am Angriff auf Polen oder die Erschießung polnischer Offiziere in Katyn, kam Der Monat mehrmals zu sprechen. Sie mündeten in die Forderung eines »Moskauer >Nürnberger Prozesses« (Wanda Bronska-Pampuch) und einer Anklage gegen Stalin sowie führende Funktionäre des stalinistischen Terrorsystems »wegen Verbrechen gegen die Menschlichkeit und wegen verschwörerischer Vorbereitung eines Angriffskrieges«. Boris Shub, Unser Freund Iwan, in: Der Monat 3 (1951), H. 30, S. 583-595, hier S. 595. Vgl. Josef Mackiewicz, Nachtrag zu Katyn, in: Der Monat 4 (1952), H. 42, S. 667 f., sowie »Wenn zwei das Gleiche tun«, in: Der Monat 9 (1956), H. 98, S. 51.

62 Vgl. Arthur L. Smith, Die Hexe von Buchenwald, Köln 1983. 
der deutschen Ardennenoffensive im Dezember 1944 in besonderer Weise abstieß und empörte. ${ }^{63}$

Als McCloy im Juli 1949 nach Deutschland kam, um US-Militärgouverneur Clay zu ersetzten, war er sich des politischen Drucks, unter dem er stand, sehr wohl bewusst: Der Kalte Krieg hatte die Kriegsverbrecherfrage sowohl in den Vereinigten Staaten als auch in der Bundesrepublik politisiert. Bis dahin hatten allein die Vereinigten Staaten rund 1900 Deutsche wegen Kriegsverbrechen verurteilt, davon mehr als 700 inhaftiert und 277 hingerichtet; 28 Todesurteile waren noch nicht vollstreckt. ${ }^{64}$ Indes beschränkte sich McCloys Zuständigkeit bei den Urteilsprüfungen und Begnadigungen nur auf die rund 140 verurteilten Personen der Nürnberger Nachfolgeprozesse, sodass sich für ihn mit Blick auf die Landsberger Häftlinge folgende Situation ergab: »Im Übergang von der bisherigen Bestrafungspolitik und im Spannungsfeld von Antikommunismus und Remilitarisierung, von hartnäckiger deutscher wie amerikanischer Kritik an den Nürnberger Prozessen und einer von ihm selbst beabsichtigten humanitären, rechtsstaatlichen und vergangenheitspolitisch gleichermaßen verantwortlichen Lösung war sein Handlungsspielraum in der Kriegsverbrecherfrage begrenzt. ${ }^{65}$

Nach der Freilassung von rund 60 Inhaftierten zum Jahreswechsel und der Einsetzung eines Prüfungsausschusses unter dem Vorsitz von David Peck im März 1950, der drei Monate später seine Arbeit aufnahm, erhoffte sich McCloy eine Abschwächung des politischen Drucks, der indes von deutscher Seite unverändert anhielt. So verabschiedete am 14. November 1950 der Bundestag eine von allen Parteien, mit Ausnahme der KPD, unterstützte Interpellation zugunsten der verurteilten Kriegsverbrecher, und zwei Tage später setzte sich Adenauer bei einem Treffen mit den Hohen Kommissaren ziemlich massiv dafür ein, sämtliche Kriegsverbrecherprozesse so schnell wie möglich auszusetzen oder zu beenden, alle Todesurteile umzuwandeln und weitreichende Begnadigungen auszusprechen. ${ }^{66}$ Und bei einer Demonstration am 7. Januar 1951 auf dem Marktplatz in Landsberg von annähernd 3000 Menschen sprachen sich nicht nur zwei Bundestagsabgeordnete der CSU und die Redner verschiedener lokaler Parteien gegen die anstehenden Hinrichtungen von Kriegsverbrechern im örtlichen amerikanischen Gefängnis aus, sondern erklärte der Bundestagsabgeordnete der Bayernpartei, Gebhard Seelos, unter starkem Beifall, im »Kampf für Gerechtigkeit, Frieden und Völkerversöhnung« müsse sich das deutsche Volk genauso »gegen die von den Nationalsozialisten an fünf Millionen Juden begangenen Verbrechen « wenden wie "gegen das unmenschliche Hinhalten der zum Tode Verurteilten Nazis « ${ }^{67}$. Als McCloy zudem noch mit dem Vorschlag eines Bundestagsabgeordneten konfrontierte wurde, die nationalsozialistischen Gewaltverbrechen `durch eine große Geste der Gnade`aus-

63 Im Mittelpunkt dieses Verfahrens stand das Massaker, das die Angehörigen der 1. SS-Panzer-Division »Leibstandarte Adolf Hitler« an einer Straßenkreuzung vor Malmedy an 72 bereits entwaffneten US-Soldaten angerichtet hatten. Alle 73 Angeklagten, unter denen sich die berüchtigten SS-Führer Sepp Dietrich und Joachim Peiper befanden, wurden im Juli 1946 für schuldig befunden, 43 von ihnen wurden zum Tode verurteilt, allerdings keines dieser Urteile jemals vollstreckt (Frei, Vergangenheitspolitik, S. 142).

64 Schwartz, Die Begnadigung deutscher Kriegsverbrecher, S. 378.

65 Reichel, Vergangenheitsbewältigung in Deutschland, S. 120.

66 Vgl. Schwartz, Die Begnadigung deutscher Kriegsverbrecher, S. 395.

67 Siehe Frei, Vergangenheitspolitik, S. 210f. (Zitat S. 211); vgl. Brochhagen, Nach Nürnberg, S. 32. 
zulöschen, erinnerte er die deutsche Öffentlichkeit unmissverständlich daran, dass es sich hierbei >um Verbrechen von historischer Dimension ২ handele und viele Deutschen anscheinend nicht wüssten, »wie die Welt Deutschland und die Horrortaten der Nationalsozialisten wahrnehme ${ }^{68}$.

Vor dem Hintergrund all der Einwirkungsversuche tat sich McCloy, der in den Tagen der Entscheidung angesichts von Morddrohungen gegen ihn und seine Familie auch persönlich einer extremen Belastung ausgesetzt war, besonders mit der Prüfung der 15 Todesstrafen schwer, bei denen es sich allein in 13 Fällen um hochrangige SSFührer der Einsatzgruppen handelte. Schließlich wandelte er von den Todesurteilen vier in lebenslängliche und sechs in Haftstrafen zwischen 25 und neun Jahren um und bestätigte nur die Todesstrafen für den Chef des SS-Wirtschafts- und Verwaltungshauptamtes, Oswald Pohl, sowie für die Einsatzgruppen- und -kommandoführer Paul Blobel, Werner Braune, Erich Naumann und Otto Ohlendorf, die im Juni 1951 vollstreckt wurden..$^{69}$ Zudem reduzierte McCloy in 52 von 54 Fällen die Haftstrafen, davon in 32 Fällen auf die bis dahin verbüßte Haftzeit, die die sofortige Freilassung dieser Gefangenen zur Folge hatte, sodass mehr als ein Drittel der Begnadigten Landsberg Anfang Februar 1951 verlassen konnte. ${ }^{70}$

Selbstverständlich fielen die Reaktionen auf die politisch hochbrisante Entscheidung gespalten aus. Einem Teil ging die Milde im Umgang mit den Verurteilten viel $\mathrm{zu}$ weit, dem anderen nicht weit genug. Hochkontrovers waren insbesondere die Strafumwandlungen bzw. Strafmilderungen für einige Wehrmachtsoffiziere und die meisten Einsatzgruppenführer. Besonders bei den Oppositionsparteien in den westlichen Staaten stieß die Nachgiebigkeit gegenüber den NS-Kriegsverbrechern und ihren Bündnispartnern auf scharfe Ablehnung. Die größte Empörung löste indes die Freilassung von Alfred Krupp von Bohlen und Halbach aus, der gerade in England und Frankreich wie kein zweiter die verbrecherische deutsche Kriegsindustrie symbolisierte. ${ }^{71}$ Und in den Vereinigten Staaten protestierte Telford Taylor vehement gegen McCloys Entscheidung. Der ehemalige Chefankläger in den Nürnberger Nachfolgeprozessen sprach von einem schweren Schlag sowohl gegen die Grundsätze des Völkerrechts als auch der Prinzipien, »für die wir in den Krieg gegangen sind $\aleph^{72}$, und brachte damit im Grunde genommen konzis zum Ausdruck, dass der amerikanische Kommissar damit die »Idee einer gerichtlichen Aburteilung der NS-Täter selbst schwer beschädigt, wenn nicht zerstört « hatte. $^{73}$

68 Schwartz, Die Begnadigung deutscher Kriegsverbrecher, S. 399.

69 Bei den zehn Begnadigungen von den in Nürnberg zum Tode Verurteilten handelte es sich in neun Fällen um Kommandoführer aus dem Einsatzgruppenprozess (Ernst Biberstein, Walter Blume, Walter Haensch, Waldemar Klingelhöfer, Adolf Ott, Martin Sandberger, Heinz Hermann Schubert, Willy Seibert und Eugen Steimle) sowie um den SS-Standartenführer Franz Eirenschmalz, gegen den im sogenannten Fall 4 (Prozess gegen Oswald Pohl und andere Angehörige des SS-Wirtschafts-Verwaltungshauptamtes) Anklage erging.

70 Frei, Vergangenheitspolitik, S. 219f. Über die von McCloy entschiedenen Einzelfälle siehe ausführlich die Übersicht bei Schwartz, Die Begnadigung deutscher Kriegsverbrecher, S. 406-414.

71 Im Übrigen wurden aufgrund der Entscheidung von McCloy nicht nur die acht weiteren im Nürnberger Krupp-Prozess (Fall 10) Verurteilten begnadigt und Anfang Februar 1951 freigelassen, sondern auch die Vermögenseinziehung aufgehoben.

72 Zit. n. Schwartz, Die Begnadigung deutscher Kriegsverbrecher, S. 403.

73 Herbert, Best, S. 441. 
Während die internationale Empörung allmählich abflaute, waren die Reaktionen in der Bundesrepublik auf McCloys realpolitisch kalkulierte Entscheidung erwartungsgemäß von Beginn an grundlegend anderer Art. ${ }^{74}$ Unbehagen angesichts der großen Milde, wie sie der stellvertretende Ankläger im Wilhelmstraßenprozess Robert Kempner bekundete, hatte absoluten Seltenheitswert. So hielten rund drei Viertel der Bevölkerung HICOG-Umfragen zufolge die Urteilsrevisionen für nicht ausreichend, und noch mehr fanden die sieben bestätigten Todesurteile für ungerechtfertigt. Die Presse wiederum, deren unmittelbare Reaktion nach Einschätzung der amerikanischen Hochkommission wider Erwarten zurückhaltend ausfiel, würdigte allgemein Sorgfalt und Ernsthaftigkeit der Entscheidung, schwamm allerdings fast ausnahmslos im Fahrwasser des grassierenden Nationalismus. Zum Ausdruck kam dies in der vor allem von der Sensationspresse initiierten neuen Kampagne gegen die verhängten Todesstrafen, an der sich neben Der Welt ${ }^{75}$ auch Die Zeit beteiligte, als sie die Parole ausgab: »Es ist zu spät zum Töten! «"76

Während die meisten Bonner Politiker, die die Entscheidung kommentierten, unter Berufung auf die im Grundgesetz abgeschaffte Todesstrafe die Todesurteile bedauerten, so beispielsweise die Sozialdemokraten Carlo Schmid und Erich Ollenhauer, verzichtete die Bundesregierung auf eine offizielle Stellungnahme. Die in der Regierungskoalition vorherrschende Einschätzung brachte bereits die Frankfurter Allgemeine Zeitung am 2. Februar 1951 zum Ausdruck, die die Entscheidung akzeptierte, allerdings die "auffallende Zurückhaltung McCloys in der Frage der verurteilten Soldaten « bemängelte. ${ }^{77}$ Und die Grundlinien ihrer zukünftig maßgeblichen Politik nicht nur gegenüber McCloy nahmen gewissermaßen die Soldatenverbände vorweg, die in ihren angesichts der anstehenden Wiederbewaffnung einem deutschen Junktim gegenüber den Amerikanern (sowie Franzosen und Engländern) gleichkommenden Stellungnahmen unmissverständlich forderten: Amnestie für die in Landsberg, Werl und Wittlich als >Kriegsverbrecher einsitzenden Wehrmachtsgeneräle und Ehrenerklärung für die deutschen Soldaten. Hierbei erpressten sie Adenauer regelrecht und

74 Das Folgende vor allem nach Schwartz, Die Begnadigung deutscher Kriegsverbrecher, S. 401; Frei, Vergangenheitspolitik, S. $221 \mathrm{ff}$.; Brochhagen, Nach Nürnberg, S. $47 \mathrm{ff}$.

75 So bemängelte in der Ausgabe vom 1. Januar 1951 der Weizsäcker-Verteidiger im WilhelmstraßenProzess, Hellmut Becker, in seinem längeren Artikel mit der Überschrift Recht, Macht und Gnade, dass McCloy auch jetzt »noch keinen reinen Tisch gemacht habe«. Besonders die sieben Todesurteile seien inakzeptabel, da die Bundesrepublik die Todesstrafe abgeschafft habe und feststehe, dass »die zum Tode Verurteilten nicht aus persönlicher Gewinnsucht, sondern aus der nihilistischen Situation ihrer Zeit heraus gehandelt haben« (zit. n. Herbert, Best, S. 630, Anm. 110).

76 So lautete die Überschrift zu ihrem Landsberg-Kommentar vom 8. Februar 1951, S. 1, in dem es zum Schluss hieß, dass es nun »auch zu spät [sei], die wirklich Schuldigen zu töten«, zit. n. Frei, Vergangenheitspolitik, S. 222, Anm. 114, der an gleicher Stelle darauf hinweist, dass die Wochenzeitung erst wenige Wochen später in der Ausgabe vom 8. März ihre Position korrigierte, als nämlich Marion Cräfin Dönhoff konzedierte, »die öffentliche Meinung sei der Auffassung, >daß eigentlich außer Hitler mehr oder weniger alle unschuldig gewesen wären und alliierte Rechtsurteile überhaupt nicht verbindlich seien<. Verantwortlich dafür seien allerdings die Sieger, denn diese sschufen neues Recht und verkündeten die These von der Kollektivschuld aller Deutschen. So fanden sich denn plötzlich die Opfer der Naziherrschaft und die Gegner des Systems mit ihren Schergen zusammen auf derselben Bank wieder«

77 Zit. n. Frei, Vergangenheitspolitik, S. 222, Anm. 115. 
erklärten, dass sie der geplanten Aufstellung einer gemeinsamen europäischen Streitkraft unter Beteiligung der Bundeswehr nicht zustimmen würden, solange sich noch ein verurteilter Kriegsverbrecher in alliierter Haft befände.

Vor diesem Hintergrund und in Anbetracht der Tatsache, dass in der westdeutschen Bevölkerung vor allem die Freilassung der verurteilen Generäle gefordert wurde und die »soldatischen Kreise« für alle Parteien (zumal der deutschnationalen und rechtsradikalen Kleinparteien) ein beachtliches Wählerreservoir darstellten, wandte sich der Bundeskanzler in einer Bundestagsitzung am 5. April 1951 »direkt an die früheren Wehrmachtsangehörigen und versprach ihnen, alles in seiner Macht Stehende zu tun, >das Los der Gefangenen zu erleichtern und ihnen baldmöglichst die Freiheit wiederzuverschaffen<. Er zeigte sich überzeugt, dass die Zahl der wirklich schuldigen hohen Offiziere so >außerordentlich gering « sei, dass damit >der Ehre der früheren deutschen Wehrmacht kein Abbruch geschieht «.$^{78}$ Adenauer zufolge würden die ehemaligen Berufssoldaten zu Unrecht für den verlorenen Krieg verantwortlich gemacht; meistens hätten sie nichts anderes als ihre Pflicht erfüllt. »Das Kapitel der Kollektivschuld der früheren Berufssoldaten«, so der Bundeskanzler wörtlich, muss »ein für allemal beendet sein. " $^{79}$

Im Windschatten von Adenauers bereitwillig abgegebener Ehrenerklärung für die frühere deutsche Wehrmacht erreichte die Kampagne zur Freilassung der noch in den alliierten Haftanstalten in Westdeutschland einsitzenden knapp 700 Kriegsverbrecher ihren Höhepunkt und führte schließlich zu der von der FDP im Frühjahr 1952 geforderten »Generalamnestie«. Die vom nordrhein-westfälischen Landesverband koordinierte Kampagne setzte den Bundeskanzler angesichts der anstehenden Verhandlungen mit den drei Westalliierten über einen Generalvertrag, mit dem das Ende des Besatzungsregimes geregelt werden sollte, massiv unter Druck, zeitigte indes keinen Erfolg. Für diesen Personenkreis, der mittlerweile mit dem verharmlosenden Kunstbegriff »Kriegsverurteilte« bezeichnet und von zahlreichen Politikern schon als »Opfer der alliierten Militärgerichte« angesehen wurde, sah dann der Deutschlandvertrag, den der Bundestag im März 1953 ratifizierte, einen gemischten Ausschuss vor. Da sich das Inkrafttreten des Vertrages verzögerte, richteten die Alliierten im August 1953 "Interimistische Gemischte Parole- und Gnadenausschüsse« ein, die sich aus Vertretern der Westmächte und der Bundesrepublik zusammensetzten. Auch um die nationalistische Rechte im Bundestagswahlkampf zu schwächen und Adenauer zu stärken, wurde in diesen Monaten ein Großteil der noch inhaftierten ehemaligen Heerführer Hitlers freigelassen. ${ }^{80}$

Darunter befand sich auch der zu 18 Jahren Haft verurteilte Generalfeldmarschall Erich von Manstein, der, nachdem er bereits aus gesundheitlichen Gründen eine Reihe von befristeten Haftverschonungen erhalten hatte, nach nur knapp dreieinhalb Jahren

78 Reichel, Vergangenheitsbewältigung in Deutschland, S. 100.

79 Zit. n. Kraushaar, Die Protest-Chronik 1949-1959, I, S. 412.

80 Ebenso wie die Franzosen und Briten entließen auch die Amerikaner schließlich 1958 die letzten inhaftierten Kriegsverbrecher. Unter den vier im Mai aus der Landsberger Haftanstalt freigelassenen Cefangenen befanden sich drei, die im Einsatzgruppenprozess zum Tode verurteilt, aber von McCloy begnadigt worden waren. Vor weiterer Strafverfolgung durch westdeutsche Behörden waren die ehemaligen SS-Oberführer Ernst Biberstein, Adolf Ott und Martin Sandberger durch das im »Überleitungsvertrag«vereinbarte Verbot doppelter Anklageerhebung geschützt. 
Haft im Mai 1953 entlassen wurde. Wie kein anderer der prominenten Wehrmachtsgeneräle, die unter anderem in den Nachkriegsjahren ihre für ein breites Publikum geschriebenen Memoiren veröffentlichten, ${ }^{81}$ beeinflusste von Manstein das geschönte Bild der Wehrmacht in der Nachkriegszeit, ob als Mitautor der im November 1945 verfassten Denkschrift der Generäle für den Nürnberger Hauptkriegsverbrecherprozess, ${ }^{82}$ oder in seinen 1955 erschienenen Memoiren mit dem Titel Verlorene Siege, oder als Berater des Bonner Verteidigungsministeriums und des Bundestages in sicherheitspolitischen Fragen. Er hatte einen entscheidenden Anteil an der Verbreitung der Legende von der »sauberen Wehrmacht«, wonach einerseits die Wehrmacht den Zweiten Weltkrieg zwar verloren, aber einen »normalen« Krieg geführt hatte und mithin nicht mit dem nationalsozialistischen Eroberungs-, Rassen- und Vernichtungskrieg identifiziert werden konnte, andererseits ihre Führung gegen die NSDAP und SS eingestellt gewesen sei und nicht nur alle wichtigen Entscheidungen Hitlers missbillig hätten, sondern als Opfer des übermächtigen Diktators betrachtet werden müssen. ${ }^{83}$

Während also diese Geschichte der politisch-justiziellen Bewältigung der Folgen des NS-Regimes und der hochpolitische Streit zwischen den Westalliierten, zumal den Amerikanern, und den Deutschen über die Beseitigung der Folgen der NS-Prozesse sowie die Kampagne zur Freilassung der Kriegsverbrecher aus den Anfangsjahren der Bundesrepublik im Monat ausgeklammert wurde, trug die Zeitschrift allerdings zur Durchsetzung des geschönten Wehrmachtsbildes in der Nachkriegszeit bei. Angesichts der Entscheidung der Vereinigten Staaten für die Westbindung und die Wiederaufrüstung des ehemaligen Kriegsgegners zählte die Frage der Wiederbewaffnung der Bundeswehr zum politisch-ideologischen »Kernbestand« (Hochgeschwender) des Monat. Insofern war die Zeitschriftenredaktion darum bemüht, die Wehrmacht als Institution zu rehabilitieren: ${ }^{84}$ erstens, indem die militärische Opposition von Teilen der Wehrmachtsoffiziere und die Legitimation des militärisch-konservativen Widerstandes gegen den »Führerstaat « hervorgehoben wurde; zweitens, indem ihre Verstrickung in die Kriegs- und Zivilisationsverbrechen und vor allem die Mitverantwortung

81 Vgl. bes. Franz Halder, Hitler als Feldherr. Der ehemalige Chef des Ceneralstabes berichtet die Wahrheit, Tübingen 1949; Heinz Guderian, Erinnerungen eines Soldaten, Heidelberg 1950; Adolf Heusinger, Befehl im Widerstreit. Schicksalsstunden der deutschen Armee. 1923-1945, Tübingen 1950; Albert Kesselring, Soldat bis zum letzten Tag, Bonn 1953; Hans Frießner, Verratene Schlachten. Die Tragödie der deutschen Wehrmacht in Ungarn und Rumänien, Hamburg 1956; Walter Warlimont. Im Hauptquartier der deutschen Wehrmacht 1939-45, Frankfurt a. M. 1962.

82 Die anderen vier Verfasser waren die früheren Wehrmachtsgeneräle Walther von Brauchitsch, Franz Halder, Walter Warlimont sowie Siegfried Westphal.

83 Vgl. Bernd Boll, Generalfeldmarschall Erich von Lewinski, gen. von Manstein, in: Gerd R. Ueberschär (Hg.), Hitlers militärische Elite, Bd. 2: Vom Kriegsbeginn bis zum Weltkriegsende, Darmstadt 1998, S. 143-152; Oliver von Wrochem, Die Auseinandersetzung mit Wehrverbrechen im Prozess gegen den Generalfeldmarschall Erich von Manstein 1949, in: ZfC 46 (1998), S. 329-353, sowie dessen Biografie: Erich von Manstein, Vernichtungskrieg und Geschichtspolitik, Paderborn 2006. Zum Bild und zur Legende der »sauberen« Wehrmacht insbesondere in den unmittelbaren Nachkriegsjahren vgl. Wolfram Wette, Das Bild der Wehrmachts-Elite nach 1945, in: Ueberschär, Hitlers militärische Elite, 2, S. 293-308.

84 Neben den bereits genannten Beiträgen siehe bes. Walter Görlitz, Schuld oder Schicksal?, in: Der Monat 3 (1951), H. 28, S. 429-432 (Rezension). Auf den Beitrag ging ich bereits an anderer Stelle der vorliegenden Untersuchung ein (siehe die entsprechenden Ausführungen in Kap. IV.1.6). 
der Wehrmachtsführung für die durch den sogenannten Kommissarbefehl von 1941 ausgelöste Ermordung politischer Kommissare der Roten Armee sowie für verbrecherische Maßnahmen gegenüber der Zivilbevölkerung in den von der Wehrmacht besetzten Gebieten verwischt wurde; drittens, indem man die Militärelite als Opfer des »dämonischen, besessenen Demagogen« (Walter Görlitz) und Usurpators Hitler charakterisierte, der sie als militärischer Oberbefehlshaber im Zweiten Weltkrieg und speziell beim Überfall auf die Sowjetunion missbrauchte; viertens, indem die rechtliche Anklagekonstruktion des Nürnberger Militärtribunals, demzufolge die militärischen Oberbefehlshaber als einheitliche Gruppe »Generalstab und OKW« anzusehen sei, als falsch betrachtet wurde, weil sie nicht »der Vorstellung von einer straffen Gliederung $\aleph^{85}$ entsprach und unausgesprochen eingeräumt wurde, dass sie zu Recht nicht als »verbrecherische Organisation« verurteilt worden war; fünftens, indem die juristische Konstruktion, die zur Verurteilung der Wehrmachtsgeneräle im Nürnberger Hauptkriegsverbrecherprozess sowie speziell in den amerikanischen und britischen Militärprozessen führte, infrage gestellt wurde, weil nämlich die Wehrmachtsführung in der Folge des "Unternehmens Barbarossa« mit einer neuen Form des Krieges konfrontiert war, dem Partisanenkrieg, für den aber einerseits das damals geltende internationale Kriegsvölkerrecht keine expliziten Rechtsnormen geschaffen hatte und für den andererseits letztlich neben Hitler auch Stalin die Verantwortung trug.

Eben dies zwang zu der "nüchterne[n] Beurteilung«, so der konservative deutsche Historiker Walter Görlitz im Monat, dass die Sowjetunion,

die in Nürnberg mit über das deutsche militärische Führerkorps zu Cericht saß, das Völkerrecht, um dessen Wahrung es ging, nur gelten ließ, wo es ihr paßte, daß sie im Crunde abendländischem Rechtsempfinden weltenfern stand. Dafür trug sie die moralische, ideologische und zum Teil auch tatsächliche Verantwortung für den Partisanenkrieg, dessen Bekämpfung die deutschen Militärbefehlshaber in Konflikt mit völkerrechtlichen Regeln brachte. Eines der Kennzeichen der alliierten Militärgerichtsverfahren ist im Grunde, daß die Vorgänge im sowjetischen oder sowjetisch beeinflußten Bereich nach Maßstäben beurteilt wurden, welche noch auf dem Crundsatz des klassischen Völkerrechts beruhten, daß der Krieg ein Kampf zwischen Staaten sei. Sicherlich ist das Recht unteilbar, dann ist aber auch die Anklage unteilbar. ${ }^{86}$

In diesem Zusammenhang erinnerte Görlitz in seiner Rezension des Buches von Hans Laternser, dem Verteidiger der Gruppe Generalstab und OKW im Hauptverfahren sowie der Generalfeldmarschälle Kesselring, List und Ritter von Leeb in den nachfolgenden Militärprozessen, ${ }^{87}$ daran, dass es den Vereinigten Staaten zweifelsohne mit den Nürnberger Prozessen auch um die Schaffung "neuer internationaler Rechtsnor-

85 Ebd., S. 430.

86 Ebd., S. 431.

87 Albert Kesselring wurde im Mai 1947 von einem britischen Militärgericht in Venedig wegen Repressalien und Geiselerschießungen zum Tode verurteilt, die später in Haft umgewandelt wurde; er wurde 1952 wegen Krankheit begnadigt. Wilhelm List wurde im Februar 1948 im Nürnberger Prozess gegen die »Südost-Generale« (Fall 7) vom amerikanischen Militärgericht wegen deutscher Vergeltungsaktionen bei der Bekämpfung von Partisanen auf dem Balkan zu einer lebenslänglichen Freiheitsstrafe verurteilt; er wurde nicht begnadigt, aber aus gesundheitlichen Cründen im Oktober 1952 entlassen. Wilhelm Ritter von Leeb wurde im Nürnberger OKW-Prozess (Fall 12) im Oktober 1948 wegen Kriegs- 
men« ging, aber dass sich die amerikanische Armee seit dem Sommer 1950 in Korea selbst im Kampf gegen eine sowjetisch beeinflusste Partisanenbewegung befand, die »eine verzweifelte Ähnlichkeit mit den Partisanengruppen« besaß, mit denen sich »die deutschen Befehlshaber auseinanderzusetzen hatten. [...] Von solchen Dingen hatte sich die alte Haager Landkriegsordnung noch nichts träumen lassen.«

Während Laternser als Anwalt die Freilassung seiner drei Mandanten forderte, ging es Görlitz in seinem im Januarheft 1951, also in dem Monat, in dem der amerikanische Hohe Kommissar seine Entscheidung in den Landsberger Fällen traf, um etwas anderes. Ihm schwebte etwas vor,

was möglicherweise in juristisch einwandfreier Form zu einer Revision all dieser umstrittenen Prozesse führen könnte: die Anpassung der internationalen Rechtsnormen an die veränderten Formen des Krieges. Wir benötigen ein neues internationales Recht. Richtig verstanden könnten auf diese Weise sowohl der Nürnberger Prozeß wie die ihm angehängten Ceneralsverfahren, »OKW-« und »Südostprozeß«, die beide der Überprüfung bedürfen, zum Meilenstein des Fortschritts werden. Fraglos müssen Kriegsverbrechen bestraft werden, fraglos ist hierbei jedoch eine genaue Definition des Begriffes erforderlich. Die Echtheit und Tiefe des Rechtsbewußtseins bildet die Grundlage unserer abendländischen Begriffswelt. ${ }^{88}$

Während McCloys Entscheidung angesichts des Ausmaßes der Strafsenkung gegenüber den NS-Kriegsverbrechern im Grunde genommen die Idee einer gerichtlichen Aburteilung der NS-Täter selbst schwer beschädigte, wenn nicht zerstört hatte und einen Prozess in Gang setzte, in dessen Verlauf alle noch verbliebenen Kriegsverbrecher freigelassen werden sollten, sodass sich schlussendlich die deutschen Forderungen erfüllten, ging Der Monat noch einen Schritt weiter. In Anbetracht der im Zeichen des Kalten Krieges stehenden zweiten Phase der amerikanischen Deutschlandpolitik, die durch den Übergang von der bisherigen Bestrafungspolitik zu einer Politik der Westintegration und Wiederbewaffnung des einstigen Kriegsgegners gekennzeichnet war, und angesichts der deutschen Forderungen nach einer Amnestie für die in den westalliierten Gefängnissen einsitzenden Wehrmachtsgeneräle und einer »Wiederherstellung der Ehre der deutschen Soldaten« sowie auf dem Hintergrund der erklärten Bemühungen der Zeitschrift, die Wehrmacht als Institution und ihre Führung zu rehabilitieren, bot die Redaktion Görlitz ein Forum für seine Auffassung, wonach die Kriegsverbrecherprozesse auf einer mangelnden juristischen, historischen und moralischen Grundlage gestanden hätten. Während zum selben Zeitpunkt - nach einem von McCloy arrangierten Treffen in seiner Bad Homburger Villa zwischen dem als überzeugten Feind des deutschen Militarismus bekannten neuen Oberbefehlshaber der NATO in Europa, General Dwight D. Eisenhower, und den beiden ehemaligen Wehrmachtsgenerälen Hans Speidel und Adolf Heusinger - Eisenhower eine von Adenauers Militärberatern vorbereitete Ehrenerklärung für den »deutschen Soldaten

verbrechen und Verbrechen gegen die Menschlichkeit zu einer Freiheitsstrafe von drei Jahren verurteilt, die zur Zeit der Verkündigung des Urteils als verbüßt galten.

88 Ebd., S. 432. 
als solchen « aus Gründen der amerikanischen Staatsräson abgab, ${ }^{89}$ griff Görlitz bei seinem unverkennbaren Ziel der Reinwaschung der Wehrmacht und seiner Führung in das Arsenal jener deutschen, aber auch amerikanischen Kritiker, die das Internationale Nürnberger Militärtribunal wegen der Beteiligung der Sowjetunion ablehnten. Bei seiner hiermit verbundenen Absicht, die Legitimität der (west-)alliierten Kriegsverbrecherprozesse, zumal der Militärgerichtsverfahren, mit dem fadenscheinigen Argument infrage zu stellen, dass wo kein internationales Kriegsvölkerrecht ist, auch kein Kriegsunrecht entstehen kann, scheute sich der deutsche Historiker mit Blick auf die unter der Beteiligung der Wehrmacht während des Zweiten Weltkrieges in Ostund Südosteuropa im Kontext des Partisanenkrieges begangenen Kriegs- und Zivilisationsverbrechen, nicht nur der Sowjetunion eine Mitverantwortung zuzuschieben, sondern auch unmissverständlich darauf hinzuweisen, dass auch die amerikanische Armee im Koreakrieg mit eben jenem Phänomen konfrontiert war, mit dem sich bereits die Wehrmachtsführung auseinanderzusetzen hatte.

Durch die in diesem Zusammenhang vertretene These einer sogenannten verzweifelten Ähnlichkeit hinsichtlich der Kriegsführung der amerikanischen und deutschen Befehlshaber im Kampf gegen eine »sowjetisch beeinflußte Partisanen-Bewegung" (Görlitz) wurden allerdings zum einen indirekt die Wehrmachtsverbrechen mit den von der amerikanischen Armee angewandten militärischen Maßnahmen zur Bekämpfung des Partisanenkriegs in Korea in eins gesetzt - in beiden Fällen existierten keine kriegs- und völkerrechtlichen Bestimmungen -, und fand zum anderen unter der Hand im Monat ein zentrales Element der von der breiten deutschen Front gegen die »Siegerjustiz« geäußerten entschiedenen Kritik Raum. Hinter dem politischen Kampfbegriff stand bekanntlich die Absicht, den Zweiten Weltkrieg und die von den Deutschen begangenen Massenverbrechen unter die Kategorie des "normalen Krieges« zu subsumieren. Nicht die Kriegs- und Zivilverbrechen, sondern ausschließlich der militärische Erfolg der Alliierten über die Deutschen sei die eigentliche Grundlage für die Strafverfahren, lautete der Hauptvorwurf. Hieraus folgte dann die stereotype Kritik, dass Kriegsverbrechen nicht nur von den Deutschen begangen worden seien und mithin die NS-Prozesse durch nicht anderes als die Willkür der Sieger begründet sei.

Während sich bei der Auseinandersetzung mit dem nationalsozialistischen Totalitarismus und seinen vergangenheitspolitischen Dimensionen im Monat zeigen ließ, dass sich die Imperative der US-amerikanischen Besatzungspolitik in Westdeutschland gewandelt hatten, kann angesichts der vorliegenden Untersuchungsergebnisse mit Blick auf den von der Zeitschriftenredaktion unter der Ägide Laskys formulierten antitotalitären Anspruch resümierend festgestellt werden: Der von ihr propagierte Antitotalitarismus wurde hinsichtlich der (vergleichenden) Beschreibung und Analyse des nationalsozialistischen und sowjetkommunistischen Herrschaftssystems in erster Linie als Antikommunismus verstanden und folglich nicht eingehalten. Inso-

89 Das Treffen fand am 22. Januar 1951 statt und am folgenden Tag erklärte Eisenhower auf dem Frankfurter Flughafen vor der Presse: »Ich für meinen Teil glaube nicht, daß der deutsche Soldat als solcher seine Ehre verloren hat. [...] Wie ich dem Kanzler und anderen deutschen Herren, mit denen ich gestern abend gesprochen habe, gesagt habe, bin ich zu der Überzeugung gekommen, daß ein wirklicher Unterschied zwischen deutschen Soldaten und Offizieren als solchen und Hitler und seiner kriminellen Cruppe besteht.«(Zit. n. Frei, Vergangenheitspolitik, S. 218) 
fern besaß der herrschaftskritische Terminus zweifelsohne eine Schlagseite und hatte einen instrumentellen Charakter; hierbei existierten Parallelen zur angesprochenen Grundausrichtung des »Kongresses für kulturelle Freiheit« bis Mitte der 1950er-Jahre. Die beiden totalitären Herrschaftssysteme wurden einschließlich ihrer länderspezifischen Vorgeschichte sowohl was quantitative als auch qualitative Aspekte anbelangt mit unterschiedlichen Maßstäben untersucht. Andererseits wurden im Kontext der politisch-justiziellen Auseinandersetzung mit der nationalsozialistischen Geschichte zentrale vergangenheitspolitische Themen und Dimensionen ausgeblendet und gegen die neonazistischen und rechtsradikalen Gefährdungen in der Bundesrepublik erst in der zweiten Hälfte der 1950er-Jahre deutlich Position bezogen.

Der Antitotalitarismus war im Monat eine Kampfkategorie des Kalten Krieges, mit dem der (sowjetische) Kommunismus delegitimiert und die NS-Vergangenheit neutralisiert und relativiert werden sollte. Unter dem Anschein einer sich universell gebenden Herrschaftskritik wurde im Zeichen des Antikommunismus durch die Hervorhebung der persönlichen Rolle Hitlers und der engeren NS-Führungsclique ein simplifizierendes und dämonisierendes Bild des NS-Staates gezeichnet, indem die Mitverantwortung und Mitwirkung der bürokratischen, diplomatischen, medizinischen, militärischen und wirtschaftlichen Eliten in das verbrecherische System kaschiert wurde, was ihre Rehabilitierung erleichterte. Der Vergleich zwischen dem Nationalsozialismus und dem Sowjetkommunismus in seiner historischen Gestalt des Stalinismus fragte im Sinne der identifizierenden Totalitarismustheorie nicht nach Differenzen, sondern nach strukturellen Gemeinsamkeiten und suchte sie ausschließlich in den Herrschaftssystemen. Hierbei wurde insbesondere Arendts Totalitarismusstudie für politisch-ideologische Zwecke instrumentalisiert.

\section{IV}

Insofern stand der Antitotalitarismus des Monat in einer engen Beziehung zu dem in der frühen Bundesrepublik von der Regierung und fast aller im Bundestag vertretenen Parteien immer wieder beschworenen antitotalitären Konsens. Denn dieser verknüpfte die Distanzierung des Nationalsozialismus angesichts des »drohenden Bolschewismus« geschickt mit dem außen- und innenpolitischen Kampf gegen den (sowjetischen) Kommunismus.

Gleichwohl blieb der Nationalsozialismus für den westdeutschen Teilstaat ein historisches Bezugsereignis von überragender Bedeutung und war die Negativfolie für die Legitimierung des neuen politischen Systems. ${ }^{90}$ Die Bundesrepublik hat sich von Anfang an zum Grundsatz der Gesamtnachfolge bekannt und trat die Erbschaft der NS-Diktatur an. Hierbei verstand sie sich als Rechtsnachfolger des von den Siegermächten aufgelösten Deutschen Reiches von 1871 und machte zugleich geltend, mit seinem Vorgänger definitiv zu brechen. Die konstitutiven Organe und die bei der Beratung des Grundgesetzes maßgeblichen Personen und Parteien betrachteten insbeson-

90 Ich stütze mich für das folgende aufM. Rainer Lepsius, Das Erbe des Nationalsozialismus und die politische Kultur der Nachfolgestaaten des »Großdeutschen Reiches«, in: Ders., Demokratie in Deutschland. Soziologisch-historische Konstellationsanalysen. Ausgewählte Aufsätze, Göttingen 1993, S. 229-248, sowie Reichel, Vergangenheitsbewältigung in Deutschland, S. $126 \mathrm{f}$. 
dere in den Strukturschwächen der Weimarer Republik die entscheidende Bedingung für den Aufstieg der NSDAP und die Machtübertragung auf Hitler. Zum Bezugsereignis für die zweite deutsche Republik wurde das Jahr 1930, also der Übergang von der parlamentarischen zur präsidialen Demokratie Hindenburgs. Mit Blick auf das Ende von Weimar wurde die neue politische Herrschaftsordnung "weder plebiszitär noch präsidentiell, sondern parlamentarisch-repräsentativ« zugeschnitten. Darin drückte sich ein »doppeltes Misstrauen« aus:

Zum einen gegenüber den unter krisenhaften Bedingungen offenbar leicht manipulierbaren Volksmassen und zum anderen gegenüber unberechenbaren und unverantwortlichen Volkshelden und Volksführern. Der demokratische Souverän galt nicht viel, der gegen seine extremistischen Auswüchse zu schützende Parteienstaat umso mehr. Aus der hochpolitisierten, antagonistischen Weimarer Klassengesellschaft sollte eine sozial und ökonomisch befriedete pluralistische Gesellschaft werden. Und an die Stelle der missglückten Versöhnung des monarchischen mit dem demokratischen Strukturprinzip - als Synthese von parlamentarischer Regierungsverantwortung und plebiszitärer Präsidentenschaft - sollte eine parlamentarische Kanzlerdemokratie treten. ${ }^{91}$

Die berühmte Formel »Bonn ist nicht Weimar ${ }^{92}$ war hierbei Mahnung und Zielvorgabe zugleich. Deshalb war die aus den Erfahrungen der späten Weimarer Jahre entstandene Bonner Demokratie nicht nur repräsentativ, sondern begriff sich zunächst defensiv. In den Mittelpunkt des politischen Interesses rückte die Abwehr tatsächlicher oder vermeintlicher Feinde der freiheitlich-demokratischen Grundordnung. Hierfür stellte das Grundgesetz eine "ganzes Arsenal an Stabilitäts- und Sicherungsinstrumenten « bereit, die von der Fünfprozentklausel bis zu der Möglichkeit des Verbots verfassungswidriger Parteien durch das Bundesverfassungsgericht (Art. 21 Abs. 2) reichte. Davon machte die in den ersten Jahren nicht sehr selbstbewusste, unter gehörigem Bewährungsdruck stehende und mit der ständig drohenden Intervention des amerikanischen Hochkommissars lebende zweite deutsche Republik Anfang der 1950er-Jahre mit dem Verbot der neonazistischen SRP Gebrauch.

Für die Bundesrepublik war also der Nationalsozialismus ein historisches Bezugsereignis von konstitutiver Bedeutung und wurde als das totalitäre Gegenmodell zum westdeutschen Nachfolgestaat sozusagen "normativ internalisiert «. ${ }^{93}$ Indes geschah dies in einer für die unmittelbare Nachkriegszeit charakteristischen Art. Denn der Kalte Krieg und der sowjetische Kommunismus »nährten die Bedrohungsängste« großer Teile der westdeutschen Bevölkerung und ihrer politischen Repräsentanten. Vor diesem Hintergrund erschien es konsequent, »keinen Wesensunterschied zwischen >brauner< und >roter< Diktatur zu machen, die kommunistische höher als die neonazis-

91 Ebd., S. 126.

92 Siehe Fritz René Allemann, Bonn ist nicht Weimar, Köln/Berlin (West) 1956 sowie ders., Brief aus Westdeutschland: Bonn ist nicht Weimar, in: Der Monat 7 (1955), H. 76, S. 333-341; vgl. ders., Bonn ist nicht Weimar. Zehn Jahre danach, in: Der Monat 17 (1965), H. 200, S. 7-17.

93 Lepsius, Das Erbe des Nationalsozialismus und die politische Kultur der Nachfolgestaaten des »Großdeutschen Reiches«, S. 233. 
tische Gefahr zu bewerten und gegen beide als extremistische Gefährdungen für die junge pluralistische Demokratie Front zu machen « ${ }^{94}$.

Insofern wies der von der politischen Klasse beschworene Antitotalitarismus in den 1950er-Jahren (siehe Kapitel I.4.5) eine überaus problematische Dimension auf: Antifaschistisch war dieser vor allem der Vergangenheit gegenüber gemeint, antikommunistisch aber vor allem der Gegenwart. Die Rechts-Links-Symmetrie wurde mit dem Verbot der SRP 1952 und dem der KPD 1956 scheinbar gewahrt, in Wirklichkeit jedoch hatte, was sich an der Strafverfolgung extremistischer Gruppierungen zeigte, der Antitotalitarismus eine Schlagseite, weil es sehr viel riskanter war, eine als kommunistisch verdächtige Position einzunehmen als eine neonazistische. Denn nach dem Ausbruch des Koreakrieges galt nicht mehr die Eindämmung der rechtsradikalen Gefahr als die vordringlichste Aufgabe, sondern die Bekämpfung der als akut empfundenen kommunistischen Bedrohung. Die Instrumente der »wehrhaften Demokratie« richteten sich hauptsächlich gegen die Linke, wobei die auf dem rechtem Auge blinde politische Justiz rücksichtslos gegen Personen vorging, die des Kommunismus verdächtigt wurden oder nicht bereit waren, sich von ihrer kommunistischen Überzeugung zu distanzieren.

Dass die Bundesrepublik die Abkehr vom Nationalsozialismus im populären Antitotalitarismus tagespolitisch geschickt mit der Ablehnung des stalinistischen Kommunismus verknüpfte und ihn als innenpolitisches Instrument gebrauchte, mit dem man jegliche vermeintliche oder tatsächliche Opposition von links im Keime erstickte, wurde im Monat ausgeblendet. Wie auch die Tatsache keine grundsätzliche Bedeutung erlangte, dass angesichts des Feindbildes des Kommunismus in den frühen Jahren der Bundesrepublik eine konstitutive NS-Ideologie ermöglicht wurde, sich erneut in einer politischen Relegitimierung zu versuchen. Denn durch den Kalten Krieg konnte sich der Antikommunismus bzw. -bolschewismus behaupten, ${ }^{95}$ und die Westdeutschen konnten glauben, zumindest in dieser Hinsicht seit Langem auf der richtigen Seite gestanden $\mathrm{zu}$ haben. ${ }^{96}$ Mit anderen Worten: »Im Zeichen des Anti-Totalitarismus konnten manche, die, zum Teil noch aus nationalsozialistischer Erziehung heraus, lei-

94 Reichel, Vergangenheitsbewältigung in Deutschland, S. 127.

95 Nur in einem Beitrag setzte sich Der Monat ausdrücklich von dem in den rechtsradikalen Kreisen der frühen Bundesrepublik grassierenden Antibolschewismus ab. Im Augustheft des Jahres 1951 distanzierte sich das Redaktionsmitglied Alfred Kellner überzeugend von der Zeitschrift Nation Europa und seinem Herausgeber Arthur Ehrhardt, weil das hier in den ersten sechs Heften versammelte >Gedankengut eine politische Tendenz zum Ausdruck brachte (von ehemaligen NS-»Barden« wie Hans Grimm, Will Vesper, Heinrich Zillich, Gerhard Schumann und Bruno Brehm), die die bis dahin »raffinierteste«, weil im Crunde genommen »konsequenteste Fortsetzung des nationalsozialistischen Traumes von der >Neuen Europäischen Ordnung`darstellte. Vor dem Hintergrund der engen Affinität zur NS-Politik und NS-Ideologie stellte Kellner bezüglich des sogenannten Antibolschewismus von Nation Europa, wie der Rechtsradikalen insgesamt, fest, dass dieser mit dem Kampf der westlichen Demokratien speziell gegen den Stalinismus »nicht das geringste gemein hat und nicht etwa dem Streben nach Menschlichkeit und Gerechtigkeit« entsprang, sondern nur dem Wunsch, den »östlichen Totalitarismus« durch eine »faschistische Diktatur« zu ersetzen. Siehe ak (d. i. Alfred Kellner), Falschmünzer, in: Der Monat 3 (1951), H. 35, S. 539 f.

$96 \mathrm{Vgl}$. in diesem Sinne die kurzen Ausführungen ebenfalls von dem deutschen Historiker in dem Beitrag von Alfred Kellner, Die ruhigen Deutschen. Völkerpsychologie mit Fragezeichen, in: Der Monat 11 (1959), H. 126, S. 72-75 (Rezension), hier S. $74 \mathrm{f}$. 
denschaftliche Antikommunisten waren, sich während des `Kalten Krieges schnell als vermeintlich gute Demokraten >bewähren und bei den Westmächten anbiedern. ${ }^{97}$

Während in der Auseinandersetzung mit dem Sowjetkommunismus im Monat in den 1950er-Jahren nicht zuletzt das hohe Niveau der Beiträge grundsätzliche qualitative Unterschiede und Differenzen zum `normalen<, plumpen Antikommunismus in der frühen Bundesrepublik aufwies und in keinem Beitrag eine Affinität zur NS-Ideologie festgestellt werden konnte, gebrauchte man allerdings in der unmittelbaren Anfangsphase den Begriff des "christlichen Abendlands", also einen Topos, den bereits die NSPropaganda zur Legitimation des Zweiten Weltkrieges benutzte und besonders nach der Kriegswende von Stalingrad einsetzte, um den deutschen Vernichtungskrieg zum europäischen bzw. abendländischen Abwehrkampf gegen den Bolschewismus umund hochzustilisieren. Hierbei trug der primär antikommunistische Antitotalitarismus des Monat überaus intolerante Züge.

Vor dem Hintergrund der Deutung des Totalitarismus als sozusagen logische Entwicklung der Säkularisierung war demnach zwar mit dem Nationalsozialismus eine totalitäre Macht verschwunden, die weitaus gefährlichere, der "gottlose Bolschewismus«, aber geblieben und bedrohte die Welt. Hierbei fungierten wechselweise der Abendlandbegriff und der Begriff »freie Welt«, um eine radikale Kampfbereitschaft gegen den östlichen Totalitarismus auszudrücken. Unter den meisten Autoren des Monat galt es als ausgemacht, dass man nach einer kurzen weltgeschichtlichen Kampfpause vor dem alsbald zu erwartenden Endkampf zwischen den beiden als Siegern aus dem Weltkrieg hervorgegangenen Supermächten USA und Sowjetunion stehe. Und die Vertreter des militanten Antikommunismus sahen diesen Kampf anfangs im Blickfeld eines jahrhundertealten Konfliktes, bei dem sich die sogenannte westliche Freiheit und die östliche Unfreiheit gegenüberstanden. Die neue Schlachtordnung hieß abendländische Freiheit gegen den Totalitarismus, die es überhaupt erst erlaubte, dass sich ein breites Spektrum von christlichen, liberalen und konservativen Denkern sowie demokratische Sozialisten und ehemalige Kommunisten in die antibolschewistische Phalanx des Monat einreihen konnten. So entstand anfangs aus dem Abendlandbegriff und dem Antikommunismus eine politisch extrem aufgeladene Kategorie des Antitotalitarismus, der Züge eines »Kreuzzuges gegen den Kommunismus« annahm.

Das redaktionelle Vorwort des mit dem Titel Das Schicksal des Abendlandes überschriebenen ersten Heftes war hierbei richtungsweisend und mündete in die Frage: »Wird die westliche Zivilisation, die uns als Erbteil der letzten zweieinhalb Jahrtausende überliefert worden ist, dem Ansturm ungeheuerlichen Ausmaßes gewachsen sein, der ihr ganz augenscheinlich heute droht? ${ }^{98}$ Angesichts des heraufbeschworenen Dritten Weltkrieges führte die Propagierung der Verteidigung der »Freiheit« unter der Führung der USA gegen den östlichen Totalitarismus dazu, dass im selben Heft Bertrand Russell und Franz Borkenau Überlegungen anstellten, inwiefern ein

97 Martin Broszat, Referat auf dem vom Institut für Zeitgeschichte am 24. November 1978 veranstalteten öffentlichen Kolloquium zu dem Thema »Totalitarismus und Faschismus. Eine wissenschaftliche und politische Begriffskontrovers«, in: Institut für Zeitgeschichte, Totalitarismus und Faschismus, S. 32-38, hier S. 33.

98 Der Monat 1 (1948), H. 1, S. 3. 
sofortiger Waffengang unternommen werden sollte, dem durch die existenzielle weltpolitische Situation seine Legitimation verliehen wurde. ${ }^{99}$

Während also der Antitotalitarismus hinsichtlich der vergleichenden Analyse des Nationalsozialismus und des Sowjetkommunismus im Monat nicht erfüllt und in Wirklichkeit vornehmlich als Antikommunismus verstanden wurde, der wiederum in der unmittelbaren Anfangsphase sogar eine Affinität zur NS-Ideologie besaß, in der Hochphase der Konfrontation mit dem Sowjetkommunismus intolerante Züge aufwies und letztlich eine Kampfkategorie im Kalten Krieg darstellte, wurde die Zeitschrift dem antitotalitären Anspruch und Selbstverständnis in einem anderen Themenfeld durchaus gerecht: nämlich bei der Auseinandersetzung mit dem beunruhigenden und erklärungsbedürftigen Phänomen, dass zahlreiche Künstler, Wissenschaftler, Schriftsteller, Philosophen, Journalisten und Publizisten, kurz: Intellektuelle, der Faszinationskraft des deutschen Nationalsozialismus einerseits und des Sowjetkommunismus andererseits erlagen und die beiden Herrschaftssysteme zumindest eine Zeit lang unterstützt hatten. Die Frage, wie es möglich war, dass der Totalitarismus und die als geschlossene Denksysteme aufgefassten totalitären Ideologien auf zahleiche Intellektuelle eine geradezu »magische Anziehungskraft« (de Mendelssohn) ausüben konnten und ihnen zum Nationalsozialismus respektive zum Sowjetkommunismus, zumal in seiner stalinistischen Herrschaftsform, eine Menge »eingefallen « (Arendt) war, avancierte zum eigentlichen Schlüsselthema des Monat; in erster Linie natürlich für Lasky und den engeren Mitarbeiterkreis, aber im Grunde genommen auch für die meisten Autoren. Denn der »Verrat des Intellektuellen« (Julien Benda) in der ersten Hälfte des 20. Jahrhunderts zählte zu den lebensgeschichtlichen Grunderfahrungen, dass nämlich Intellektuelle sich im Namen einer exklusiven und partikularen National-, Volks-, Rassen- oder Klassenidentität engagierten und ihre eigentliche Funktion nicht in der Verteidigung ewiger, universeller und interessefreier Werte wie Gerechtigkeit, Wahrheit und Vernunft sahen. Die Denkfigur des Intellektuellen als Priester

99 Bertrand Russell, Der Weg zum Weltstaat, in: Ebd., S. 4-8; Franz Borkenau, Nach der Atombombe, in: Ebd., S. 9-16. Ausdrücklich verwendet wurde der Abendlandbegriff in der Konfrontation mit dem Sowjetkommunismus auch in dem Beitrag Wards (Ist der Krieg mit Russland unvermeidlich?), die schrieb, dass die »Zivilisation des Abendlandes« auf »gewaltige Claubensakte « gegründet wurde auf den Glauben, dass die Menschen als »Kinder Gottes frei und gleichberechtigt geboren seien und dass einzelne Menschenleben unendlichen Wert« besäßen. Im Gegensatz hierzu machte der sowjetische Kommunismus den einzelnen Menschen zu einer »Nummer in einem Polizeistaat«, die wie in einem »kollektiven Bienenstock« ausschließlich »Zwangsarbeit« leisten müssten. Mithin werde das Abendland, so Ward, durch den »Kommunismus angespornt, den »Glauben an Gott und den Glauben an den Menschen « wiederherzustellen (S. 7). Zur ideengeschichtlichen Einbettung des Monat in die bundesrepublikanische Nachkriegsgesellschaft mit Blick auf die Säkularisierungsthese bzW. »Abfall von Cott-Theorie« zur Erklärung des Totalitarismusphänomens und dem zeitgenössischen »antitotalitären« Diskurs im Kontext von Antibolschewismus bzw. Antikommunismus im Zuge des Kalten Krieges sowie der Bedeutung des Begriffes »christliches Abendland« vgl. Hermand, Kultur im Wiederaufbau, S. 77-88, der hierbei, wie gesehen, ausdrücklich auf den Monat eingeht (S. 86-88), sowie grundsätzlich Axel Schildt, Zwischen Abendland und Amerika. Studien zur westdeutschen Ideenlandschaft der 50er-]ahre, München 1999 (bes. S. 21-82). 
von Diesseitsreligionen, als (Partei-)Ideologe säkularer Heilslehren, prägte die Auseinandersetzung über die politische und intellektuelle Kollaboration mit dem Nationalsozialismus (bzw. dem italienischen Faschismus ${ }^{100}$ ) oder dem (sowjetischen) Kommunismus von prominenten »Fällen «, ${ }^{101}$ die für nicht wenige der Autoren des Monat in Anbetracht der eigenen Vergangenheit immer auch explizit oder implizit eine selbstkritische war. ${ }^{102}$ Indes: Dass in diesem Zusammenhang die Rolle der Intellektuellen im »Jahrhundert des Totalitarismus« (Karl Dietrich Bracher) und ihre Verführbarkeit hinsichtlich des deutschen »Führerstaates « im Vergleich zum Stalinismus in einem geringeren Umfang ins Licht gerückt wurde, stellt angesichts der Untersuchungsergebnisse der vorliegenden Arbeit keine Überraschung dar.

Da auf dieses vielschichtige Thema aus Raumgründen nicht weiter eingegangen werden kann, soll hier nur festgehalten werden, dass der Monat die politische und intellektuelle Verstrickung in den Nationalsozialismus respektive in das NS-Herrschaftssystem insbesondere bei der Auseinandersetzung mit Ernst Jünger, ${ }^{103}$ Gustav Gründgens, ${ }^{104}$ Wilhelm Furtwängler, ${ }^{105}$ Arno Breker, ${ }^{106}$ Knut Hamsun ${ }^{107}$ und dem Existenzialismus des einflussreichsten deutschen Philosophen des 20 . Jahrhunderts, Martin Heidegger, ${ }^{108}$ thematisierte; zudem ging man auf die Rolle und Bedeutung des »Kronjuristen« des >Dritten Reiches`, Carl Schmitt, für die Genese und Entwicklung des NS-Unrechtssystems ein. ${ }^{109}$ Die »Vergangenheitsbewältigung« namhafter Intel-

100 Vgl. bes. Edouard Roditi, Der Fall Ezra Pound oder die Grenzen der ästhetischen Wertschätzung, in: Der Monat 1 (1949), H. 10, S. 107-113.

$101 \mathrm{Vgl}$. in diesem Zusammenhang exemplarisch zwei Beiträge: Den fulminanten Vortrag auf dem Berliner »Kongreß für kulturelle Freiheit« im Juni 1950 von Peter de Mendelssohn, Die Versuchung des Intellektuellen, in: Der Monat 2 (1950), H. 22/23, S. 384-386 (siehe Kap. I.5), sowie den auf hohem Niveau geschriebenen Rezensionsaufsatz von François Bondy, Rebellen als Musterschüler (der Band enthält Kapitel über Knut Hamsun, Jean Giono, Ernst ]ünger und Cottfried Benn) sowie Czeslaw Milosz, Verführtes Denken. Mit einem Vorwort von Karl Jaspers, Köln/Berlin (West) 1953. Vgl. auch Luigi Barzini, Curzio Malaparte. Ein Erinnerungsblatt, in: Der Monat 12 (1959), H. 133, S. 51-57, wo gezeigt wurde, wie Malaparte zuerst die Nähe zum italienischen Faschismus suchte, und in den Nachkriegsjahren die zur sogenannten neuen Macht des Kommunismus, d. h. insbesondere zur KPI.

102 Die zahlreichen Beiträge zu diesem Thema wurden im Verlauf dieser Untersuchung an verschiedenen Abschnitten aufgeführt, sodass sie an dieser Stelle nicht genannt werden müssen.

103 Peter de Mendelssohn, Gegenstrahlungen. Ein Tagebuch zu Ernst Jüngers Tagebuch, in: Der Monat 2 (1949), H. 14, S. 149-174; vgl. auch Alfred Weber, Flucht in die Wildnis. Randbemerkungen zu Ernst Jüngers politische Schriften, in: Der Monat 3 (1951), H. 29, S. 542-545.

104 Friedrich Luft, Gustav Gründgens. Geschichte eines Aufstiegs in drei Phasen, in: Der Monat 10 (1958), H. 116 , S. 59-66.

105 H. H. Stuckenschmidt, Furtwängler-Ende einer Epoche. Zur ersten Wiederkehr des Todestages, in: Der Monat 8 (1955), H. 86, S. 65-70.

106 Alfred Kellner, Arno Breker. Porträt eines Bildhauers und Architekten, in: Der Monat 12 (1960), H. 142, S. 59-67.

107 Peter de Mendelssohn, Knut Hamsun, Erleuchtung und Verblendung des Zerrissenen, in: Der Monat 5 (1953), H. 55, S. 50-70; hierbei handelte es sich um eine stark gekürzte Fassung des gleichnamigen Kapitels aus seinem Essayband Der Geist in der Despotie. Versuche über die moralischen Möglichkeiten des Intellektuellen in der totalitären Gesellschaft.

108 Kurt Rossmann, Martin Heideggers Holzwege, in: Der Monat 2 (1950), H. 21, S. 236-245.

109 Und zwar im bereits referierten Beitrag von Walther Hofer, Der »völkische Rechtsstaat«. Zur nationalsozialistischen Rechtspolitik, in: Der Monat 11 (1959), H. 125, S. 46-58 (siehe Kap. IV.1.9). Zu einer 
lektueller einerseits ${ }^{10}$ und die Kritik am Wiedereindringen von einstigen überzeugten Nationalsozialisten in den akademischen Lehrbetrieb andererseits, zumal wenn sie weiterhin die »Pseudowissenschaft des tausendjährigen Jahrzwölfts « vertraten, ${ }^{111}$ war auch im Grunde genommen die conditio sine qua non, um gegenüber der wichtigsten Zielgruppe des Monat, den deutschen Intellektuellen, ${ }^{112}$ glaubwürdig zu erscheinen im Kampf für die politische, kulturelle und intellektuelle Freiheit und gegen die Unterdrückung von Intellektuellen in totalitären Systemen ${ }^{113}$ sowie in Bezug auf die Auseinandersetzung mit dem Phänomen der Anziehungskraft des Kommunismus im Allgemeinen und dem Stalinismus im Besonderen. Denn insbesondere in der frühen Phase der Bundesrepublik bestand die konkrete Gefahr, dass sich zahlreiche westdeutsche Intellektuelle ein zweites Mal auf ein totalitäres Herrschaftssystem einlassen und der Faszinationskraft des stalinistisch-bolschewistischen Modells erliegen würden, weil sich die Sowjetunion und das SED-Regime zur Legitimation der neuen politischen Ordnung des Antifaschismusmythos ${ }^{114}$ bedienten und sich nicht ohne Erfolg als sogenannte wahre Friedensmacht inszenierten. ${ }^{115}$ Darüber hinaus konnten in diesem Kontext explizit oder implizit die »intellektuellen Wurzeln« des Nationalso-

frühen Nachkriegspublikation von Carl Schmitt vgl. Golo Mann, Carl Schmitt und die schlechte Juristerei, in: Der Monat 5 (1952), H. 49, S. 89-92 (Rezension).

110 Vor diesem Hintergrund wurden zeitgenössische Veröffentlichungen von rechtsradikalen, rechtsoder nationalkonservativen Intellektuellen, die eine unverkennbare Affinität zur NS-Ideologie erkennen ließen, vehement kritisiert. Vgl. hierzu exemplarisch den Beitrag: Ernest ]. Salter, Konservative Revolution?, in: Der Monat 2 (1950), H. 21, S. 313-317 (Rezension).

111 Vgl. bes. den brillanten Beitrag: Marianne Regensburger, Ein ideologisches Lexikon, in: Der Monat 9 (1956), H. 98, S. 65-68 (Rezension), Zitat S. 68. Neben der radikalen Kritik sowohl am der rassistischantisemitischen NS-Ideologie anknüpfenden Wörterbuch als auch an der Rolle des deutschen Soziologen Pfeffer im Nationalsozialismus und im Nachkriegsdeutschland war es für die Rezensentin abschließend erschreckend und unbegreiflich, dass die beiden »renommierte[n] Wissenschaftler Arnold Gehlen und Helmut Schelsky »eine Arbeit dieses Autors in das von ihnen herausgegebene Lehr- und Handbuch zur modernen Cesellschaftskunde aufnehmen konnten« (S. 68).

112 Daneben zählte ja das Bildungsbürgertum, Schüler, Studenten, konfessionell nicht gebundene oder liberale Protestanten sowie Sozialdemokraten zur anvisierten Lesergruppe (siehe Kap. I.4.3).

113 Neben den zahlreichen auf dem Berliner »Kongreß für kulturelle Freiheit«1950 gehaltenen Vorträgen und Redebeiträgen (siehe Kap. I.5) vgl. die sechsteilige Reihe Die Intellektuellen in der Krise der Gegenwart mit folgenden Autoren: Jean-Paul Sartre, Man schreibt für seine Zeit, in: Der Monat 1 (1948), H. 1, S. 47-51; James T. Farrell, Was braucht die Literatur, in: Der Monat 1 (1949), H. 4, S. 66-71; Max Frisch, Kultur als Alibi, in: Der Monat 1 (1949), H. 7, S. 82-85; Rudolf Hagelstange, in: Der Monat 1 (1949), H. 11, S. 69-73; Theodor Plievier, Humanität und Staat, in: Der Monat 2 (1949), H. 13, S. 14-22, sowie Albert Camus, Der Künstler und die Freiheit, in: Der Monat 2 (1950), H. 17, S. 522-526.

114 Vgl. hierzu bes. Antonia Grunenberg, Antifaschismus - ein deutscher Mythos, Reinbek bei Hamburg 1993.

115 Als Prototypen des quasi totalitären kommunistischen (Partei-)Intellektuellen galt mit Blick auf das SED-Regime neben Johannes R. Becher (Präsident des Kulturbundes zur demokratischen Erneuerung Deutschlands, von 1952 bis 1956 Leiter der Deutschen Akademie der Künste und ab 1954 erster Kulturminister der DDR) insbesondere Bertolt Brecht, sodass beide zur Zielscheibe der Kritik wurden. Vgl. zu Becher besonders die beiden Beiträge zum sogenannten Thema »Der Fall Johannes R. Becher« in: Der Monat 3 (1951), H. 29: Stefan Andres, An einen Staatssklaven-Bildner, S. 487-490, und Rudolf Hagelstange, Der Verrat aus Furcht, S. 491-494, außerem John T. Becher schrieb einen Brief an seinen Vater, S. 488 f., sowie zu Brecht: Herbert Lüthy, Vom armen Bert Brecht, in: Der Monat 4 (1952), H. 44, S. 115-144. 
zialismus und des (Sowjet-)Kommunismus infrage gestellt werden, denn vom antitotalitären Standpunkt des Monat erschien eine »umfassende Kritik der totalisierenden Staats- und Ganzheitsfixierung der hegelianischen Ontologie, Erkenntnislehre und Staatsphilosophie« unentbehrlich. ${ }^{116}$ Hierbei ging es um die Herausbildung eines in der deutschen Vergangenheit nur in wenigen Fällen anzutreffenden antitotalitären Intellektuellen, d.h. kritischen, demokratischen Intellektuellen, zumal des politisch aktiven. Eben dieser verkörperte das Ideal, um unter dem Primat des Antikommunismus die »Re-Orientation«-Ziele des Monat zu realisieren, nämlich die westlich-liberaldemokratischen Werte in die bundesrepublikanische Gesellschaft hineinzutragen und zu einem integralen Bestandteil der politischen Kultur und des Geisteslebens des westdeutschen Teilstaates zu machen. ${ }^{117}$

\section{VI}

Der Monat folgte also den US-amerikanischen Interessen sowohl in der unmittelbaren Frühphase des Kalten Krieges, die selbstverständlich angesichts eines drohenden Krieges mit der Sowjetunion unter einem besonderen Stern stand und letzten Endes bis Stalins Tod reichte, als auch über den gesamten Zeitraum in den 1950er-Jahren, die in der vorliegenden Untersuchung im Fokus stehen. Angesichts der hier interessierenden qualitativen und quantitativen (vergleichenden) Analyse des Nationalsozialismus und des Sowjetkommunismus konnte diese Tatsache nicht nur beim Vergleich des nationalsozialistischen mit dem sowjetkommunistischen Herrschaftssystems, zumal in der stalinistischen Phase, sondern auch und vor allem in der Auseinandersetzung mit der Geschichte des >Dritten Reiches festgestellt werden. Gewissermaßen als Vorbild fungierte hierbei Willi Münzenbergs Zeitschriftenprojekt Die Zukunft, denn die Parallelen zum Monat waren nicht nur aufgrund der (mit-)tonangebenden handelnden Akteure offensichtlich, ${ }^{118}$ sondern auch mit Blick auf die Finanzierung: In beiden Fällen stammten die finanziellen Mittel aus staatlichen Regierungsstellen, die sich angesichts der jeweils zeitgenössischen politisch existenziell aufgeladenen weltpolitischen Situation in inhaltlichen und politischen Konzeptionen niederschlug. ${ }^{119}$ Zudem ging es auch und vor allem von Anbeginn mittels der altbewährten Agitpropmethode sowohl bei der Auseinandersetzung mit dem Totalitarismusphänomen als auch mit der

116 Hochgeschwender, Freiheit in der Offensive?, S. 194.

117 Erinnert sei daran, dass angesichts der bei der Operation »Talk Back« vorherrschenden Auffassung der Kalte Krieg auf der politischen Linken, also bei Sozialdemokraten, Gewerkschaften und Linksintellektuellen, entschieden würde, die SPD im Fokus der politisch-konzeptionellen Ausrichtung des Monat stand (siehe Kap. I.4.3). Insofern zählten sicherlich Intellektuelle aus dem linksliberalen Spektrum zur wichtigsten Zielgruppe.

118 Zur Erinnerung: Aus der Redaktionsleitung der Zukunft stammten die für den Monat überaus einflussreichen und bedeutenden Exkommunisten Arthur Koestler und Richard Löwenthal sowie Manès Sperber für den »Kongreß für kulturelle Freiheit«.

119 Indes muss, wie bereits zum Ausdruck kam, mit Blick auf die Finanzierung der Zeitschrift Die Zukunft einschränkend gesagt werden, dass diese bis zum heutigen Tage in der Forschungsliteratur umstritten ist. Gleichwohl spricht vieles dafür, dass bei der Gründung und der Finanzierung das französische Außenministerium, namentlich die Pressestelle, entscheidend beteiligt war. Ich folge hier der Auffassung von Walter, Deutsche Exilliteratur 1933-1950, 4, S. 129-132. 
Geschichte des `Dritten Reiches um das Prinzip der indirekten, diskret gesteuerten Meinungsbildung (worauf ich weiter unten hinsichtlich des Monat zurückkomme werde). Indes sah sich Der Monat, nachdem der NS-Staat besiegt war, im Gegensatz zur Die Zukunft ${ }^{120}$ nur noch mit einem existierenden totalitären Herrschaftssystem, dem Stalinismus, konfrontiert, mit dessen Terrorpolitik und seiner in den meisten Fällen einer religiösen Heilserwartung gleichkommenden vielschichtigen Anziehungskraft insbesondere die zahlreichen Exkommunisten persönliche, in vielen Fällen traumatische Züge besitzende Erfahrungen gemacht hatten. ${ }^{121}$ Nicht zuletzt aus diesem Kreis der ehemaligen gemeinhin begeisterten Anhänger der kommunistischen Idee stammten im Monat die Exponenten eines radikalen Antikommunismus. Als leidenschaftliche >kalte< Krieger sah sich die Fraktion um Borkenau, Koestler, Burnham, Hook oder auch Fischer nach Ende des Zweiten Weltkrieges mutatis mutandis als Cold War Liberal im angelsächsischen, zumal US-amerikanischen Sinn, wobei gerade die Vertrautheit mit dem Innenleben der kommunistischen Parteien sowie der einstigen durch die Moskauer Komintern initiierten und durch den Pariser Münzenbergapparat auf vielfältige Weise orchestrierten Agitproppolitik ihnen ihrem Selbstverständnis nach eine unverzichtbare Rolle im politischen und ideologischen Kampf zuschrieb. Insofern waren diese Exkommunisten davon überzeugt, dass sie aufgrund ihrer Spezialkenntnisse und Erfahrungen als Experten im Kampf gegen die totalitäre Bedrohung des Sowjetkommunismus und der von Moskau dominierten kommunistischen Bewegung unentbehrlich wären. Analog zu ihrem früheren manichäischen Weltbild als Kommunisten (Hitler oder Stalin, Kapitalismus oder Sozialismus) fühlten sich die Exkommunisten im Gegensatz zu den ehemaligen Kommunisten, die sich nach ihrem Austritt aus der Partei ins Privatleben zurückgezogen hatten, berufen und auserwählt, »den Kampf gegen den Kommunismus zu führen«, schrieb Arendt 1953 in ihrem Essay Gestern waren sie noch Kommunisten. Ebendieser Renegatentypus, der seine Kenntnisse fortan der anderen Seite anbot, sei dadurch zweifelsohne imstande, »eine öffentliche Karriere, wenn auch unter anderen Vorzeichen, weiterverfolgen zu können«. Indes war der Anspruch, allein im Besitz der genauen Kenntnisse der (sowjetischen) kommunistischen Bewegung zu sein und die damit verbundene Forderung, als Schrittmacher und Lehrmeister in diesem Entscheidungskampf anerkannt zu werden, mit einem zentralen Problem verbunden. Als »umgekehrte Kommunisten« hatten sie nicht nur das Vorzeichen ihres Alleinanspruches auf Wahrheit ausgetauscht, sondern auch ihr instrumentelles und reduktionistisches Politikverständnis in die demokratisch-liberale Gesellschaft hineingetragen. Der prinzipielle Vorwurf, den Arendt an die Exkommunisten richtete, wandte sich gegen das Rezept, »totalitäre Mittel zu gebrauchen, um totalitäre Gefahren zu bekämpfen«. Für sie war es die »alte Geschichte«, wonach der Zweck die Mittel heiligt. »Wo gehobelt wird, da fallen Späne. $\aleph^{122}$

120 Zur Erinnerung: Zum Zeitpunkt der Gründung des Zeitschriftenprojektes galt nach dem Münchener Abkommen im September 1938 als der Hauptgegner der außenpolitisch eine territoriale Expansionspolitik verfolgende Nationalsozialismus. Nach dem Hitler-Stalin-Pakt im August 1939 galt es, den antifaschistisch-demokratischen Kampf gegen zwei totalitäre Feinde bzw. »Diktaturstaaten« (Willi Münzenberg) zu führen.

121 Siehe Kap. II.2 und II.2.1.

122 Hannah Arendt, Gestern waren sie noch Kommunisten (1953), in: Freitag, Nr. 27 vom 28. Juni 1996, S. 1; vgl. auch Klaus Naumann, Hannah Arendt und die Ex-Kommunisten, in: Mittelweg 36, 2 (1993), H. 2, S. 30-40. 
Dieses selbst totalitären Elementen und Tendenzen innewohnende Politikverständnis schlug sich freilich auch in der Kritik des `braunen und >roten Totalitarismus im Monat nieder, dessen aktuelle Spielart in Form des Bolschewismus es mit allen Mittel zu diskreditieren, zu delegitimieren und zu bekämpfen galt. ${ }^{123} \mathrm{Wie}$ die gemäßigten, liberalen Antikommunisten aus dem Kreis der für die grundsätzliche inhaltliche und konzeptionelle Ausrichtung einerseits und die (vergleichende) Auseinandersetzung mit dem facettenreichen Phänomen des Totalitarismus andererseits überaus einflussreichen Renegaten im Monat - genannt seien hier besonders Lasky, Bondy, Salter, Löwenthal, Macdonald, Silone, Dallin, Nikolajewsky, Bronska-Pampuch (d. i. Alfred Burmeister) oder auch Reuter ${ }^{124}$ - waren sie in dem Zeitschriftenorgan

123 Während noch Borkenau und Koestler im Rahmen ihres leidenschaftlichen Engagements für den Monat und den »Kongreß für kulturelle Freiheit« im Kampf gegen den Sowjetkommunismus für eine radikale westliche Außenpolitik und einen präventiven Waffengang plädierten - beim Berliner Kongress sprachen sie sich wie auch James Burnham für ein militärisches Eingreifen der US-Armee in Korea aus -, ging vor allem Burnham noch einen Schritt weiter. Der mit Blick auf die US-amerikanische Außenpolitik im Kalten Krieg einflussreiche Renegat und CIA-Berater sprach sich angesichts des weltweit immer stärker werdenden Kommunismus für den Einsatz von Atombomben aus. Indes sei hier angemerkt, dass eine solche Position zumindest für den Monat und den letztlich von der Redaktion vertretenen gemäßigten Antikommunismus inakzeptabel war und sich auch in den dort erschienenen Burnham-Beiträgen nicht wiederfand. Auf dem Berliner »Kongreß für kulturelle Freiheit« stellte jedoch der amerikanische Extrotzkist in seinem Referat klar, dass er für den Besitz von Atombomben sei, solange sie sich in den Händen der USA, statt der Sowjetunion, befinden, weil sie der »einzige Schutz der Freiheit des westlichen Europas« seien. James Burnham, Die Rhetorik des Friedens, in: Der Monat 2 (1950), H. 22/23, S. 448-455, hier S. 452. Die Bedeutung der »Großen Drei« Vertreter eines radikalen Antikommunisten ließ besonders nach dem Tod Stalins sowohl im Monat als auch im »Kongress für kulturelle Freiheit« immer mehr nach. Vgl. Hochgeschwender, Freiheit in der Offensive?, S. 174. Danach spielte im Grunde genommen nur noch Borkenau, zumindest für den Monat, eine herausragende Rolle, nämlich im Kontext der wichtigen theoretischen und politischen Diskussion um den Charakter des nachstalinistischen Herrschaftssystems (siehe Kap. IV. 2.6). Denn während Burnham keinen Beitrag mehr veröffentlichte, war Koestler wiederum hinsichtlich des (sowjetischen) Kommunismus nur noch im Rahmen der von ihm im Dezemberheft 1953 (H. 63) angestoßenen Debatte um »politische Neurosen« (siehe Kap. IV.3.4) aktiv.

124 Mit Blick auf Ernst Reuter sollen in diesem Zusammenhang noch zwei Seiten beleuchtet werden, die für mich aber zu ein und derselben Medaille gehörten. Einerseits scheute sich Berlins regierender Bürgermeister im Rahmen der Berliner Blockade auf einer Massenkundgebung der SPD bekanntlich nicht zwei zentrale historische Metaphern der unmittelbar zurückliegenden Ceschichte in sehr charakteristischer Weise umzukehren, die auch für mich an die >Durchhalteparolen der NS-Zeit< erinnerten, als Reuter suggerierte, dass sich der Kampf der Bevölkerung Berlins und Westdeutschlands sowie der Alliierten um Berlin hinsichtlich der Sowjetunion mit dem Kampf ebendieses Landes um Stalingrad gleichsetzen ließ (siehe Kap. I.3) Dass der Exkommunist hier sozusagen im Fahrwasser des »Rot=Braun-Vergleichs « schwamm, ist für die Hochphase des Kalten Krieges nur allzu typisch gewesen. Den deutschen Vernichtungskrieg gegen die Sowjetunion indes indirekt mit Stalins brutaler, menschenverachtender Blockadepolitik in eins zu setzen, ist selbst im Nachhinein betrachtet illegitim und nicht zu rechtfertigen gewesen. Andererseits beschreibt Hochgeschwender in seiner Studie über den »Kongreß für kulturelle Freiheit«, dass Ernst Reuter mit Blick auf die NS-Vergangenheit und speziell den deutschen Antisemitismus eher eine abwehrende Haltung einnahm, ohne indes »Anhänger der >Schlußstrich«-Mentalität« gewesen zu sein. Er zeigt dies anhand eines sozusagen vergangenheitspolitischen Vorfalls, der zum Auslöser eines ernsthaften Zerwürfnises zwischen Reuter und Lasky wurde, das einzige »in ihrer mitunter sehr engen Zusammenarbeit«. Genau genommen ging es um folgenden Konflikt: Reuter hatte Anfang 1951 - also wenige Monate 
(mit-)verantwortlich für den sozusagen den Erfordernissen des Kalten Krieges entsprechenden, mit unterschiedlichen Maßstäben bewerteten Vergleich des nationalsozialistischen und des sowjetkommunistischen Herrschaftssystems, zumal des Stalinismus - außerdem für das eindimensionale, reduktionistisch gezeichnete Bild des deutschen »Führerstaates und der primär abstrakten Auseinandersetzung mit seinen Gewaltverbrechen und der fast vollständigen Vernichtung der europäischen Juden sowie der Ausblendung der konkreten politischen, sozialen und gesellschaftlichen Vorgeschichte. Insofern trugen sie die Mitverantwortung dafür, dass im Monat das zeitgenössische gesicherte Forschungs- und Erkenntniswissen über die Geschichte des >Dritten Reiches`, das in nicht geringem Maße aus dem Kreis der Exkommunisten sowie zahlreicher in dem Periodikum veröffentlichenden Autoren und dem US-amerikanischen Regierungsapparat selbst stammte, nicht zufällig nicht nur nicht zur tatsächlichen Aufklärung ebenjener zurückliegenden jüngsten deutschen Vergangenheit herangezogen und genutzt wurde, sondern man zudem zentrale vergangenheitspolitische Fälle und Dimensionen systematisch ausblendete. ${ }^{125}$ Sowohl bei den radikalen

nach dem Berliner »Kongreß für kulturelle Freiheit« und der Aufhebung der Berliner Blockade und dem Ende der Luftbrücke - Werner Krauss nach Westberlin eingeladen, wodurch dem Schauspieler, der als Darsteller des berüchtigten antisemitischen Hetzfilm Jud Süß (1940) von Veit Harlan zu »einigem Ruhm gelangt war«, die Gelegenheit gegeben wurde, nach dem Kriegsende in der Stadt zum ersten Mal wieder öffentlich aufzutreten. Im Verlauf von tumultartigen Proteste gegen diesen ersten Auftritt Krauss', die sowohl vor als auch innerhalb des Theaters stattfanden, ging die Polizei mit enormer Härte gegen Studenten vor, die den letzten Endes vergeblichen Versuch unternommen hatten, den Versammlungsort zu stürmen. Gleichwohl wurde die Vorstellung abgebrochen, wobei wiederum Lasky im Theater die Protestaktion gegenüber den »aufgebrachten Besuchern zu rechtfertigen suchte. Daraufhin wurde er beschimpft und niedergeschrien. « Reuter wiederum, so Hochgeschwender, »weigerte sich, sich gegenüber den von der Polizei verletzten Studenten oder dem Leiter der ]üdischen Cemeinde Berlins, Heinz Galinski, zu entschuldigen, und beharrte darauf, daß die Einladung an Krauss vertretbar gewesen sei« (Freiheit in der Offensive?, S. 360 ff.), wo er auch den näheren »re-orientation «-Hintergrund der alles andere als nur privaten Fehde zwischen Reuter und Lasky erläutert, denn dem Chefredakteur des Monat ging es Ende 1950/Anfang 1951 dem allerorten umsichgreifenden Neonazismus und Antisemitismus, der sich nicht zuletzt im zeitgleichen politischen Skandal um Veit Harlan manifestierte und ohne Zweifel insbesondere für die jüdischen Opfer und Überlebenden des NS-Gewaltsystems einen erschütternden, traurigen Höhepunkt darstellte, entgegenzutreten. Dass in der »Anti-Harlan-Protestbewegung« auch und vor allem der »Kongreß für kulturelle Freiheit« und DerMonat involviert war, wurde bereits erwähnt (siehe bes. Kap. I.4.4 mit den entsprechenden Hinweisen auf die hierbei in der »Lasky-Zeitschrift«veröffentlichten Beiträge).

125 Siehe meine Ausführungen über die systematische Ausblendung der westdeutschen »Vergangenheitsbewältigungspolitik« im Monat hier im Schlusskapitel. Bei den Exkommunisten machte allerdings Koestler, der Prototyp des antikommunistischen Intellektuellen, eine bemerkenswerte Ausnahme. In seinem Eröffnungsbeitrag über »politische Neurosen« thematisierte Koestler, nachdem er bereits frühzeitig in seinem im Januar 1944 im New York Times Magazine erschienenen Artikel Warum Greueltaten nicht geglaubt werden auf die nationalsozialistische Judenvernichtung zu sprechen kam (siehe Kap. II.4.3), die Verdrängung des deutschen Massenmordes an rund sechs Millionen Juden in den »Gaskammern von Auschwitz, Belsen und anderen Vernichtungslagern« beim sogenannten Durchschnittsdeutschen. Angesichts der »Last der Schuld«stellte Koestler ausdrücklich fest, dass »viele gutwillige und intelligente Deutsche«, wenn man in »ihrer Gegenwart auf Auschwitz und Belsen zu sprechen« kam, mit »eisernem Schweigen und einem »gekränkten Gesichtsausdruck« reagierten; denn: »[Ü]ber solche Dinge redet man einfach nicht, und damit Punktum.« (Arthur Koestler, Politische Neurosen, in: Der Monat 6 (1953), H. 63, S. 227-236, hier S. 228f.) Dass es in der Debatte über »Politische Neurosen« insbesondere angesichts des Kommunismus als »welt- 
als auch bei den liberalen antikommunistischen Exkommunisten waren die gemachten totalitären Erfahrungen so prägender Natur, dass ihrer politischen Einschätzung und Wahrnehmung nach der Totalitarismus stalinistischer Couleur Ende der 1940er- 1 Anfang der 1950er-Jahre zwangsläufig kurz vor der Machtergreifung in Westdeutschland und den Kernländern Westeuropas stand. Insofern teilten sie diese - im Nachhinein angesichts der militärisch primär auf die Sicherung des eigenen Territoriums abzielenden stalinschen Außenpolitik, aber als unbegründet - erwiesene Sorge mit vielen Zeitgenossen. Indes waren sie sich der tatsächlich existierenden Gefahr gewahr, die durch die sowjetische Kulturpolitik mit ihren weltweiten Friedens- und Schriftstellerkongressen und diversen Zeitschriften und Zeitungen entstanden war, sodass es selbstverständlich ernsthafte Gründe gab für ihre Befürchtung, dass der »Westen« die sogenannte Schlacht um die Intellektuellen verlieren könnte.

Wie lässt sich nun die Mitarbeit und das zum Teil leidenschaftliche Engagement der antikommunistischen, keineswegs a priori antitotalitären Renegaten für den Monat im Kampf gegen den sowjetischen Totalitarismus mit all seinen politischen Implikationen, wie beispielsweise der hier besonders interessierenden Frage der intellektuellen Unabhängigkeit und Redlichkeit, erklären? Vermutlich waren es besonders aufseiten der deutschen Exkommunisten ein schlechtes Gewissen und ein politisches Verantwortungsbewusstsein dafür, dass sie einerseits den Sieg des Nationalsozialismus nicht verhindert hatten und in Deutschland im Januar 1933 Hitler die Macht »ergreifen« konnte und sie andererseits explizit oder implizit zum Untergang der Weimarer Republik beitrugen. Denn als führende Parteifunktionäre bzw. -intellektuelle der KPD (z. B. Borkenau, Koestler, Löwenthal oder Reuter) leisteten sie einen aktiven Beitrag dazu, dass die erste deutsche Republik von Anbeginn auch von der antidemokratischen politischen Linken bekämpft wurde und mithin auch von dieser Seite keine Chance bekam, sich zu stabilisieren; denn die "Katastrophe« Hitler und das nationalsozialistische Regime waren selbstverständlich weder Zufall noch historische Notwendigkeit, sondern auch der fehlenden bzw. nur rudimentär vorhanden politischen Kultur in Deutschland geschuldet. Vor diesem Hintergrund sind die teilweise eine Schlüsselfunktion einnehmenden und eine überragende Bedeutung habende Rolle der genannten, einen militanten und liberalen antikommunistischen Flügel repräsentierenden Exkommunisten im Monat zu bewerten und zu verstehen - wobei dies selbstverständlich nicht auf die bisweilen europaweit meistgelesene Kulturzeitschrift reduziert werden kann, sondern zugleich auf die mit ebendiesem Periodikum assoziierten weltweit erscheinenden diversen anderen namhaften kulturpolitischen Zeitschriften (Encounter, Preuves, Tempo Presente etc.) und auch grundsätzlich auf die liberal-antikommunistische Intellektuellenorganisation »Kongreß für kulturelle Freiheit« bezogen werden muss -, die aber von den fünf unterschiedlich bekannten und einflussreichen Renegaten Glaser, Wittfogel ${ }^{126}$, Buber-Neumann, Weißberg-Cybulski

liche Religion « und der bei zahlreichen (Links-)Intellektuellen anzutreffenden Faszinationskraft der kommunistischen Idee und Partei um die These von der inneren Verwandtschaft subjektiver und kollektiver Seelenstörungen ging, braucht hier nicht zu interessieren und wurde bereits gezeigt (siehe Kap. IV.3.4).

126 Mit dem >Falk Karl August Wittfogel werde ich mich zu einem späteren Zeitpunkt in einem eigenständigen Aufsatz auseinandersetzen. Dabei werde ich vor allem auf die qualitativen Unterschiede zwischen dem Renegaten Wittvogel und den vier anderen genannten ehemaligen Kommmunisten ausführlicher eingehen. 
und Orwell streng unterschieden werden müssen. ${ }^{127}$ Bei dem bekennenden unabhängigen Sozialisten George Orwell, der sicherlich zu den politisch einflussreichsten antitotalitären Intellektuellen Europas des 20. Jahrhunderts und zu einem der prominentesten Renegaten und Autoren des Monat zählte (siehe Kap. II.4.4) muss differenzierter argumentiert werden. Der Seismograf für totalitäre Gefahren und überzeugte Gegner jedweder antidemokratischer Herrschaftssysteme, verstand seinen (anti-)utopischen Roman 1984 ja nicht nur als kritische Auseinandersetzung mit dem deutschen und sowjetischen Totalitarismus, sondern gleichzeitig als Warnung vor dem unter bestimmten Umständen in allen modernen Staaten triumphierenden totalen Überwachungsstaat, einschließlich seines Heimatlandes England und der angelsächsischen Welt. Angesichts seines frühen Todes im Januar 1950 veröffentlichte Orwell aber nur in den unmittelbaren Anfangsjahren im Monat. Hierbei besaßen insbesondere seine abgedruckten Bücher Farm der Tiere und 1984 eine überragende Bedeutung für die Beschreibung und Analyse des Totalitarismus, zumal in der sowjetischen Variante (siehe

127 Unabhängig von der hier nicht zu klärenden Frage, was in den fünf Fällen die Redaktion des Monat jeweils tatsächlich veranlasste, motivierte oder intendierte die Beiträge zu veröffentlichen, lässt sich meines Erachtens folgendes sagen. Bei den drei Letztgenannten erscheint die Sache eher eindeutig. Die drei ehemaligen Kommunisten nutzten den Monat sozusagen aus persönlichen und/ oder politischen Gründen als Publikationsort oder wurden von der Redaktion gebeten, ihre Arbeiten der Zeitschrift zu überlassen. Von Claser und Weißberg-Cybulski erschienen, wie gesehen, jeweils (Teil-)Vorabdrucke ihrer autobiografischen Renegatenberichte. Siehe Georg K. Glaser, Geheimnis und Gewalt. Ein Bericht, Stuttgart/Hamburg 1953, in: Der Monat 4 (1951/52), H. 37, S. 3-37; H. 38, S. 155-182; H. 39, S. 270-302; H. 40, S. 372-402 [Kap. I.6 Anm 96. ], sowie Alexander Weißberg-Cybulski. Das Grosse Verhör. Aus der Praxis des NKWD, in: Der Monat 3 (1951), H. 35, S. 490-502. Der Beitrag von Weißberg-Cybulski besaß insbesondere bei der Beschreibung und Analyse des stalinistischen Terrors Mitte der 1930er-Jahre im Monat eine große Bedeutung besaß und beeinflusste nicht zuletzt auch in diesem Kontext Arendts Interpretation dieses Terrorphänomens in ihrer Totalitarismusstudie stark; mit den entsprechenden Auswirkungen hinsichtlich der »Analyse des Sowjetkommunismus im Monat siehe bes. die beiden Kap. IV.2.4 und IV.2.9. - Bei Buber-Neumanns Beitrag: Aus dem Leben eines KPD-Funktionärs. Heinz Neumanns Schicksal in Deutschland, China und Sowjetrußland, in: Der Monat, 9 (1957) H. 103, S. 44-66, handelte es sich um Auszüge einzelner Kapitel ihres Buches Von Potsdam nach Moskau. Stationen eines Irrweges, Stuttgart 1957. Darüber hinaus veröffentlichte Buber-Neumann keinen weiteren Beitrag im Monat. Cleichwohl besaß die einer internationalen Öffentlichkeit bekannte Renegatin sowohl im Monat als auch im Kongreß für kulturelle Freiheit eine überragende Bedeutung. Während aber die antitotalitäre Intellektuelle und Publizistin angesichts ihrer gemachten totalitären Erfahrung gerade in ihrem berühmten autobiografischen Renegatenbericht Als Gefangene bei Stalin und Hitler die nationalsozialistische und sowjetkommunistische Diktatur gleichermaßen fokussierte und vor allem die für die beiden totalitären Herrschaftssysteme charakteristischen Konzentrationslager beschrieb und analysierte und hierbei den konkreten NS-Terror im Frauenkonzentrationslager Ravensbrück sowie die ihr ab Sommer 1942 bekannten respektive miterlebten Ermordungen und Vergasungen von europäischen Juden nicht aussparte (siehe Kap. II.2.1.), wurde sie und ihr zum Klassiker avanciertes Buch im Monat im Rahmen der durch den Kalten Krieg geschuldeten Totalitarismusdiskussion in erster Linie für antikommunistische Zwecke genutzt - beispielsweise mit Blick auf die frühe Totalitarismusdiskussion in Frankreich, die ineinanderverschachtelten sogenannten Kravchenko- und Rousset-Prozesse, die sowjetischen Lager und die französische Linke sowie den Prozess Buber-Neumanns gegen den KPDFunktionär Carlebach Anfang 1950 in Frankfurt am Main einerseits (siehe Kap. III), die vergleichende Analyse der totalitären Herrschaftssysteme des Nationalsozialismus und des Sowjetkommunismus andererseits (siehe Kap. IV.3.). 
Kap. IV.2 und bes. Kap. IV.3). Insofern passte sich der Monat sozusagen den >Ideologen des Antikommunismus nicht zuletzt in den Vereinigten Staaten, Englands und der Bundesrepublik Deutschland an, die vor allem 1984 in der Auseinandersetzung mit dem "Großen Bruder" Sowjetunion politisch und ideologisch instrumentalisierten, weil ihnen in der Hochphase des Kalten Krieges die Darstellung der totalitären Gesellschaft sehr gelegen kam. Trotz seiner im Spanischen Bürgerkrieg gemachten traumatischen Erfahrungen mit dem stalinistischen Terror, als Orwell, der im Gegensatz $\mathrm{zu}$ vielen linksradikalen Intellektuellen in Europa, zumal den späteren antikommunistischen Renegaten wie Koestler, Sperber oder Ignazio Silone, zu keinem Zeitpunkt mit dem »Stalin-Regime« sympathisierte, im Frühjahr 1937 als Anhänger der trotzkistischen POUM den angesprochenen "Bürgerkrieg im Bürgerkrieg" erlebte und nur knapp mit dem Leben davonkam (siehe Kap. II. 2). ${ }^{128}$

Insofern gab es hier in zentralen Punkten eine enge Übereinstimmung im politischen Denken und Handeln zwischen den namentlich genannten Vertretern der einen militanten und liberalen antikommunistischen Flügel repräsentierenden Exkommunisten des Monat und des "Kongresses für kulturelle Freiheit« sowie dessen Pariser Zentrale unter der Leitung von Josselson einerseits und den für die Genesis der CIA und den vom US-Geheimdienst initiierten verdeckten Operationen maßgeblich verantwortlichen führenden Regierungspolitikern unter Truman und im Nationalen Sicherheitsrat andererseits. Dies zeigte sich schließlich auch in ihrer Haltung zur Rolle der CIA bei der Finanzierung von verdeckten Operationen und speziell des »Kongresses für kulturelle Freiheit«, die ja sogar in der unmittelbaren Anfangsphase unter ausdrücklicher Missachtung der US-amerikanischen Verfassung und von rechtsstaatlichen Grundsätzen geschah und die nicht nur unmittelbar nach der Aufdeckung der

128 Meines Erachtens hätte Orwell den militanten Antikommunismus (trotz bestehender persönlicher Verbindung und theoretisch-politischer Gemeinsamkeiten zu den Ex-Kommunisten Borkenau, Burnham und insbesondere zu Koestler) als auch den liberalen Antikommunismus des Monat, wie er sich mit Blick auf die 1950er Jahre insgesamt betrachtet in die inhaltliche und konzeptionelle Ausrichtung bei der (vergleichenden) Auseinandersetzung mit dem Nationalsozialismus und dem Sowjetkommunismus tatsächlich niederschlug, nicht mitgemacht oder in irgendeiner Form unterstützt. Ich denke, dass für Orwell, der als überzeugter Gegner des englischen Kolonialismus und Imperialismus sowie als unabhängiger Sozialist jede Form von sozialer und politischer Unterdrückung ablehnte, der politische und intellektuelle Preis, den er fast unweigerlich zu zahlen gehabt hätte, zu hoch gewesen wäre; das Cleiche gilt freilich auch in Bezug auf den »Kongress für kulturelle Freiheit». Selbstredend hätte Orwell es begrüßt, dass auch durch den Monat die Dissidenten hinter dem Eisernen Vorhang gewissermaßen >Munition، geliefert bekamen für ihrem Kampf gegen das totalitäre System in Moskau sowie speziell gegen das SED-Regimes, und dass sie auch durch die Lektüre seiner Bücher nicht "geisteskrank" (Hannes Stein) wurden und der Verzweiflung anheim fielen. Indes: Vor dem Hintergrund der Tatsache, dass er zum einen nicht nur jeden Totalitarismus auf der Welt bekämpfte und bekämpft wissen wollte, damit er nicht »auf der Welt triumphieren könnte« (George Orwell) und zum anderen entschieden gegen das Leugnen, Verharmlosen oder Relativieren von Massenverbrechen bzw. Massakern seit Anfang des 20. Jahrhundert war, wie er es abwechselnd von der politischen Linken und Rechten erlebte, hätte Orwell angesichts seines antitotalitären politischen und intellektuellen Selbstverständnisses mit Blick auf die in der vorliegenden Arbeit präsentierten Untersuchungsergebnisse und den angesprochenen historisch-politischen Implikationen (Stichwort: NS-»Vergangenheitsbewältigungspolitik«, Fortexistenz des Antibolschewismus bzw. Antikommunismus in der Bundesrepublik und massive Verfolgung von Kommunisten bzw. vermeintlichen Kommunisten als »Staatsfeinde« etc.) sicherlich nicht die Augen verschlossen. 
CIA-Finanzierung des »Kongresses« Mitte der 1960er-Jahre von Kennan, ${ }^{129}$ sondern selbst noch nach dem Ende des Kalten Krieges von wichtigen Akteuren wie Harpprecht und Laqueur ohne den leisesten Hauch von Bedenken mit allen Mitteln verteidigt wurde. ${ }^{130}$

Mit Blick auf den »Kongreß für kulturelle Freiheit« kommt Hochgeschwender zu der Auffassung, dass es angesichts der von der CIA in die auf intellektuellen Netzwerken beruhenden Organisation »eingespeisten Finanzen« eine gestaffelte Zugehörigkeit der einzelnen Mitglieder, also der Intellektuellen, gab. Man könnte sogar fast von "gestaffelten Netzwerken« sprechen. Demnach gab es erstens einen »inneren Zirkel«, der »über alle Hintergründe informiert war«, zweitens einen »weiteren Kreis jener«, die zwar "nicht unmittelbar eingeweiht waren, aber manches ahnten«, und drittens die "großen Gruppen der Nichtwissenden «. ${ }^{131}$ Hier wird nun der Versuch unternommen, eben diese Kategorisierung angesichts der vorliegenden Untersuchungsergebnisse auf den Monat zu beziehen, wobei kein Anspruch auf Vollständigkeit erhoben wird und die inhaltliche und politische Zuordnung sich nur auf die in diesem Zusammenhang maßgeblichen Autoren beschränkt.

129 Georgef. Kennan schrieb anlässlich der Aufdeckung der CIA-Finanzierung des »Kongresses« Mitte der 1960er-Jahre und der damals in Gang gekommen Welle der Empörung in einem privaten Brief an Shepard Stone von der Ford-Stiftung: »Der Kongress ist eine wertvolle Einrichtung, die, wie mir scheint, in der westlichen Welt einen dauerhaften Platz haben sollte. Der Skandal um das CIA-Geld war völlig unberechtigt und sorgte für mehr Aufsehen, als die Affäre eigentlich verdient gehabt hätte. Ich hatte wegen dieser Gelder nie die geringsten Gewissensbisse. Das Land [die USA] hat kein Kultusministerium, und die CIA war verpflichtet, zu tun, was in ihren Kräften stand, um in die Bresche zu springen. Man sollte sie deswegen loben, anstatt sie zu kritisieren. Es ist unfair, dass sie wegen ihrer Versäumnisse so scharf verurteilt und dann getadelt werden soll, wenn sie einmal etwas Konstruktives und Vernünftiges macht. Und der Kongress selbst wäre in Not geraten, wenn er das Geld nicht angenommen hätte, das ihm in der besten Absicht ohne Hintergedanken oder Bedingungen zur Verfügung gestellt wurde.«(Zit. n. Walter Laqueur, Mein 20. Jahrhundert. Stationen eines politischen Lebens, Berlin 2009, S. 103.)

130 So verteidigt Harpprecht in seiner Rezension der Studie Sündenfall der Intellektuellen von Ulrike Ackermann die vom US-amerikanischen Kongress nicht legitimierte »partielle Finanzierung des `Kongresses und seiner Zeitschriften durch die $\mathrm{CIA}$ « damit, dass niemand die »rationalen Erklärungen für die kulturellen Aktivitäten des Geheimdienstes zur Kenntnis nehmen « wollte»(für die sonst keine andere amerikanische Regierungsinstitution unter der rigiden Kontrolle der Abgeordneten und Senatoren aufzukommen vermochte)«; zumal schließlich auch niemand danach fragte, »wer wohl für die sogenannten Kulturoffensiven der Sowjets und ihrer Satelliten bezahlte oder von wem manche Zeitschriften, die heute noch existieren, ihre Subsidien empfingen« (Die geistige Résistance nach 1945, in: Die Neue Gesellschaft/Frankfurter Hefte 48 [2001], S. 314-317, hier S. 316). Und an anderer Stelle rechtfertigt er die CIA-Finanzierung mit folgenden Worten: »Die Zeitschrift >Der Monat « wurde aus unvernünftig haushaltstechnischen Cründen aus den Fonds der CIA subventioniert, weil die Abgeordneten kaum bereit gewesen wären, die Mittel für solchen Luxus zu genehmigen. [...] Wie gern hätte ich jedoch die CIA für die Autoren des >Monat < weißbluten lassen! Die Agentur, die sich anderswo in der Welt die schrecklichsten Idiotien leistete und die gewiß für manches Verbrechen verantwortlich ist, hat ihr Geld niemals für einen besseren Zweck ausgegeben.« (Zit. n. Martin, Orwell, Koestler und all die anderen, S. $21 \mathrm{ff}$.)

131 Hochgeschwender, Remigranten im Umfeld der Zeitschrift Der Monat und des Congress for Cultural Freedom (CCF), S. 185. 
Zur ersten Gruppe der Intellektuellen, die einen sogenannten inneren Zirkel bildeten und über alle Hintergründe informiert waren, zählte folgender Personenkreis: Neben dem amerikanischen Hohen Kommissar John J. McCloy ${ }^{132}$ sowie dem Herausgeber und Chefredakteur Melvin J. Lasky, dem Mitherausgeber Hellmut Jaesrich sowie Alfred Kellner, Harald Hurwitz und dem »Ost-Agenten « Erich Nohara ${ }^{133}$ aus dem Redaktionsteam ${ }^{134}$ und den beiden späteren (Mit-)Herausgebern Fritz René Allemann und Klaus Harpprecht zählten hierzu neben dem späteren sozialdemokratischen Berliner Bürgermeister und Bundeskanzler Willy Brandt die Exkommunisten Arthur Koestler, Franz Borkenau, Richard Löwenthal, Manés Sperber, Ernst Reuter, Ernest J. Salter, Ruth Fischer, Wanda Bronska-Pampuch (d. i. Alfred Burmeister), François Bondy (Herausgeber der französischen Monat-Schwesterzeitschrift Preuves), Ignazio Silone und Nicola Chiaromonte (die beiden Herausgeber der italienischen Kongresszeitschrift Tempo Presente), James Burnham (der nachweislich als CIA-Berater fungierte), Sidney Hook und Dwight Macdonald. Zudem der Herausgeber der amerikanischen Kongresszeitschrift Commentary, Elliot E. Cohen, der wie die drei Letztgenannten zu den einflussreichen Exponenten der New York Intellectuals zählte. Von den USamerikanischen Politikern und Diplomaten zählten zu dem »inneren Zirkel« der langjährige Direktor des Politischen Planungsstabes, Georgef. Kennan, der amerikanische Historiker und politische Berater der US-amerikanischen Administration (u.a. im OSS-Apparat in Washington und nach Kriegsende in Paris für Averell Harriman, den Leiter der Organisation für Wirtschaftliche Zusammenarbeit in Europa und mithin verantwortlich für die Marschallplan-Hilfe) Arthur M. Schlesinger jr. sowie Walter Lippmann. Darüber hinaus der einflussreiche englische Politiker von der Labour Party, Richard H. S. Crossmann, Joachim G. Leithäuser, Ludwig Marcuse, Norbert Mühlen sowie die beiden Herausgeber der englischen Kongresszeitschrift Encounter, der Exkommunist Stephen Spender und der Extrotzkist Irving Kristol (von dem abschließend noch die Rede sein wird). ${ }^{135}$

132 Vgl. John ]. McCloy, Deutschland und die Satelliten. Zur Diskussion der Oder-Neiße-Frage, in: Der Monat 8 (1956), H. 94, S. 75 f. Dass dessen Vorgänger, der Militärgouverneur der amerikanischen Besatzungszone in Deutschland, Lucius D. Clay, ebenfalls zu ebendiesem inneren Zirkel gehörte, versteht sich wohl von selbst, allerdings erschien von ihm kein Beitrag im Monat.

133 Laut Lasky arbeitete Erich Nohara für den sowjetischen Geheimdienstapparat. Mitteilung an den Verfasser in einem Gespräch im November 2001 in Berlin.

134 Inwiefern die beiden Redaktionsmitarbeiter Hans R. Hentschel und Wolfgang Stiebler darunter subsumiert werden können, vermag ich nicht zu sagen. Dafür gibt es prima vista keinen Beleg. Es ist durchaus vorstellbar, dass sie nicht zu den »Eingeweihten«zählten. Allerdings ist es auch für die vorliegende Untersuchung ohne Bedeutung, weil meines Wissens beide nicht im Monat veröffentlichten, auch nicht unter einem Pseudonym, und insofern hier auch keine Rolle spielen.

135 Zu diesem Kreis der »Eingeweihten« zählte auch Friedrich Torberg, der Chefredakteur der in Wien herausgegebenen Schwesterzeitschrift des Monat, Forum. Seine Bedeutung und die »seiner« Zeitschrift steht mit Blick auf den »Kongreß für kulturelle Freiheit« im Allgemeinen und den unter der Ägide der Pariser Zentrale herausgegebenen Kongresszeitschriften im Besonderen außer Frage. Allerdings spielte Torberg, der im Übrigen einen radikalen Antikommunismus vertrat, in dieser Arbeit keine Rolle, und insofern kann er von mir nicht unter die erste Kategorie rubriziert werden. Dasselbe gilt auch für den deutschen Verleger Wolf Jobst Siedler, den französischen Exkommunisten, Schriftsteller, Kunsttheoretiker und Politiker André Malraux, der zu einem der herausragendsten zeitgenössischen europäischen Intellektuellen zählte, sowie für den schweizer Schriftsteller und Philosophen Denis de Rougemont, die alle drei besonders im »Kongreß für kulturelle Freiheit« eine 
Zur zweiten Gruppe, also jenem weiteren Kreis der Intellektuellen, die zwar nicht über alle Hintergründe unmittelbar eingeweiht waren, aber "manches ahnten«, nicht zuletzt aufgrund des individuellen politischen Urteilsvermögens oder weil sie als originärer Teil des "Lasky-Netzwerkes« im Monat veröffentlichten - ohne dass sich dies indes inhaltlich in den einzelnen Beiträgen niederschlug oder unmittelbar erkennbar war; die Autoren schrieben zu dem Themenkomplex Totalitarismusphänomen im Allgemeinen und (vergleichende) Auseinandersetzung mit dem Nationalsozialismus und dem Sowjetkommunismus im Speziellen, wozu sie sozusagen von der Redaktion gebeten oder den Auftrag bekamen, ohne dass dadurch ihre intellektuelle Unabhängigkeit und Freiheit sowie kulturpolitische oder wissenschaftliche Wahrheitsorientierung infrage gestellt wurde, insofern hätte also der jeweilige Beitrag auch an anderer Stelle publiziert werden können ${ }^{136}$-, zählte folgender Personenkreis: Peter de Mendelssohn, Günther Birkenfeld, Raymond Aron, Hugh R. Trevor-Roper, Walter Görlitz, David Rousset, Louis Fischer, Georg Fischer, H. Stuart Hughes, Jules Monnerot, Leslie A. Fiedler, Richard H. Rovere, Bertrand de Jouvenel, Salvador de Madariaga, Michael Freund, Friedrich Luft, Golo Mann, George Orwell, Margarete Buber-Neumann, Rudolf Hagelstange, Winfried Martini, Boris Meissner, Theodor Plivier, Richard H. Rovere, A. Rossi (d. i. Angela Tasca), Barbara Ward, John Hersey, Irving Howe, Karl A.

wichtige Rolle spielten und zudem im Monat veröffentlichten. Außerdem war de Rougemont sogar zeitweise Präsident des Exekutivkommitees des Kongresses und laut Saunders (Wer die Zeche zahlt ..., S. 94) wurde sein auch noch heute bestehendes »Centre Européen de la Culture «in Cenf»mit geheimer Unterstützung der CIA (von der ihm angeblich nicht bekannt war)« gegründet, mit dem er die Ziele weiter verfolgte, die er zuvor bereits u. a. mit Bondy zusammen in der Europäischen Föderalistischen Union anstrebte. Für die zweite Phase des Monat, also die »Nach-Lasky-Periode« in den 1960er-Jahren, muss besonders Brzezinski genannt werden, der seinerzeit bereits vor Kennedys Amtsantritt als US-Präsident als dessen Berater hinsichtlich der Ostpolitik fungierte. Während der letzten Jahre von Johnsons Amtszeit war er dann Mitglied des politischen Planungsrats des State Department und zog 1968 als außenpolitischer Chefberater von Hubert Humphrey in den Wahlkampf. Später wurde er unter anderem, nachdem er die »Nixon-Kissinger-Außenpolitik« kritisiert hatte, im November 1976 Leiter des Nationalen Sicherheitsrates des neugewählten Präsidenten Jimmy Carter. Hierbei erwarb Brzezinski sich den Ruf eines »Falken« innerhalb der US-amerikanischen Administration, der in Bezug auf die Politik gegenüber der Sowjetunion einen harten Kurs das Wort redete und die von Nixon und Ford in Gang gekommene Entspannungspolitik ablehnte. Vor dem Hintergrund seines politischen Antikommunismus sind sowohl seine im Verlauf dieser Untersuchung genannten Totalitarismusstudien zu sehen als auch seine in den 1960er-Jahren im Monat erschienenen Beiträge. Vgl. bes. seinen Beitrag im Rahmen der Monat-Umfrage angesichts des Wandlungsprozesses des sowjetischen Herrschaftssystems seit dem Tod Stalins unter Chruschtschow unter dem Titel Was kommt nach Chruschtschow? Eine Umfrage, in: Der Monat 15 (1963), 174, S. 15-28, hier S. $17 \mathrm{ff}$; mit weiteren Beiträgen von Wolfgang Leonhard, Gert Ruge, Werner Phillip, William E. Griffith, Stephan G. Thomas, Ernest J. Salter, R. V. Burks. Die Umfrage wurde mit einem Aufsatz von Löwenthal eingeleitet (Chruschtschows unfertiger Staatsstreich. Vom Preis der Permanenz der Parteiherrschaft, S. 7-14) und von Robert Conquest abgeschlossen (Die >Liberalisierung،. Eine Bestandsaufnahme, S. 29-37). Zu Brzezinski vgl. auch: al., Nicht mehr monolithisch, in: Der Monat 15 (1963), H. 172, S. 80 (Rezension).

136 In vielen Fällen geschah dies auch tatsächlich. Wie gesehen, handelte es sich ja häufig um Beiträge, die zum Beispiel zuvor in anderen internationalen Zeitschriften erschienen, die nicht zu den sogenannten Kongress-Zeitschriften zählten. Häufig handelte es sich hierbei um den (fast) kompletten Abdruck von Büchern oder um Auszüge aus Büchern der Autoren, die wissenschaftliche Publikationen darstellten. 
Wittfogel, David J. Dallin, Boris Nikolajewski, Milovan Djilas, Richard Wright, Czeslaw Milosz sowie Walter Z. Laqueur. ${ }^{137}$

Des Weiteren zählten zu ebendieser Gruppe neben der mit Peter de Mendelssohn verheirateten österreichischen Schriftstellerin, Essayistin und großen Journalistin Hilde Spiel, u. a. der bedeutende britische Sozialphilosoph, Politologe und Ideenhistoriker Isaiah Berlin, der übrigens Avancen seitens der operativen Führung des »Kongresses für kulturelle Freiheit« im Vorfeld der Berliner Versammlung im Juni 1950 mit der Begründung ablehnte, die »öffentliche Unterstützung einer antikommunistischen

137 Der 1921 in Breslau geborene und 1938 nach Palästina emigrierte renommierte Historiker Walter Laqueur wird von mir unter die zweite Kategorie rubriziert, obwohl er »offizieller Repräsentant des Kongresses in Israel«war (Saunders, Wer die Zeche zahlt ..., S. 202). Nachdem Laqueur im Monat zuerst unter dem Pseudonym Mark Alexander schrieb (siehe Brief aus Jerusalem: Die geteilte Stadt, in: Der Monat 6 [1954], H. 67, S. 33-39) veröffentlichte er bekanntlich den wichtigen Aufsatz Die >Affäre Kastner . Wo liegt die Grenze zwischen Heldentum und Verrat?, in: Der Monat 7 (1955), H. 84 , S. 553-563, der hinsichtlich der Analyse des Nationalsozialismus und speziell beim Thema »Die nationalsozialistischen Massenverbrechen und die >Endlösung der Judenfrage« (Kap. IV.1.8) eine große Bedeutung besaß, weil Laqueur die Vernichtung der europäischen Juden durch das NS-Regime thematisierte. Das heißt, er setzte hier sich mit dem Holocaust an den ungarischen Juden in der Schlussphase des Zweiten Weltkrieges substanziell auseinander. Dieser Beitrag zählte zu einem der seltenen Fälle im Monat, wo die deutschen Gewaltverbrechen und einige führende SS-Täter (wie zum Beispiel Adolf Eichmann) sowie vor allem ihre spezifischen Funktionen konkret zur Sprache kamen. Mithin wurde der Holocaust nicht mit den sowohl in der bundesrepublikanischen Nachkriegsgesellschaft als auch im Monat ins Bild passenden »prominenten «, zumeist als Verbrecher apostrophierten Himmler oder Heydrich in Verbindung gebracht. Insofern besaß ebendieser Laqueur-Beitrag eine hohe beschreibende und analytische Qualität. Ob und welche Funktion er möglicherweise in den Augen der Zeitschriftenredaktion des Monat in jenen Jahren spielte, ist mir nicht bekannt, muss also unbeantwortet bleiben. Ob Laqueur seinerzeit zu dem sogenannten inneren Zirkel des »Kongresses für innere Freiheit« oder des Monat zählte und über alle Hintergründe, also auch über die CIA-Finanzierung, informiert war, muss hier offengehalten werden. Dass er ab 1955 die Kongresszeitschrift Soviet Survey als monatlich erscheinendes Nachrichtenmagazin herausgab, ist sicherlich ein starkes Indiz dafür, taugt aber nicht als sicherer Beleg, da schließlich bei Laqueur zum damaligen Zeitpunkt tatsächlich auch Unwissenheit und Uninformiertheit möglich waren. Auch wenn Laqueur bereits damals mit Lasky befreundet war und insofern einiges dafür spricht, dass er von Anbeginn zu den »Eingeweihten« zählte, folge ich in diesem Fall seinem persönlichen Urteil. Laqueur schreibt nämlich dazu in seinem persönlichen Erinnerungsbuch: »Meine Mitarbeit im Kongress dauerte ungefähr zehn Jahre, aber ich war nie voll angestellt. An einigen Konferenzen habe ich teilgenommen, aber ich gehörte nicht zum inneren Kreis, und meine Kenntnisse zur Entscheidungsfindung habe ich ausschließlich aus zweiter Hand." (Laqueur, Mein 20. Jahrhundert, S. 107) Unabhängig davon muss Laqueur zumindest für die damalige Epoche nicht nur nach Auffassung vom eigentlichen »Chef« des Kongresses für kulturelle Freiheit und CIA-Mitarbeiter Michael Josselson als seiner der besten internationalen Experten für die Sowjetunion betrachtet werden. »Unter seiner Leitung erstellte der Soviet Survey Analysen des intellektuellen, künstlerischen und politischen Lebens im Ostblock, die dem Leser einen Einblick boten, der sim Vergleich mit anderen westlichen Publikationen einzigartig〈war. [...] Seltsamerweise fühlten sich«, schreibt Saunders, »selbst einige kommunistische Zeitschriften dazu animiert, Material aus dem Soviet Survey für ihre Belange zu verwenden, so dass Josselson beunruhigt an Laqueur schrieb: `Wir wollen nicht, dass prosowjetische Publikation[en] ihre Propaganda zum Teil mit unserem Material krönen.«(Wer die Zeche zahlt ..., S. 202) - Ich möchte an dieser Stelle nur noch hinzufügen, dass das Josselson-Urteil von dem hohen Niveau der Kongresszeitschrift Soviet Survey selbstverständlich, wie gesehen, analog auch auf den Monat hinsichtlich der Auseinandersetzung mit dem facettenreichen Themenkomplex Sowjetkommunismus galt. 
Bewegung könne seine Verwandten in Osteuropa gefährden «. ${ }^{138}$ Beide waren sozusagen für den Kongress aktiv und veröffentlichten auch im Monat, allerdings hatten sie in der vorliegenden Untersuchung keine Bedeutung.

Zur dritten Gruppe, also der großen Gruppen der Nichtwissenden, zählte folgender Personenkreis: Hannah Arendt ${ }^{139}$, Herbert Lüthy, Hans Kohn, Karl Jaspers, Waldemar Gurian, John Dewey, Alan Bullock, Walther Hofer, Thomas Mann, Hans Sahl, Herman Kesten, André Gide, Theodor W. Adorno, Wilhelm Röpke, Joseph A. Schumpeter, Bertrand Russell, Carl Linfert, Hans Schwab-Felisch, Alfred Weber, Marianne Regensburger, Kurt Rossmann, Dolf Sternberger, Eugen Kogon, Rüdiger Proske, Rudolf Augstein, Andreas Biss, Karl Dietrich Bracher, Herman Broch, Albert Camus, Norman Cohn, Edward Crankshaw, Ludwig Dehio, John Dewey, Theodor Eschenburg, Fritz Erler, Ferdinand Friedensburg, Otto Heinrich von der Gablentz, Georg K. Glaser, Wilhelm Grewe, Joachim Günther, Sebastian Haffner, Ernst Halperin, Friedrich A. Hayek, Theodor Heuss, G. f. Hudson, Martin Jänicke, Robert M. W. Kempner, Hans Kudszus, Eugen Lerch, Hans Joachim Lieber, Sabina Lietzmann, Karl Löwith, Erich Lüth, Alfred von Martin, Friedrich Meinecke, Clara Menck, Alfred Polgar, Gerhard Ritter, Herbert Ritvo, Kurt Rossmann, Peter Schmid, Joseph Scholmer, Hugh SetonWatson, Walter T. Stace, John Strachey, Gustav Stern, Jacob L. Talmon, A. J. P. Taylor, Lionel Trilling, Matthias Walden, Alex Weißberg-Cybulski, Karl Heinz Wocker, Bertram D. Wolfe.

Das engagierte und ambitionierte doppelte Programm des Monat, durch das Konzept der reorientation die intellektuelle Entwicklung Westdeutschlands entscheidend $\mathrm{zu}$ beeinflussen sowie seine ideell-kulturelle Integration in den Westen mitzugestalten und gleichzeitig einen anspruchsvollen, konsequenten scharfen Antikommunismus zu verfolgen, drückte sich allerdings in der angesprochenen Redaktionspolitik aus. Durch die Auswahl der Themen und Autoren, die Festlegung der Berichterstattung und Kommentierung und durch die (systematische) Ausblendung von Themen mit einer bestimmten Brisanz wurden bereits im Vorfeld entscheidende Weichen gestellt. Dies zeigte sich besonders im Hinblick auf die Auseinandersetzung mit der

138 Saunders, Wer die Zeche zahlt ..., S. 93 f.; Berlin wurde 1909 in Riga geboren, siedelte 1919 nach England über und starb 1997 in Oxford.

139 Mit meinem heutigen Wissen über Hannah Arendt und auf der Grundlage der Forschungsliteratur zu der prominenten Autorin des Monat komme ich hier heute zu einer anderen Einschätzung. Für mich zählte sie zu der zweiten Cruppe, also zu dem Kreis der Intellektuellen, die zwar nicht über alle Hintergründe unmittlbar eingeweiht waren, aber »manches ahnten«. Zu dieser Erkenntnis bin ich im Laufe der Jahre u. a. nach einer erneuten Lektüre der verschiedenen Hannah-Arendt-Briefwechsel gekommen, wie zum Beispiel dem mit Karl Jaspers und mit ihrem Ehemann Heinrich Blücher. Zum Anderen ist für meine neue Einschätzung von zentraler Bedeutung, dass durch den Hamburger Kommunismusforscher Reinhard Müller anhand der Decheffrierung neu erschlossener Dokumente neue Erkennntisse über das frühere Mitglied der KPD, Heinrich Blücher, zu Tage gefördert wurden. Demnach war dieser womöglich bereits in den 1920er und dann in den frühen 1930er Jahren Mitarbeiter des illegalen Nachrichtendienstes der KPD. Nicht zuletzt durch die jahrelangen Aktivitäten im kommunistischen Parteinachrichtenapparat von Blücher, der sich Müller zufolge übrigens später anscheinend um eine Stelle im US-amerikanischen Ceheimdienst OSS bewerben wollte, konnte meiner Überzeugung nach Arendt die CIA-Hintergründe des Kongresses für kulturelle Freiheit und des Monat realistisch einschätzen. Ich werde hierzu zu einem späteren Zeitpunkt in einem eigenständigen Aufsatz über Hannah Arendt und ihre besondere Rolle im Kongress und Monat ausführlicher eingehen. 
Geschichte des >Dritten Reiches` wie seiner vergangenheitspolitischen Dimensionen und stellte den immer wieder beschworenen und behaupteten Antitotalitarismus infrage. Die Redaktionspolitik wurde in diesem Zusammenhang einerseits an der Tatsache deutlich, dass - so die Grundthese - nicht zufällig unter anderem Bücher systematisch ausgewählt, d.h. abgedruckt (ganz oder in Auszügen) oder rezensiert wurden. Andererseits daran, dass die besprochenen Bücher entweder gezielt von Autoren des inneren Zirkels $<$ besprochen wurden, damit sie von vornherein auf der von der Redaktion anvisierten "Linie« lagen, oder von den Intellektuellen der sogenannten zweiten Gruppe, deren jeweilige Ansichten und Positionen nicht nur bekannt waren, sondern zumeist explizit oder implizit mit denen der Redaktion korrespondierten. Hierbei waren natürlich Überschneidungen mit den Intellektuellen der großen dritten Gruppe möglich, wobei indes in diesen Fällen der jeweilige Rezensionsbeitrag nicht im engeren Sinn planbar war und insofern direkte oder indirekte Eingriffe der Zeitschriftenredaktion nicht a priori ausgeschlossen waren - mit Ausnahme bei den prominenten Autoren/-innen. Auch wenn es keinerlei Anzeichen dafür gibt, dass es bei den herausragenden Intellektuellen vom Rang eines Raymond Aron, ${ }^{140}$ Herbert-

140 Selbstverständlich war die Redaktion des Monat oder auch die Pariser Zentrale des »Kongresses für kulturelle Freiheit« auch aus heutiger Sicht nur gut beraten, den vielen herausragenden Intellektuellen nicht irgendwelche Direktiven zu erteilen. Zum einen waren sie einfach zu intelligent, zu professionell und möglicherweise bei vielen mit ihnen eng befreundeten Autoren auch zu loyal, zum anderen war ihnen freilich klar, dass auch nur der kleinste Versuch in dieser Richtung für sie, aber selbstverständlich auch für die zeitgenössischen Regierungen der Vereinigten Staaten in den 1950er-und 1960er-Jahren, mit einer politischen Katastrophe geendete hätte. Pars pro Toto steht hier der spätere selbstkritische autobiografische Erfahrungsbericht von Aron, der hier (im Cegensatz zu Ulrike Ackermann in ihrer Studie Sündenfall der Intellektuellen, S. 110 f.; siehe mein Hinweis in der Einleitung) ungekürzt zitiert wird - auch weil dessen Einstellung und Position zur CIA in bemerkenswerter Form deutlich wird. Indes muss ich konzedieren, dass ich nicht alles von Aron, der vollkommen zu Recht besonders wegen seines brillanten, scharfsinnigen politischen Denkens zu einem der bedeutendsten europäischen antitotalitären Intellektuellen des 20. Jahrhunderts gezählt werden muss, für 〉bare Münze« nehme: »Heute erinnern mich diese Unternehmungen«, schreibt Aron, »an den «Kongreß für kulturelle Freiheit<, dessen Rolle, Einfluß und schließlich skandalöses Ende [sic!] ich nicht übergehen will. Wir nahmen an, der Kongreß würde durch amerikanische Stiftungen finanziert. In einer Untersuchung über den CIA erwähnte die >New York Times` [in der Ausgabe vom 27. April 1966] den Kongreß als eine der Organisationen, die von dieser berüchtigten Agency [sic!] finanziert würden, wobei die Stiftungen nur als Deckmantel dienten. Von diesem Moment an entfernte ich mich vom Kongreß, der mit Unterstützung der Ford Foundation unter einem anderen Namen noch einige Jahre weiterlebte. Für Denis de Rougemont, Manès Sperber, Pierre Emmanuel, mich und alle anderen, die in der einen oder anderen Weise im Rahmen des Kongresses mitarbeiteten, stellten sich zwei Fragen: Hätten wir es wissen oder zumindest ahnen können? Hätten wir, wenn uns die Herkunft der Gelder bekannt gewesen wäre, jede Art von Mitarbeit abgelehnt? Bezüglich der ersten Frage neige ich zu der Antwort, daß es uns wohl an Neugier gefehlt hat, denn es gab viele Anzeichen, die uns hätten stutzig machen können. Aber die Finanzierung durch die Stiftungen war plausibel, und auf jeden Fall sagte und schrieb ich immer nur, was ich persönlich dachte, wenn ich an Colloquien teilnahm oder Artikel für die Zeitschrift `Preuves ‘ verfaßte. Ich wurde nicht vom Kongreß bezahlt, dieser gab mir lediglich die Gelegenheit, Ideen zu verteidigen und zu erläutern, die damals Verteidiger nötig hatten. Bleibt die zweite Frage: Hätten wir die Finanzierung durch den CIA hingenommen, wenn wir davon gewußt hätten? Wahrscheinlich nicht, obwohl diese Weigerung letztendlich unvernünftig gewesen wäre. Ich schrieb zahlreiche Artikel in >Preuves 
Lüthy ${ }^{141}$ oder Hannah Arendt, ${ }^{142}$ also bei Autoren/-innen mit einem "großen « Namen, seitens der Zeitschriftenredaktion um Lasky auch nur den Versuch eines wie auch immer gearteten Eingriffes gegeben hat und es schlechterdings auch nicht vorstellbar ist, dass ihnen irgendetwas bzw. -jemand die Feder hätte diktieren können, hat es ebendiese Versuche sehr wohl gegeben. Entgegen der immer wieder nicht zuletzt von den (mit-)verantwortlichen Mitarbeitern des Monat selbst noch in der Gegenwart verbreiteten Legenden ${ }^{143}$ ist es neben einem bereits bekannten Fall ${ }^{144}$ zumindest ein weiteres

dort meine Meinung mit dem gleichen Freimut wie in jeder anderen Zeitschrift. Der ebenfalls vom Kongreß ins Leben gerufene `Encounter < ist in England bis heute die erste und beste Monatsschrift in englischer Sprache. Keine dieser Zeitschriften«, stellt Aron vollkommen zu Recht fest, »hätte sich entwickeln können, wenn sie als ein Instrument des Geheimdienstes der Vereinigten Staaten firmiert hätte. Der Kongreß konnte seine - tatsächlich erfüllte - Aufgabe nur durch Verschleierung oder, wenn man so will, mit Hilfe der Lüge des Weglassens erfüllen, eine Lüge, die weiterhin meine Erinnerungen an den Kongreß belastet, obwohl ich noch gern an die Colloquien von Rhodos, Rheinfelden und, etwas später, als er seinen Namen geändert hatte und kein Geld mehr vom CIA empfing, von Venedig zurückdenke. Mögen andere eine historische Bilanz des `Kongresses für Kulturelle Freiheit ziehen, ich für mein Teil bereue meine Mitwirkung dort nicht, denn er übte einen nicht zu überschätzenden Einfluß auf die europäischen Intellektuellen aus. Mir ist vor allem die Erinnerung an das Zusammentreffen mit einigen bedeutenden Persönlichkeiten wie Georgef. Kennan und Robert Oppenheimer wertvoll. Im «Kongreß haben wir«, so Aron weiter, »die amerikanische Außenpolitik oder Gesellschaft niemals prinzipiell verteidigt, und wir schrieben in der Zeitschrift >Preuves` genauso wie in anderen Zeitschriften. Freilich hatten wir etwas Gemeinsames, nämlich die Ablehnung des Kommunismus. Aber unser pluralistischer Antikommunismus, der Sozialisten wie Konservative gleichermaßen umfaßte, unterschied sich wesensmäßig von dem Prosowjetismus jener Intellektuellenorganisationen, die dazu verurteilt waren, die Wahrheit zu verschleiern.« (Aron, Erkenntnis und Verantwortung, S. 187, Hervorh. des Verf.)

141 Im Gespräch mit dem Verfasser im Juli 2001 in Basel teilte Lüthy mit, dass er sich an keine wie auch immer gearteten Eingriffe seitens der Zeitschriftenredaktion des Monat wie auch der »Kongreß«Leitung und der Preuves-Redaktion erinnern könne.

142 Bei meinen Recherchen im Hannah-Arendt-Archiv an der Carl von Ossietzky Universität in Oldenburg konnte ich keinen Hinweis für irgendwelche Eingriffe finden. Im Briefwechsel zwischen Arendt und der Zeitschriftenredaktion ging es in erster Linie um formale Aspekte: Zum Beispiel im Zusammenhang mit der deutschen Übersetzung der im Monat erschienenen Kapitel aus der amerikanischen Originalausgabe ihrer Totalitarismusstudie, oder um die Frage, ob Aufsätze, die Arendt anderen Zeitschriften versprochen hatte, nicht doch möglichweise im Monat erscheinen könnten.

143 So behauptet Harpprecht, der immerhin Mitte der 1960er-Jahre mit Hellmut Jaesrich und Peter Härtling gemeinsam den Monat herausgab sowie redaktionell leitete und nach seinen Monat-Aktivitäten u. a. als Chef der berühmten sogenannten Schreibstube von Willy Brandt fungierte, in seiner bereits erwähnten Rezension der Studie Sündenfall der Intellektuellen von Ackermann mit einer bemerkenswerten Chuzpe, dass sich angesichts der partiellen Finanzierung des »Kongresses für kulturelle Freiheit« und seiner Zeitschriften durch die CIA niemand »um die Versicherung der Redakteure und Autoren [kümmerte], dass nicht der geringste Druck auf sie ausgeübt wurde.« (Die geistige Résistance nach 1945, S. 316) Es ist also schlicht unwahr, wenn er weiterhin ebenjene Legende fortspinnt, die nicht zuletzt mit dem »notorischen Lügner« Lasky seinen Anfang nahm, der jahrelang jedweden Vorwurf einer CIA-(Mit)-Finanzierung vehement abstritt und die Öffentlichkeit regelrecht belog, bis er dann durch den besagten New York Times-Artikel vom 27. April 1967 gezwungen war, die Wahrheit zu sagen.

144 So konnte Hochgeschwender für den Monat aus den Quellen einen Eingriff belegen, dass der Leiter der Pariser Zentrale des »Kongresses für kulturelle Freiheit«, Michael Josselson, im November 1961 dem Autor Boris Guldenberg, der Teile seines Buches Latin America and the Cuban Revolution im 
Mal zu einem Eingriff gekommen: bei dem seinerzeit noch eher unbekannten jungen Autor Martin Jänicke; ${ }^{145}$ zudem zeigen die Erfahrungen, die der jüdische Historiker Fritz Stern mit der Redaktion der amerikanischen Schwesterzeitschrift Commentary machte, exemplarisch, mit welchen Methoden man bei den Kongresszeitschriften zumindest gegenüber jüngeren, international zum damaligen Zeitpunkt noch nicht unbedingt anerkannten Intellektuellen operierte, um einen Beitrag auf die gewünschte Linie zu bringen. ${ }^{146}$

Monat veröffentlichen wollte, nahegelegt hat, Passagen umzuschreiben, in denen die Verstrickung von US-Außenminister John Foster Dulles und der United Fruit Company in die Militärintervention der USA 1954 in Guatemala sichtbar geworden wäre (Hochgeschwender, Freiheit in der Offensive?, S. 168 f.) Wie auch immer es sich dann genau zugetragen hat: Der geplante Beitrag von Culdenberg erschien nicht im Monat. Außerdem konnte er zwei weitere Eingriffe seitens Josselsons belegen, wobei es sich in einem Fall um einen direkten Eingriff in die Redaktionspolitik des Encounter ging. So blockierte er die Veröffentlichung eines amerikakritischen Artikels (America, America) des früheren Mitherausgebers der Zeitschrift, Dwight Macdonald, mit der Begründung, dass der Beitrag möglicherweise die »Sponsoren des CCF verärgern könnte« (ebd., S. 168). In dem anderen Fall kritisierte Josselson den österreichischen Herausgeber der Kongresszeitschrift Forum, Friedrich Torberg, und zwar wegen dessen zu militanten Antikommunismus (vgl. ebd., S. 493 f.).

145 So teilte mir der Berliner Sozial- und Politikwissenschafter Martin Jänicke im November 1999 in einem Gespräch in Berlin mit, dass ein Mitarbeiter der Redaktion des Monat den telefonischen Versuch unternahm, direkt Einfluss auf ihn zu nehmen und Druck auszuüben. Konkret ging es darum, dass Jänicke als damaliger Student der Soziologie an der Freien Universität Berlin in den Jahren des Nachstalinismus einen Beitrag zur SED-Diktatur in der Zeitschrift veröffentlichen sollte und er aufgefordert wurde, den Herrschaftsaspekt des Terrors mehr und deutlicher hervorzuheben, da dieser in seinen Ausführungen anscheinend gar nicht oder zu wenig herausgestellt wurde. Dazu war indes Jänicke, der erst Jahre später mit seiner 1964 erschienenen Studie Der dritte Weg. Die antistalinistische Opposition gegen Ulbricht seit 1953 einem interessierten Publikum bekannt wurde, bis er sich dann mit seiner wichtigen kritischen Studie Totalitäre Herrschaft. Anatomie eines politischen Begriffes (1971) einen Namen machte, nicht bereit. Um welchen Artikel es sich genau handelte, konnte Jänicke nicht mehr sagen, zudem wäre es auch möglich, dass es um einen Beitrag in den 1960er-Jahren ging und insofern nicht die »Lasky-Redaktion« verantwortlich war.

146 Der heute selbstredend unbestritten als »großer Historiker (Norbert Frei) geltende, 1926 in Breslau geborene und am 30. September 1938, dem Tag des Münchener Abkommens, mit seiner Familie nur wenige Wochen vor dem Novemberpogrom zur Flucht nach New York gezwungene, US-amerikanische Staatsbürger Fritz Stern schildert dies nämlich in seinen Lebenserinnerungen Fünf Deutschland und ein Leben. Er berichtet, wie er nach einem Aufenthalt im Sommer 1954 in Westberlin (hier nahm er u. a. an einem Doktorandenseminar teil, das von Franz L. Neumann, Ernst Fraenkel und Otto Suhr an der Freien Universität gehalten wurde) eine »lehrreiche Erfahrung mit den antikommunistischen Praktiken« der seinerzeit »angesehen liberalen Zeitschrift Commentary« machte. Nachdem er dem damaligen Chefredakteur Bob Warshow, »einem bewundernswert, moralisch überzeugenden Menschen«, einen Bericht über seine »bewegten« Erlebnisse in der geteilten Hauptstadt übergab, bat dieser ihn einige Monate später, eine Rezension über Ernst von Salomons »tendenziösem und bombastischem Buch Fragebogen«zu schreiben. Nachdem er dies tat, verstarb Warshow allerdings ganz plötzlich, »und der Text«, so Stern (der nun ausführlich zu Wort kommen soll, weil sein Erfahrungsbericht für sich steht, keines weiteren Kommentars von mir bedarf und indirekt ein bedenkliches Licht auf den Monat wirft, wo es vermutlich in einzelnen Fällen nicht anders zu ging), »wurde mir von jemand anderem zurückgeschickt - in Druckfahnen und zu spät, um noch etwas ändern zu können. Meine Erörterungen über den Nationalsozialismus waren durch allerlei redaktionelle Eingriffe grundlos mit antikommunistischen Kommentaren angereichert worden. Als ich mich weigerte, den abgeänderten Text unter meinem Namen erscheinen zu lassen, wurde 
Andererseits gibt es begründete Anhaltspunkte für die Vermutung, dass es für bestimmte Intellektuelle nicht möglich war, in dem Zeitschriftorgan zu publizieren, obwohl sie geradezu prädestiniert gewesen wären angesichts der damals bekannten historisch-politischen Erkenntnisse, also der zeitgenössischen Forschungsergebnisse, einen Beitrag zur Aufklärung der Geschichte des >Dritten Reiches $<$ und seiner tief und weit in die bundesrepublikanische Nachkriegsgesellschaft reichenden vergangenheitspolitischen Implikationen zu leisten: ${ }^{147}$ Nämlich wenn hierdurch das von der Redaktion des Monat für die gesamten 1950er-Jahre gezeichnete Bild des »Führerstaates«, das natürlich gleichermaßen in einem indes nicht genau zu bestimmenden Maß in die durch den nationalsozialistischen Vernichtungskrieg und den Holocaust mit einer historisch beispiellosen vergangenheitspolitischen Schuld bzw. Verantwortung belastete »Adenauer-Gesellschaft« hineinwirkte, (mit-)konstituierte und entlastete, sowie dem vornehmlich durch die weltpolitische Konfrontation mit dem sowjetischen Totalitarismus für die US-amerikanische Deutschlandpolitik alles andere als uneingeschränkte Priorität geltenden Versuch seiner politisch-justiziellen Sanktionierung, in einem fundamentalen Widerspruch gestanden hätte oder auch nur ansatzweise infrage gestellt worden wäre. Und wenn es außerdem für die "Lasky-Redaktion« nicht möglich gewesen wäre, einen potenziellen Beitrag - entgegen der eigentlichen Absicht des Autors oder der Autorin, nicht in irgendeiner Form im Kalten Krieg antikommunistisch zu instrumentalisieren - wie zum Beispiel in den beiden sicherlich herausragendsten Fällen, der renommierten emigrierten Totalitarismusforscherin Hannah Arendt und

ich von Elliot Cohen, dem legendären Herausgeber von Commentary, am Telefon angebrüllt. Ich sei bloß ein Flüchtling, ich verhielte mich sunamerikanisch`, und wenn ich nur vernünftig sei, könne er im öffentlichen Leben etwas saus mir machen . Diese Einschüchterung, gepaart mit einer in Aussicht gestellten Belohnung, empfand ich als abstoßend, und ich beharrte auf meinem Standpunkt. Später hat er sich entschuldigt, aber der übellaunige Angriff vermittelte mir eine Ahnung davon, was vom illiberalen Antikommunismus zu erwarten war.« (Fritz Stern, Fünf Deutschland und ein Leben. Erinnerungen, München 2007, S. 275) - Zum »Kongreß für kulturelle Freiheit« wiederum ging Stern quasi zeitgleich auf kritische Distanz, nachdem er mit dem >liberalen< Antikommunismus der amerikanischen Sektion, dem American Committee for Cultural Freedom, im Mai 1954 ähnliche negative Erfahrungen machte und die er auch hinfort nicht aufgab. Nachdem nämlich Stern nach seinen Bemühungen für den Kongress, »unter Kollegen Spenden für die Bemühungen des Kommitees [zu sammeln], >die Intellektuellen [...] für einen verantwortungsbewußten und ernsten Kampf gegen den kommunistischen Totalitarismus zu moblisieren«, dann vom Vorsitzenden um Hilfe bei einem geplanten Buch The Party Line, »über die Versuche der Kommunisten in den Vereinigten Staaten, >die öffentliche Meinung zu manipulieren «, gebeten wurde, wurde Stern die Projektskizze vorgelegt. Die begann, schreibt Stern, »mit der Behauptung, es sei notwendig, die Anfälligkeit spolitisch unbedarfter Humanisten und Bürgerrechtler zu untersuchen. Ich schrieb zurück, daß ich zwar das Potential einer solchen Untersuchung sähe, aber >ernste Zweifek an der Projektskizze hätte, da man sein unhistorisches und unwissenschaftliches Verfahren < vorschlage: Das, was erst noch zu untersuchen sei, werde als gegeben vorausgesetzt. Meine detaillierte Kritik«, so Stern, »beendete ich mit dem Hinweis, wenn das Projekt, von dem ich noch nichts gehört hätte, tatsächlich [wie behauptet] sanhaltende Begeisterung bei den Mitgliedern [ausgelöst habe], ist es vielleicht besser, wenn ich das Komitee verlasse`. Statt einer Antwort auf meinen Brief erhielt ich eine Einladung zur nächsten Mitgliederversammlung. Auch darauf verzichtete ich.«(Ebd., S. 276)

147 Ob dies im einzelnen Fall dann seitens der Akteure mit einer fehlenden Bereitschaft koinzidierte, im Monat zu veröffentlichen, kann hier nicht beantwortet werden, ist auch für meine Argumentation nicht von Bedeutung und kann zudem nur durch zukünftige Forschungsarbeiten beantwortet werden. 
dem in jenen Jahren zu einem der berühmtesten politischen Schriftstellern zählenden George Orwell; dessen Veröffentlichung des kompletten Buches 1984 wurde auch mit Blick auf die alles andere als spannungsfreie Auseinandersetzung zwischen den beiden früheren angelsächsischen »Anti-Hitler-Koalitionären« aus den Vereinigten Staaten von Amerika und Großbritannien durch richtungsweisende einleitende Worte der Redaktion in diesem Sinne benutzt (ich komme darauf im nächsten Abschnitt zurück). Pars pro toto steht in diesem Zusammenhang, der emigrierte deutsche Behemoth-Autor Franz Neumann, der im Zuge seiner OSS-Tätigkeit nicht nur eine überragende Bedeutung für das Nürnberger Militärtribunal und die unter der Ägide der Vereinigten Staaten durchgeführten sogenannten zwölf Nachfolgeprozesse hatte, sondern frühzeitig die auch aus einer kapitalismuskritischen Perspektive begründete Auffassung nach nicht radikal genug angelegte US-amerikanische Entnazifizierungspolitik vehement kritisierte. ${ }^{148}$

Sicherlich stellte Neumann aus den dargelegten Gründen einen herausragenden Fall dar. Gleichwohl hätte ich aber stattdessen meine These beispielsweise auch anderen in Deutschland bzw. Österreich geborenen, vom Nationalsozialismus ins Exil gezwungenen internationalen Intellektuellen exemplifizieren können, die ebenfalls zum Kreis der zeitgenössischen prominenten NS- und Totalitarismusforscher, Sozial- und Politikwissenschaftler oder Philosophen zählten: Neben früheren Freunden, Kollegen und Mitarbeitern von Neumann aus dem OSS-Apparat des State Departement, die zum Kreis der überzeugten kapitalismuskritischen "Anti-Anti-Kommunisten« zählten, wie zum Beispiel Herbert Marcuse, sei der bereits angesprochene emigrierte Politikwissenschaftler Ernst Fraenkel genannt. Er war wie sein Freund, Kollege und politischer Kampfgefährte aus den Weimarer Jahren, Neumann, ebenfalls nach Kriegsende im US-amerikanischen Staat beschäftigt. Er arbeitete in den Jahren 1944 bis 1951 in der Verwaltung für auswärtige Wirtschaftsbeziehungen (Foreign Economic Administration), im State Department sowie im Heeresministerium (Department of the Army) und fungierte vor allem als Berater für sozial- und verfassungsrechtliche Fragen in der amerikanischen Militärregierung und der »Marshall-Plankommission« in Korea. Zudem war er bekanntlich nach seiner Rückkehr als amerikanischer Staatsbürger in das Land, in das er wegen des Holocaust nicht wieder zurückkehren wollte, im Jahre 1951 nicht nur maßgeblich an der Gründung der Deutschen Hochschule für Politik in Westberlin, dem späteren Otto-Suhr-Institut (OSI) der Freien Universität Berlin, beteiligt, wo er bis zu seiner Emeritierung 1967 unterrichte, sondern zählte zu den »bedeutendsten Gründungsvätern der deutschen Politikwissenschaft« (Kurt Sontheimer) in der jungen Bundesrepublik Deutschland. Meiner Ansicht nach war es eben nicht dem Zufall geschuldet, dass Fraenkel neben den bereits genannten Gründen nicht im Monat veröffentliche (siehe meine entsprechenden Ausführungen in Kap. IV.1.11), sondern aus grundsätzlichen (kultur-)politischen Gründen: Einerseits plädierte der Autor des »Doppelstaates « vor dem Hintergrund seiner funktionalistischen Interpretation des NS-Herrschaftssystems analog zu Neumann hinsichtlich der Planungen für das Nachkriegsdeutschland für radikale Veränderungen der ökonomischen und politischen Strukturen und insofern stand er in einem Gegensatz zu den angesichts des Kalten Krieges veränderten Besatzungsdirektiven der US-amerikanischen Militärregierung in Westdeutschland und mithin der antikommunistischen 
und prowestlichen Funktion und Zielen des Monat; andererseits bestanden meiner Auffassung nach zwischen dem Theoretiker der pluralistischen Demokratie und dessen Version der repräsentativen Demokatie und dem politischen Selbstverständnis der Zeitschriftenredaktion des Monat qualitative Differenzen. Vgl. dazu meine abschließenden Ausführungen im folgenden Abschnitt dieses Schlusskapitels. - Darüber hinaus kann ich die für mich nach politisch-strategischen Gesichtspunkten vorgenommene gezielte Auslassung von bestimmten Personen auch anhand der mit Blick auf die wechselvolle Ceschichte des Totalitarismusbegriffs überaus bedeutenden Intellektuellen Sigmund Neumann und Karl Popper ausführlicher durchdeklinieren. Der vor dem Nationalsozialismus zur Emigration gezwungene jüdische Sozial- und Politikwissenschaftler Sigmund Neumann veröffentlichte, wie gesehen, 1942 in den Vereinigten Staaten sein ambitioniertes theoretische Werk Permanent Revolution. The Total State in a World at War, das nicht nur in seinem amerikanischen Gastland in der Wissenschaft als bedeutende Studie und ex post zu Recht als »Klassiker der vergleichenden Diktaturfoschung« (Alfons Söllner) apostrophiert wird. Sein damals nicht zuletzt für die zukünftige Totalitarismusforschung nicht wegzudenkender Begriff der "permanenten Revolution « bezog sich zweifelsohne insbesondere am Ende der Untersuchung in dem Kapitel über den Zweiten Weltkrieg schwerpunktmäßig auf das NS-Regime. Gleichwohl zog Neumann im Gegensatz zu anderen einflussreichen Exponenten der zeitgenössischen Totalitarismusforschung, die - wie zum Beispiel Borkenau mit seiner Studie The Totalitarian Enemy - ihre Begriffsbestimmung und -verwendungsweise in starkem Maße von den politischen und militärischen Konstellationen abhängig machten, sodass es in den Jahren 1941 bis 1945 inopportun erschien, die Sowjetunion unter Totalitarismusverdacht zu stellen, neben den militärisch verbündeten totalitären Staaten Deutschland, Italien und Japan, auch die stalinistische Sowjetunion in die historische Erforschung der modernen Diktaturen des 20. Jahrhunderts ein. Indes waren im Gegensatz zu anderen Studien und Büchern sowohl die Untersuchungsergebnisse des neumannschen Buches als auch der Autor selbst für die Monat-Redaktion in der Hochphase des Ost-West-Konfliktes eben nicht antikommunistisch instrumentalisierbar (siehe zu Siegmund Neumanns Totalitarismusstudie meine Ausführungen im Einleitungskapitel mit der entsprechenden Forschungsliteratur). Angemerkt sei nur noch, dass im Monat der Name Sigmund Neumann erst in der »Zweiten Phase«, der »Nach-Lasky-Ära«, auftauchte, nämlich in dem oben ausführlich referierten Aufsatz Totalitäre und demokratische Revolution von Richard Löwenthal in H. 146 im November 1960. - Auf den großen Philosophen und Theoretiker der offenen Gesellschaft, Karl Popper (The Open Society and Its Enemies. 2 Bde., London 1945), berief sich die Redaktion des Monat in der unmittelbaren Anfangsphase explizit, um das »eigene« westliche System der sfreien Welt politisch-ideengeschichtlich zu begründen und andererseits den Kampf gegen den Sowjetkommunismus zu legitimieren sowie seine zur totalitären Herrschaftsideologie geronnene Theorie des Marxismus-Leninismus zu kritisieren. Da aber Popper im Monat nicht veröffentlichte und auch im »Kongreß für kulturelle Freiheit« keine aktive Rolle spielte und ihm allenfalls eine indirekte Bedeutung, nämlich als »Ideengeber«, zugesprochen werden kann, vermute ich, dass die Redaktion um Lasky aus "guten« Gründen Popper nicht als Autor gewann, zumal dieser auch höchstwahrscheinlich nicht bereit gewesen wäre, in der alles andere als ideologiefreien Monatszeitschrift zu veröffentlichen: Nämlich aufgrund der Interpretation des Totalitarismusphänomens seitens der Redaktion auf dem politisch-ideen- 
geschichtlichen Boden der »Gott-Abfall-Theorie«. Denn diese bestand für Popper in der Gefahr angesichts der zeitgenössischen Gegnerschaft gegenüber dem Kommunismus speziell sowjetischer Couleur zu einer regelrechten Feindideologie zu gerinnen, die entgegen dem Bekenntnis zur politischen Theorie des Liberalismus keinesfalls per se genuin antitotalitär war und nicht frei von antiliberalen und -demokratischen Tendenzen hinsichtlich der Begründung und Verteidigung der offenen Gesellschaft im Sinne der kritischen Philosophie der Politik von Karl Popper. Für Popper waren ja nicht nur sämtliche auf den Utopien des Rassismus, des Antisemitismus, des Nationalismus oder des Kommunismus/Sozialismus gegründeten Staatsmodelle immer in der Gefahr zur totalitären oder autoritären Diktatur bzw. Despotie abzugleiten, sondern alle geschlossenen Gesellschaftsmodelle, insofern auch die zum Dogma, zur Ideologie erstarrte christliche "Abfall von Gott«-Theorie des Monat zur Verteidigung der Freiheit, der westlichen Demokratien und der sozialen Marktwirtschaft in Europa (respektive des freien »Unternehmertums « in den Vereinigten Staaten) zur Legitimierung des Antikommunismus. - Im Gegensatz hierzu vermag ich mit Blick auf den seinerzeit in München an der Sophie-Scholl-Universität lehrenden Eric Voegelin nicht genau zu sagen, warum der zumindest ideengeschichtlich bedeutende und einflussreiche »Politische-Religion-Theoretiker« nicht zum »Aufgebot« des Monat zählte. Vermutlich war seine Kritik an den institutionellen, politischen, geistigen und sozialpsychologischen Zuständen in der Bundesrepublik mit Blick auf die unmittelbar zurückliegende Vergangenheit zu scharf. Vgl. hierzu Eric Voegelin, Hitler und die Deutschen, München 2006. Bei Carl Joachim Friedrich, dem Verfasser der in der Hochphase des Kalten Krieges erschienenen Studie Totalitäre Diktatur (während bei der 1956 in den Vereinigten Staaten veröffentlichten Ausgabe, wie eingangs gesagt, noch sein damaliger Mitarbeiter Zbigniew Brzezinski als Koautor firmierte, kann Friedrich für die im Jahr darauf in Deutschland erschienene Fassung als alleiniger Autor betrachtet werden) wiederum erscheint der »Fall« eindeutig, obwohl er ganz anders gelagert war. Wie gezeigt werden konnte (siehe Kap. V.2) handelte es sich bei seiner klassischen Totalitarismustheorie um keine Demokratietheorie. Denn sein Modell entsprach nicht der Gegenüberstellung von Demokratie und totalitärer Herrschaft, sondern vielmehr dem Gegensatzpaar von totalitärer und konstistutioneller Diktatur - wie es in der besonders von Carl Schmitt geprägten Verfassungsdiskussion der Weimarer Republik üblich war. Sein Konzept der »totalitären Diktatur« stellte ja einen Rechtfertigungsversuch der amerikanischen Besatzungspolitik als einer verfassungsmäßigen (konstitutionellen) Diktatur dar. Der Begriff diente dazu, die sowjetische Besatzungsmacht anzuprangern und die US-amerikanische andererseits zu legitimieren. »Das unmittelbare Anliegen der dualistischen Gegenüberstellung der konstitutionellen und der totalitären Diktatur lag also«, so Lietzmann (Von der konstitutionellen zur totalitären Diktatur, in: Söllner/Walkenhaus/Wieland, Totalitarismus, S. 174-192), »in der Zerstreuung letzter Zweifel darüber, daß die konstitutionelle Variante (und mit ihr die amerikanische Besatzungspolitik), wenn sie auch nicht demokratisch sei, sondern einer Diktatur gleichkomme, die Demokratie doch zu errichten trachte. Es ging Friedrich um die glaubwürdige Rechtfertigung und die politikwissenschaftliche Legitimation einer konstitutionellen Diktatur der amerikanischen Besatzungsmacht und damit zugleich in erheblichem Maßum eine Selbstrechtfertigung, da er die amerikanische Militärregierung mehrere Jahre als `Govern-mental Affairs Adviser«, im Stab General Clays, in Fragen der Verfassungs- und Regierungsstrukturen, beraten hatte.« (S. 178) - 
Vor diesem Hintergrund wiederum ist für mich im Hinblick auf den Monat klar, warum Friedrich nicht in dem Periodikum veröffentlichte, zumal nicht zu dem hier interessierenden Thema Kritik des Nationalsozialismus und des Sowjetkommunismus. Lasky und die Akteure des »inneren Zirkels« sowie in den US-amerikanischen Regierungsstellen dürften um den politischen und ideologischen Sprengstoff der klassischen Totalitarismustheorie Friedsrichs und seiner Theorie der »totalitären Diktatur« gewusst haben. Abgesehen davon war außerdem auffallend, dass in den 1950er-Jahren in keinem Beitrag zum Totalitarismusphänomen oder zur (vergleichenden) Analyse der totalitären Herrschaftssysteme des Nationalsozialismus und des Sowjetkommunismus (siehe Kap. IV und bes. IV.3) irgendein Verweis auf Friedrichs 6-Punkte-Katalog zur Addition von Merkmalen totalitärer Herrschaft erfolgte, obwohl es das Modell der identifizierenden Totalitarismustheorie verkörperte.

Ob die Entscheidungen von der US-Militärregierung (OMGUS) und später der Hohen Kommission (HICOG), vom Chefredakteur des Monat (Melvin J. Lasky), vom Generalsekretär des »Kongresses für kulturelle Freiheit« (Michael Josselson) in der Pariser Zentrale, oder von dessen ehemaligen Vorgesetzten und früheren Leiter des »covert action«-Departments der CIA (Thomas Braden) getroffen wurden, oder ob die zentralen Weichen direkt in den Vereinigten Staaten gestellt wurden, vom Leiter des Office of Policy Coordination und Verantwortlichen für die Durchführung der verdeckten Operationen in Friedenszeiten in der CIA (Frank Wisner), oder sogar höchstpersönlich vom Direktor des Politischen Planungsstabes in Washington (Georgef. Kennan bzw. dessen Nachfolger, Paul Nitze, der Ende 1949 das Amt übernahm) - wofür es ernst zu nehmende Hinweise gibt ${ }^{149}$-, kann hier nicht endgültig beantwortet werden und muss durch zukünftige Forschungsarbeiten geklärt werden. Dasselbe gilt für die Frage, ob es angesichts der CIA-Finanzierung des »Kongresses für kulturelle Freiheit« in diesem Zusammenhang hinsichtlich der Kritik des Nationalsozialismus und des Sowjetkommunismus tatsächlich irgendwelche CIA-Imperative zur Steuerung des Publikationsorgans gab.

Gleichwohl wird hier folgende These vertreten: Auch wenn es in Anbetracht des bisherigen Forschungsstandes speziell zur Geschichte der CIA und der Quellenlage nur schwer vorstellbar ist, dass es diese nicht gab - dafür hatte einerseits das angesichts der existenziellen weltpolitischen Herausforderung mit dem Sowjetkommunismus unter der Federführung der CIA ins Leben gerufene und mit der linksliberal-antikommunistisch ausgerichteten Intellektuellenorganisation »Kongreß für kulturelle Freiheit« unmittelbar verknüpfte, ambitionierte kulturpolitische Projekt eine zu herausragende Bedeutung für die US-amerikanische Regierung, andererseits war die inhaltliche Ausrichtung des Monat zu eng gekoppelt mit den außenpolitischen Interessen der Vereinigten Staaten in der durch den Übergang von Antinazismus

149 So antwortete Bondy auf die Frage, ob der »Kongreß für kulturelle Freiheit« letzten Endes nicht mehr als eine »subtil gesteuerte CIA-Propaganda" gewesen sei in der 3SAT-Sendung Kulturzeit vom 26. Juni 2000: »Ich gestehe, dass wir nicht neugierig genug waren. Wir hätten es wissen sollen, aber wir wussten es einige Jahre lang nicht. Und als wir es wussten, gab es eine ziemlich arge Verwirrung. Nachträglich wissen wir, wieviel für diesen Kongress vorgearbeitet worden war in Amerika, dass wir glaubten, Geschichte zu machen, während sie in Wirklichkeit woanders gemacht worden ist. Wir lebten also in einer gewissen Illusion [...]. Inzwischen waren wir eher fremdgeleitet [... ]. Ich habe den Eindruck, dass die entscheidenden Weichenstellungen in Amerika getroffen wurden.« 
zum Antikommunismus geprägten zweiten Phase der US-amerikanischen Deutschlandpolitik in den Jahren des Kalten Krieges: Möglicherweise bedurfte es bei dem Zeitschriftenorgan nicht zwingend schriftlicher oder mündlicher Direktiven des USamerikanischen Geheimdienstes und der für die Durchführung der verdecken Operationen verantwortlichen Abteilungen, die dem Politischen Planungsstab im State Department unterstellt waren und in letzter Instanz vom jeweiligen Direktor kontrolliert wurden. Denn zumindest Laskys direkter Vorgesetzter, der Generalsekretär vom »Kongreß für kulturelle Freiheit« Josselson, war ja CIA-Mitarbeiter. Zudem handelte es sich bei den beiden Personen um Experten im Bereich der sogenannten Medienund Informationspolitik, die außerdem umgeben waren von ehemaligen versierten Mitarbeitern aus dem Münzenbergapparat, sodass sie aus guten Gründen die auf vielfältige Weise orchestrierten kommunistischen Agitation- und Propagandamethoden nun unter umgekehrten Vorzeichen für die Interessen der Vereinigten Staaten und ihre immer wieder neu auszurichtende Deutschlandpolitik auch für die Steuerung des Monat nutzbar machten. Andererseits respektierte ja Lasky von Anbeginn gewisse Grenzen und vermied es, dass der Monat sich mit bestimmten kontroversen Fragen der deutschen Innenpolitik und der amerikanischen Innen- und Außenpolitik ausdrücklich auseinandersetzte. Insofern besaß er in der inhaltlichen Gesamtkonzeption ungewöhnlich viel Freiheit, und diesen Handlungsspielraum nutze er aus. Sobald Lasky allerdings ebenjene nicht genau zu bestimmende Grenze überschritten hätte und in der Zeitschrift irgendein Artikel erschienen wäre, der nicht auf der jeweils aktuell erwünschten (kulturell-)politischen und ideologischen Linie der US-amerikanischen Regierung gelegen und insofern für Ärger in Washington gesorgt hätte, wäre Lasky so meine These - von der CIA und speziell vom Berliner Büro des US-Geheimdienstes, oder auch von OMGUS und später HICOG, umgehend zurechtgewiesen worden. ${ }^{150}$

\section{VII}

Neben der dargelegten deutschlandspezifischen ideengeschichtlichen und kulturpolitischen Konzeption und Funktion des Monat, in dessen Fokus angesichts der weltpolitischen Kalten-Kriegs-Totalität primär die Intellektuellen des westdeutschen wie des ostdeutschen Teilstaates standen, um die seitens der beiden verbliebenen Supermächte USA und Sowjetunion mit allen Mitteln gerungen und gekämpft wurde, sodass zu Recht von einer »Schlacht um die Intellektuellen« (Harpprecht) gesprochen werden kann, war das einflussreiche Periodikum indes noch auf einem mit dem "großen« Konflikt durch kommunizierende Kanäle unmittelbar verbundenen Terrain aktiv: In der für die politisch-finanziellen »Schattenmänner und Strategen aus dem Weißen Haus in Washington machtpolitisch alles andere als unbedeutenden Auseinanderset-

150 Exemplarisch dafür steht dieser Vorfall: So berichtet der Journalist, Buchautor und damalige USVerbindungsoffizier in Berlin, George Bailey, in einem Interview mit Erich Schmidt-Eenboom davon, dass Lasky 1952 in dem Berliner Lokal »Volle Pumpe« eine »despektierliche Rede gegen die ClA gehalten « hatte, sich anschließend, »nachdem anwesende US-Geheimdienstoffiziere ihn denunziert hatten, beim Stadtkommandanten verantworten (musste). Als geschickter Rhetoriker«, schreibt Schmidt-Eenboom, »stellte er die hintertragenden Schmähungen seines Geldgebers in andere Zusammenhänge und rettete sich so vor drohenden Schwierigkeiten mit der Agency« (Schmidt-Eenboom, Geheimdienst, Politik und Medien, S. 356). 
zung zwischen den drei westalliierten Staaten selbst um den westdeutschen Teilstaat und ehemaligen Feind, der seine zweite Chance bekam, im »Westen anzukommen« und seine Zukunft kulturell, ideologisch und politisch nicht auf einem neuerlichen abenteuerlichen »Sonderweg« zu suchen. Der Monat war nämlich für die Vereinigten Staaten mit Blick auf die junge Bundesrepublik auch ein Instrument gegenüber England und Frankreich, das sein fundamentum in re in divergierenden ideengeschichtlichen, politischen und gesellschaftlichen Grundfragen und-modellen besaß und durch den gemeinsam ausgetragenen Krieg gegen »Hitler-Deutschland« nur auf Eis gelegt wurde. Dies spielte bereits im Nürnberger Hauptkriegsverbrecherprozess, den Nachkriegsplanungen und den Entnazifizierungsmaßnahmen eine nicht unbedeutende Rolle, brach sich aber besonders seit dem Ausbruch des Ost-West-Konfliktes Bahn. Hierbei mündete die traditionelle Rivalität angesichts eines vermeintlich drohenden Schreckbildes einer totalitären Gesellschaft ${ }^{151}$ nicht zuletzt in eine fundamentale Kritik am imperialistischen Charakter des Kolonialismus Großbritanniens ${ }^{152}$ und Frankreichs, ${ }^{153}$ die anlässlich der dramatischen Suezkrise im Jahre 1956 ihren Höhepunkt fand, als die beiden alten Kolonialmächte durch ihr außenpolitisches Abenteuer einen nuklearen Konflikt zwischen den Vereinigten Staaten und der Sowjetunion heraufbeschwörten. ${ }^{154}$

151 In diesem Zusammenhang scheute sich die Redaktion des Monat sogar nicht, für diesen Zweck Orwells Parabel 1984 als antikommunistisches Propagandainstrument gegen den englischen Sozialismus zu Zeiten der Labour-Regierung zu benutzen, indem sie England sozusagen auf direktem Weg in den Totalitarismus zusteuern sah. Wie gezeigt (siehe Kap. IV.3.2) brachte dies die Lasky-Redaktion in den einleitenden Worten zur Veröffentlichung des ersten Teils von 1984 entgegen der eigentlichen Intention des unabhängigen Sozialisten Orwell zum Ausdruck, indem sie 1949 England als ein Land charakterisierte, das beim Prozess der "Verstaatlichung und Bürokratisierung«so bedeutende Fortschritte gemacht hätte, wie es noch nicht einmal der zeitgenössische englische Sozialismus erwarten ließ und das durch die »Preisgabe der persönlichen Freiheit« seine »eigenen Schwächen mit den Greueln von Faschismus und Stalinismus«vereinigte (vgl. Der Monat 2 [1949], H. 14, S. 115).

152 So besonders durch den Vorabdruck von Arendts Kapitel »Die imperialistische Legende und der imperialistische Charakter« aus ihrer Totalitarismusstudie, das der Monat 1950 (H. 24) veröffentlichte. Siehe hierzu u. a. die entsprechenden Hinweise in Kap. IV.3.2.

153 Auch wenn dieses Thema hier nicht weiter ausgeführt werden kann: Der französische Kolonialismus wurde besonders scharf angegriffen. Nachdem die Kolonialpolitik insbesondere in Indochina von Beginn an verurteilt wurde, erreichte sie ihren Höhenpunkt während des algerischen Befreiungskampfes. Vgl. exemplarisch den brillanten Aufsatz von Herbert Lüthy, Frankreichs Hauptstadt: Algier. Algerien desintegriert das Mutterland, in: Der Monat 10 (1958), H. 118, S. 22-35.

154 Da die Suezkrise, wie gezeigt, mit dem ungarischen Volksaufstand im Herbst 1956 koinzidierte, verfolgte die Weltöffentlichkeit sowohl die Entwicklung im Nahen Osten als auch in Osteuropa mit besonderem Interesse und größter Besorgnis, zumal die Doppelkrise Erinnerungen wachrief mit den großen Katastrophen von 1914 und 1939 sowie dem Überfall der Wehrmacht auf die Sowjetunion 1941. Dies schlug sich selbstverständlich im Monat nieder. Besonders die Dezemberausgabe 1956 ( 9 , H. 99), die mit dem aussagekräftigen Titel Tage, die die Welt erschütterten erschien, enthielt einige Beiträge, die der aufgeladenen weltpolitischen Situation Rechnung trugen und die Ereignisse genau beschrieben: z. B. Fritz René Allemann, Der Westen, Deutschland und die osteuropäische Revolution, S. 3-13; Ernst Halperin, Bei der ungarischen Jugend, S. 14-18; François Bondy, Ungarns Augenblick der Freiheit, S. 19-32; Herbert Lüthy, Der Splitter und der Balken, S. 77-84; M[elvin] J. L[asky], Tagebuch von der Grenze, S. 86-90. - Zur Suezkrise: Nachdem Ende Oktober israelische Truppen überraschend ägyptische Stellungen auf der Sinai-Halbinsel angriffen - angeblich um einer Bedrohung von Seiten Ägyptens zuvorzukommen - und Großbritannien und Frankreich vergeblich ein 
Selbstverständlich hatte dies auch Konsequenzen für die inhaltliche Ausrichtung des Monat und soll darum in aller Kürze vor dem Hintergrund der vorliegenden Untersuchungsergebnisse beschrieben und im Hinblick auf das prima vista nicht unmittelbar erkennbare, weil nicht explizit formulierte politische Selbstverständnis der Zeitschriftenredaktion ausgebreitet werden.

Angesichts der Interpretation, wonach für die Genesis der totalitären Regime im 20. Jahrhundert die Französische Revolution von weitreichender Bedeutung war, weil mit ihr das Zeitalter der Revolutionen begann und die eigentliche Schreckensgeschichte der Moderne ihren Anfang nahm, erschien - wie gesehen - nicht zuletzt die Jakobinerherrschaft und die Ideen von 1789 im Monat als eigentlicher Gegenstand der Kritik. Hierbei galt Rousseau als eigentlicher »Erfinder« der Ausformung der demokratischen Theorie als Theorie der »Volkssouveränität« und wurde als Hauptverantwortlicher für den seitdem einsetzenden umfassenden Säkularisierungsprozess angesehen, der die geistige Krise der modernen Welt zur Folge hatte. Im Monat schlug sich dies in der Auffassung eines elementaren Gegensatzes zwischen einem evolutionär-repräsentativen Konstitutionalismus und einem revolutionär-plebiszitären Demokratiemodell nieder, wobei man sich zur Abstützung der sozusagen offiziellen Zeitschriftenposition in Bezug auf Ersteres vor allem auf die politische Theorie John Lockes (1632-1704) stützte, die angesichts der beiden glorreichen angelsächsischen bürgerlichen Revolutionen (Großbritannien 1688, USA 1776) seine eindeutige und bedeutende Umsetzung in den Werken der Federalists sowie der US-amerikanischen Verfassung fand. Insofern verstanden die Herausgeber des Monat und ein überwiegender Teil der prominenten und einflussreichen Autoren die Demokratie in erster Linie als eine Form der Herrschaftsbeschränkung, deren eigentlicher "Sinn« in der Verhinderung jedweder Tyrannei, auch der sogenannten Tyrannei der Mehrheit lag. Gerade angesichts der Erfahrungen aus der ersten Hälfte des 20. Jahrhunderts favorisierte man die Einteilung der politischen Gewalt in Legislative, Exekutive und Judikative, die die Verbindung zwischen der Volksvertretung und dem Volk auf ein möglichst geringes Maß reduzierte. ${ }^{155}$

Der Verlauf der Französischen Revolution hatte nämlich für die Monat-Kerngruppe um Lasky auf erschreckende Weise gezeigt, wohin Rousseaus Idee der »totalitären Demokratie« (Talmon) im Sinne einer radikalen, egalitären Utopie führt, und stellte ihnen unter Beweis, welche Gefahren jedwedem Versuch immanent waren, abstrakte

Ultimatum an die beiden Konfliktparteien gerichtet hatten, das Feuer einzustellen und sich vom Suezkanal zurückzuziehen, begannen britische und französische Einheiten mit der Bombardierung von Kairo und weiteren ägyptischen Städten. Obwohl sowohl die USA als auch die Sowjetunion auf einer Vollversammlung der Vereinten Nationen in New York die militärische Intervention verurteilen, brachten britische und französische Fallschirmjäger die Kanalzone unter ihre Kontrolle. Die Kampfhandlungen wurden erst eingestellt und die Truppen schrittweise abgezogen, nachdem der US-Präsident Eisenhower den britischen Premierminister Eden vor dem Ausbruch eines atomaren Konfliktes mit der Sowjetunion warnte und sich Eden mit seinem französischen Amtskollegen Guy Mollet verständigte.

155 Vgl. unter diesem Blickwinkel die in Kap. IV.3.2 aufgelisteten Beiträge, in denen sich zahlreiche Autoren/-innen angesichts der Erfahrungen mit den totalitären Herrschaftssystemen aus den unterschiedlichsten Gründen im Monat mit »der« Demokratietheorie und speziell der politischen Alltagswelt und -praxis bzw. rechtsstaatlichen Wirklichkeit in den westlichen liberalen Demokratien auseinandersetzten. 
metaphysische Prinzipen unmittelbar auf die Gestaltung von Staat und Gesellschaft anzuwenden. Zum Vorschein kam hierbei nicht nur eine Kritik an der Französischen Revolution und der ihr zugrunde liegenden kontinentalen Aufklärungsphilosophie, sondern eine radikale Verurteilung. Diese unerbittliche Gegnerschaft zur Französischen Revolution, die in einem Plädoyer für die Unvergleichbarkeit der Revolutionen von 1688 bzw. 1776 und 1789 mündete, folgte hierbei dem konterrevolutionären Projekt des 19. Jahrhunderts, das sich bereits mit Beginn der Revolution von 1789 konstituierte, in Bezug auf die gesamteuropäische politische Ideengeschichte einen großen Einfluss besaß und nicht zuletzt mit dem Namen von Edmund Burke verbunden war. ${ }^{156}$ Sein 1790 erschienenes Buch Reflections on the Revolution in France markierte den Beginn der gegnerischen Schriften und beeinflusste unter anderem die großen französischen Konservativen wie Louis de Bonald, Joseph de Maistre, Antoine Rivarol und später François Guizot und Alexis de Tocqueville, die im Monat immer wieder als Kronzeugen genannt wurden, um die politische und ideengeschichtliche Kritik an der 1789er-Revolution zu begründen. Denn das einigende Band zwischen den Figuren bestand in einer gemeinsamen Grundposition: Demokratie als mittelfristige unausweichliche Entwicklung der Gesellschaft; Politik als Vorbeugung gegen eine (neuerliche) Revolution, die man nicht zuletzt als Verschwörung von wenigen Politikern und Intellektuellen interpretierte; Ablehnung der reinen (»mechanischen«) Repräsentation des liberalen Parlamentarismus zugunsten einer Verfassung, die die Teilung und gegenseitige Kontrolle der Gewalten in einer gemischten Regierung (»mixed government«) vorsah, mit der der Gefahr des Missbrauchs der Macht begegnet werden sollte; ${ }^{157}$ eine antirousseauistische und gottesrechtliche Rechtsbegründung im Namen einer weitgehend nur noch gesellschaftlichen Notwendigkeit der Religion.

Das Postulat der natürlichen Ordnung und der Doktrin des Gemeinwillens trugen nach Auffassung der Zeitschrift alle Eigenschaften einer modernen weltlichen Religion in sich und im Prinzip des rousseauschen »totalen Volksstaates" (Gerhard Ritter) sah man die entscheidende Voraussetzung der späteren totalitären Tyrannis und Demagogie.

Durch die Französische Revolution erschien das französische Volk nicht nur in Gestalt der auseinandergebrochenen Teile der absolutistischen Ständegesellschaft, als dritter Stand, neben Adel und Klerus, sondern zum ersten Mal in der Geschichte drängte die überwiegende Mehrheit der Gesellschaft des Ancien Régime die Armen und Notleidenden (den »Pöbel«) in das Blickfeld der Öffentlichkeit und reklamierte das Volk und die Nation zu sein. In dieser Masse, die sich wie ein einheitlicher Körper bewegte und handelte, als ob sie Rousseaus einheitlichen Willen besitzen würde, diagnostizierte man im Monat ein zentrales Problem: Demnach repräsentierte diese atomisierte Masse ihre Einheit in einer identitären Vorstellung von Volk und Nation, die den nach dem Ende der absolutistischen Herrschaft leer gewordenen Ort der Macht gegenüber der Gesellschaft besetzten und die Souveränität für sich beanspruchten. Der souveräne Wille des Volkes legitimierte nicht nur die Machtausübung durch die konstituierten Gewalten, sondern war als oberster Gesetzgeber auch Quelle der Au-

156 Vgl. hierzu bes. Golo Mann, Was ist konservativ? Zu dem neuen Buch von Rusell Kirk, The Conservative Mind, in: Der Monat 6 (1953), H. 62, S. 183-188.

157 Vgl. hierzu bes. C. V. Wedgwood, Wie wächst die Macht? Über ein Buch von Bertrand de Jouvenel, in: Der Monat 1 (1949), H. 10, S. 96-98 (Rezension). 
torität des Rechts und der Gesetze. Insofern erschien der souveräne Wille der Nation als ein säkularisierter Nachfolger des souveränen Willens des absoluten Monarchen.

Angesichts der Grundüberzeugung des inneren Autorenzirkels des Monat, wonach die Erfahrungen des Totalitarismus lehrten, dass nach der Abwendung von Gott und dem Verlust des Glaubens durch die verzweifelten dechristianisierten Massen (der »Mob«) die Gefahr von Anarchie, Tyrannei oder "populär despotism« ständig gegenwärtig war, also auch dem modernen demokratischen Staatswesen und seinen Repräsentanten jederzeit durch sie bzw. das Volk das Vertrauen entzogen werden konnte, weil eben nicht alle Menschen von Natur aus vernünftig waren und ihre Entscheidungen nicht per se der politischen Vernunft folgten, favorisierten einige der herausragenden Autoren des Monat eine Elitenherrschaft.

Dies war auf den ersten Blick nicht immer erkennbar und wurde auch häufig nicht per se direkt vertreten, sondern ergab sich aus der hier dargelegten kritischen Analyse der Französischen Revolution und seinen angeblich mit notwendiger Konsequenz in den Totalitarismus mündeten politischen Implikationen, andererseits kam dies häufig implizit in verschiedenen Beiträgen zum Ausdruck; beispielsweise in der kritischen Auseinandersetzung mit dem politischen Theoretiker der »Eliten« und Anhänger des italienischen Faschismus, Vilfredo Pareto, ${ }^{158}$ oder mit dem großen konservativen Denker Alexis de Tocqueville, ${ }^{159}$ in dem eine ihre politischen Rechte einklagende entchristianisierte »Masse als Schreckgespenst « (A. J. P. Taylor) für die Demokratie gesehen wurde und man gewissermaßen in einer Elitenherrschaft die Rettung insinuierte. Insofern kann durchaus von einem Subtext gesprochen werden, der in diesem Kontext vielen Texten unterlag, wobei hierbei zwischen der Zeitschriftenredaktion und einem Teil der oben namentlich genannten Autoren der ersten und zweiten Gruppe einerseits sowie einer nicht quantifizierbaren Zahl von Lesern, zumal aus konservativen Kreisen, andererseits eine stillschweigende Übereinkunft herrschte. Ohne es immer direkt anzusprechen, wusste man, was gemeint war, verstand also die tatsächlichen Standpunkte und die besonders von der Zeitschriftenredaktion intendierte politische Botschaft, nicht zuletzt deshalb, weil sich ebendieser Kreis der »Eingeweihten« dem Elitedenken verpflichtet fühlte und, wenn man so will, eine Theorie demokratischer Elitenherrschaft vertrat. ${ }^{160}$ Keineswegs nur für die aus dem US-amerikanischen Regierungs- und Geheimdienstapparat und seinem näheren Umfeld stammenden Autoren um Lasky stand nämlich fest, dass auch in einer modernen Demokratie den Gebildeten respektive den »Geistigen« (Alfred Weber) und Wohlhabenden eine natürliche Führungsrolle zukam. Das Volk hatte sich in ihren Augen idealerweise der Führung einer verantwortungsvollen Elite freiwillig unterzuordnen, denn nur so erschien die

158 Vgl. Franz Borkenau, Vom Kreislauf der Eliten. Zum dreißigsten Todestage Vilfredo Pareto (19. August 1923), in: Der Monat 5 (1959), H. 59, S. 493-502.

159 Vgl. Ludwig Bergsträsser, Alexis de Tocqueville. Kritiker und Verteidiger der Demokratie, in: Der Monat 2 (1950), H. 18, S. 608-620.

160 Vgl. exemplarisch Wilhelm Grewe, Parteienstaat - oder was sonst?, in: Der Monat 3 (1951), H. 36, S. 563-577. In erfreulich direkter Form kam dies auch in dem Beitrag von Irving Kristol (Massenkultur und Demokratie, in: Ebd. 12 [1960], H. 143, S. 30-37) zum Ausdruck, der kurz nach dem Ausscheiden Laskys als Herausgeber und Chefredakteur des Monat erschien; hierbei handelte es sich um einen Vortrag von Kristol auf dem Berliner »Kongreß für kulturelle Freiheit« im Juni 1960, der Ceneralversammlung zum zehnten Jahrestag der Cründung des Kongresses. 
staatliche Ordnung durch Vernunft und Tugend und die Stabilität der parlamentarischen Demokratie sowie die Sicherung der Freiheit garantiert. ${ }^{161}$

Vor diesem Hintergrund kann abschließend auch das sich freilich nicht auf den ersten Blick erschließende eigentliche politische und intellektuelle Selbstverständnis des Monat genauer bestimmt werden, aus dem sich auch die besondere Attraktivität erklären lässt, die dieses Organ für einen Großteil seiner Autoren, zumal aus dem inneren Zirkel, besaß. Angesichts der hier dargelegten Interpretation des Totalitarismus in Gestalt des deutschen Nationalsozialismus und des sowjetischen Kommunismus dürfte nämlich gerade auf die hier publizierenden internationalen und deutschen Intellektuellen, die größtenteils unter die Kategorie des verschiedene Strömungen umfassenden politischen Konservatismus subsumiert werden können ${ }^{162}$ und bei allen zum Vorschein gekommenen Unterschieden letztlich viele zeitgenössische Topoi konservativer Modernekritik in der Tradition des bedeutendsten Historikers des 19. Jahrhunderts, Jacob Burckhardt, ${ }^{163}$ wiedergaben, ${ }^{164}$ die Verfassung der Vereinigten

161 Vgl. exemplarisch Gerhard Ritter, Die Sicherung der Freiheit, in: Der Monat 8 (1956), H. 89, S. 84-88.

162 Vgl. hierzu auch, wie bereits im Vorwort gesagt, die Diskussion in der Zeitschrift im Jahre 1962, in der es im Kern um eine Auseinandersetzung mit dem Begriff des Konservatismus und um das Selbstverständnis derjenigen ging, deren politischer Standort der verschiedene Richtungen umfassende und durch den Nationalsozialismus diskreditierte deutsche Konservatismus war: Armin Mohler, Konservativ 1962, in: Der Monat 14 (1962), H. 163, S. 23-29, und anschließend: »Was ist heute eigentlich konservativ?«, in: Ebd., H. 165, S. 48-63 (mit Beiträgen von Colo Mann, Hans-Joachim von Merkatz, Caspar Freiherr von Schrenck-Notzing und Klaus Harpprecht), sowie Dietrich Schwarzkopf, in: Ebd., H. 164, S. 45-50; »Was heißt heute konservativ«, in: Ebd., H. 166, S. 27-36 (mit Beiträgen von Eugen Gerstenmaier, Hans Zehrer und Peter Dürrenmatt), sowie »Was ist eigentlich konservativ?«, in: Ebd., H. 168, S. 86-94 (mit Beiträgen von Robert Hepp, H. A. Ludwig und Hans Birkhäuser). Vgl. hierzu bes. die beiden aus kritischer Perspektive geschriebenen Leserbriefe zu der Diskussion von Dr. Kurt Lenk/Arnhelm Neusüss in: Ebd. 15 (1962), H. 169, S. 90-94, sowie Hermann Claser, in: Ebd., S. $94 \mathrm{ff}$. So stellten Lenk/Neusüss, wie gesagt, fest, dass die Konservatismusdiskussion auch einem ganz aktuellen politischen Bedürfnis geschuldet war: »[E]s geht letztlich um die Schuldfrage an der Katastrophe des Dritten Reiches. Es geht um die Frage: ist der Faschismus Kehrseite oder Widerpart konservativen Denkens? Und in der Konsequenz: hat es zuviel oder zuwenig Aufklärung in Deutschland gegeben?« Ihrer Auffassung nach muss[te], angesichts des dem Konservatismus eigenen Ideologiebegriffs und der daraus resultierenden Ceschichtsauffassung notwendigerweise der als »Zersetzungsprozeß « gedeutete »Ablauf der Ceschichte - jedenfalls seit der Französischen Revolution - der rationalistischen Bösartigkeit lebensfeindlicher Intellektueller in die Schuhe schieben. Dieser Optik erscheint die Aufklärung lediglich als gottesferner, gescheiterter Aufstand der von vornherein ohnmächtigen Vernunft gegen die ewig gültigen Seinsgesetze. Auf diese Weise kann dann der Faschismus bequem als Ausgeburt aufklärerischer Geisteshaltung interpretiert werden, als zwangsläufige Perversion menschlichen Autonomiestrebens.«Insofern sei der Konservatismus »Opfer des Nationalsozialismus«, so Lenk/Neusüss weiter mit besonderem Blick auf Mohler, Gerstenmaier und Zehrer, nicht »als der Sieg des Irrationalismus, vom Konservatismus getragen und gefördert, sondern als letzter Aufschrei der entfesselten und entfesselnden Ratio sei der Nationalsozialismus zu verstehen« (S. 94).

163 Vgl. hierzu den wichtigen Aufsatz von Karl Löwith, Jacob Burckhardt. Der philosophische Verzicht auf Geschichtsphilosophie, in: Der Monat 4 (1952), H. 48, S. 606-613.

164 Zur zeitgenössischen Einordnung in die bundesrepublikanischen Nachkriegsjahre vgl. die bedeutenden Studien: Helga Grebing, Konservative gegen die Demokratie. Konservative Kritik an der Demokratie in der Bundesrepublik nach 1945, Frankfurt a. M. 1971 sowie Kurt Lenk, Deutscher Konservatismus, Frankfurt a. M./New York 1989, bes. S. 173-278. 
Staaten eine besondere Attraktivität ausgestrahlt haben. Denn im Gegensatz zur Französischen Revolution besaß nach ihrer Auffassung die Amerikanische Revolution entscheidende Vorzüge: Sie war eben nicht ein Aufstand des Pöbels, sondern wurde von Menschen durchgeführt, die man als Aristokratie des neuen Staatswesens betrachtete; während Erstere einen ungesunden Nationalismus entfesselte, begnügten sich Letztere damit, einen gesunden Patriotismus zu pflegen. Schlussendlich wurde durch die Amerikanische Revolution ein demokratisches Regime ins Leben gerufen, das sich für den konservativen Autorenkreis des Monat in eine "geschichtliche Kontinuität einfügte und nicht als gewaltsamer, auf dem Altar der zerstörerischen Vernunft dargebrachter Bruch mit der Vergangenheit« (Jean Solchany) und dessen Vorzüge insbesondere in der Verwurzelung des christlichen Glaubens in der amerikanischen Unabhängigkeitserklärung von 1776 und der amerikanischen Verfassung von 1788 gesehen wurde. ${ }^{165}$

Die enge Verbindung von Religion und Politik, die für die politische Kultur und Gesellschaft der USA von Anbeginn konstitutiv war, trieb allerdings im Monat insbesondere bei jenen Autoren überaus gefährliche Blüten, die sich einem ausgeprägten Elitedenken verpflichtet fühlten. So schrieb kein Geringerer als der Herausgeber der englischen Schwesterzeitschrift Encounter, Irving Kristol, in seinem Beitrag Religion und Psychoanalyse, der in der Maiausgabe des Jahres 1951 im Monat erschien, dass sich nur einige wenige Menschen den »Wahrheiten der Vernunft« beugen würden, weil im Gegensatz zur großen Masse »in ihnen die Vernunft Herr über die Triebe ist und nicht ihr Sklave«. Falls Gott nicht existierte und die »Religion eine Illusion« wäre, ohne welche »die Mehrzahl der Menschen nicht leben könnte«, dann würden sich für Kristol Psychoanalyse und Religion durch das einfache Mittel einer »doppelten Wahrheit» miteinander versöhnen.

Man könne die Menschen ruhig an die "Lügen der Religion« glauben lassen, da sie nämlich nicht ohne sie auskommen, und »überlasse die Wahrheit einigen wenigen Weisen«. Dann sind die Menschen in "Weise und Toren « aufgeteilt, in »Philosophen und gewöhnliche Sterbliche«, und der Atheismus wird zu einer »wohlgehüteten esoterischen Doktrin - »denn wenn die Illusionen der Religion« in Misskredit gerieten, "so wäre nicht abzusehen, welcher Wahn, welche unkontrollierte Seelenqual von den Menschen Besitz ergreifen würde. Es wäre dann die Pflicht der Weisen«, so Kristol, »die Religion öffentlich zu verteidigen und, falls erforderlich, sogar Polizeigewalt zu ihrer Unterstützung anzurufen, während sie die Wahrheit für sich selbst und ihre auserwählten Schüler reservieren.«166

Mit Blick auf die hier zum Ausdruck kommende Vorstellung, dass eine kleine Elite verpflichtet sei zur Abwendung einer Gefahr bzw. zur Erreichung eines Zieles, in diesem Fall die (christliche) Religion öffentlich zu verteidigen und um ihre Unterstützung der Bevölkerung zu gewährleisten, ausdrücklich auf das Mittel der Polizeigewalt zugreifen dürfe, gab es in der jüngsten politischen Vergangenheit zweifelsohne eine frappierende Ähnlichkeit mit der US-amerikanischen Regierungspolitik unter Bush jr. Wenn man so will, wurden in der Zeitschrift Der Monat auch durch Kristol in den

165 Vgl. exemplarisch die Ausführungen von Melvin ]. Lasky, Demokratischer Humanismus, in: Der Monat 2 (1950), H. 18, S. 666-668 (Rezension).

166 Irving Kristol, Religion und Psychoanalyse, in: Der Monat 3 (1951), H. 32, S. 141-152, hier S. 151 (Hervorh. des Verf.). 
Jahren des Kalten Krieges Ansätze jenes Politikverständnisses sichtbar, das durch die enge Koppelung von Religion und Politik charakterisiert war und das nicht zuletzt nach dem Schock des 11. September 2001 im Kampf gegen den internationalen Terror die aggressive Außenpolitik der US-Administration bestimmte, die hierbei unter dem maßgeblichen Einfluss der sogenannten Neokonservativen stand. Ein zentraler Baustein in der Grundphilosophie der Neokonservativen besteht darin, dass die Vereinigten Staaten als einzig verbliebene Supermacht eine "göttliche Mission« besitzen, einen dämonisierten Feind in der internationalen Welt mit der gesamten militärischen Stärke, mit imperialer Dominanz und der jederzeitigen Bereitschaft zum präventiven Krieg zu bekämpfen und zu beherrschen. Einer der wichtigsten Exponenten der "Neokons « ist William Kristol, der Sohn von Irving Kristol. Der Freund und langjährige politische Kampfgefährte von Lasky wiederum, Kristol, der bereits in den 1980er-Jahren zum überzeugten Anhänger von Reagan wurde und alles andere als zufällig als das »Urgestein der ersten Generation, Autor, Mentor - der Instanz der neokonservativen Bewegung ${ }^{167}$ gilt, hatte vor allem maßgeblichen Einfluss auf die Regierungspolitik der US-Administration unter Bush sen. Insofern schloss sich in diesem Zusammenhang sowohl personell als auch politisch-ideengeschichtlich ein Kreis aus den Jahren des Kalten Krieges, in dem Der Monat ein einflussreiches Instrument der US-Regierungspolitik war, mit der erst durch die Wahl von Barack Obama zum Präsidenten der Vereinigen Staaten im Januar 2009 zu Ende gegangenen politischen Ära. ${ }^{168}$

167 Hajo Funke, Gott Macht Amerika. Ideologie, Religion und Politik der US-amerikanischen Rechten, Berlin 2006, S. 60, der in seiner überzeugenden Untersuchung die Wurzeln des Verhältnisses von Politik und Religion in den USA analysiert und den Einfluss auf die aktuelle US-Außenpolitik freilegt.

168 Ob wiederum der »Kongreß für kulturelle Freiheit« insgesamt als »Brutstätte des Neokonservatismus, des Schreckgespenstes des 21. Jahrhundert« bezeichnet werden kann, vermag ich nicht abschließend zu sagen. Für Walter Laqueur zumindest ist der Fall klar: »Auf keinen Fall« (Mein 20. Jahrhundert, S. 124). Auf mich kann aber sein Urteil nicht zutreffen, ich hoffe es zumindest nicht, wenn er an gleicher Stelle schreibt, dass unter »denkfaulen Kommentatoren und Moderatoren die Tendenz vor[herrscht], alle Kritiker der sowjetischen und kommunistischen Politik als Neokonservative zu verunglimpfen«. 